Aus der Abteilung Nuklearmedizin

(Prof. Dr. med. J. Meller)

der Medizinischen Fakultät der Universität Göttingen

\title{
Vergleich von prä- und posttherapeutischer Dosimetrie bei \\ Radioiodtherapie von benignen \\ Schilddrüsenerkrankungen
}

\author{
INAUGURAL-DISSERTATION \\ zur Erlangung des Doktorgrades \\ für Zahnheilkunde \\ der Medizinischen Fakultät der \\ Georg-August-Universität zu Göttingen
}

vorgelegt von

Friederike Kobbe

aus

Hamm (Westf.)

Göttingen 2017 
Dekan:

Referent/in:

Ko-Referent/in:

Drittreferent/in:
Prof. Dr. rer. nat. H. K. Kroemer

Prof. Dr. Johannes Meller

PD Dr. Marios-Nikos Psychogios

Prof. Dr. Rainer Mausberg

Datum der mündlichen Prüfung: $\quad$ 22. Mai 2017 
Hiermit erkläre ich, die Dissertation mit dem Titel "Vergleich von prä- und posttherapeutischer Dosimetrie bei Radioiodtherapie von benignen Schilddrüsenerkrankungen" eigenständig angefertigt und keine anderen als die von mir angegebenen Quellen und Hilfsmittel verwendet zu haben.

Göttingen, den 


\section{Inhaltsverzeichnis}

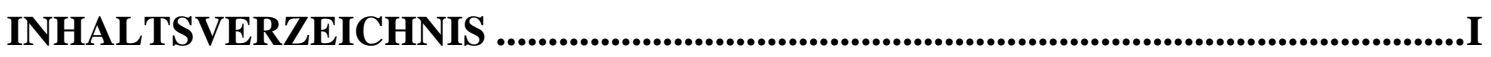

ABBILDUNGSVERZEICHNIS .............................................................................II

TABELLENVERZEICHNIS............................................................................IV

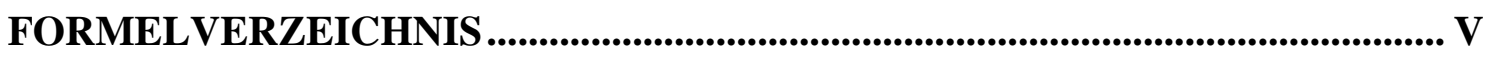

ABKÜRZUNGSVERZEICHNIS ..........................................................................VI

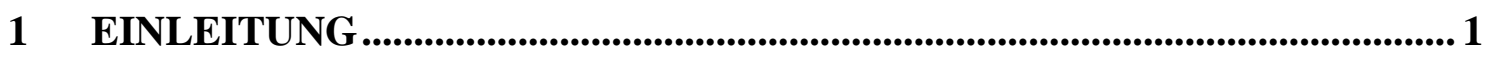

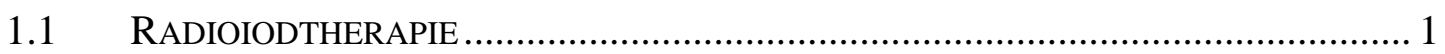

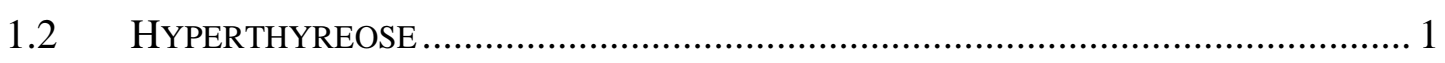

1.2.1 Funktionelle Schilddrüsenautonomie ...................................................... 3

1.2.2 Immunhyperthyreose vom Typ Morbus Basedow ...................................... 4

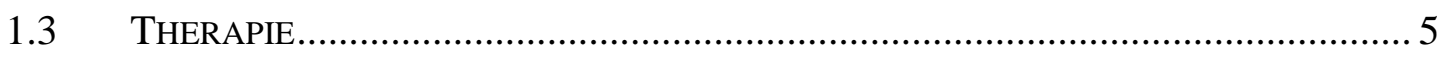

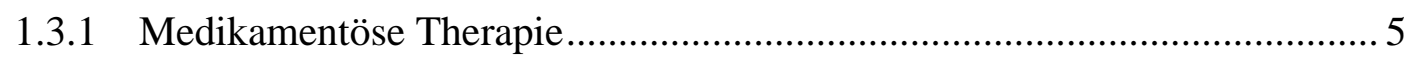

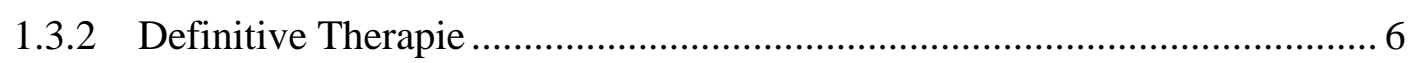

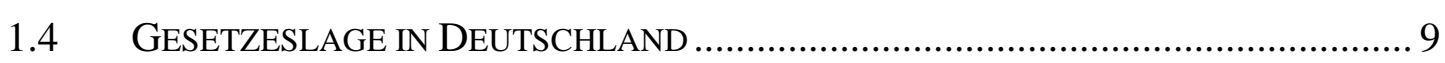

1.5 ZIEL UND HINTERGRUND DER ARBEIT ....................................................... 10

1.5.1 Abteilungsspezifischer Hintergrund der Arbeit ......................................... 10

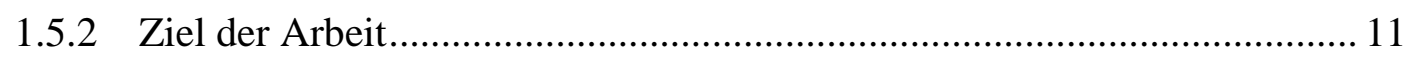

2 PATIENTEN UND METHODEN.................................................................. 11

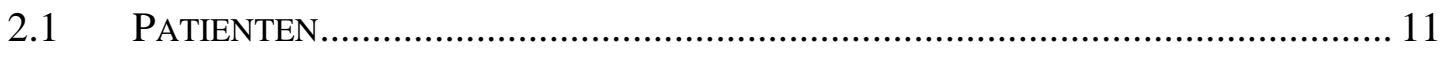

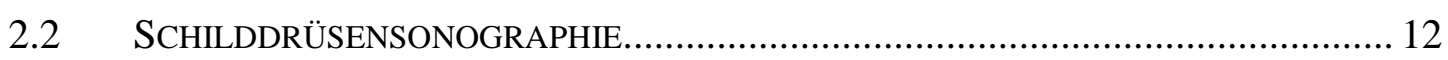

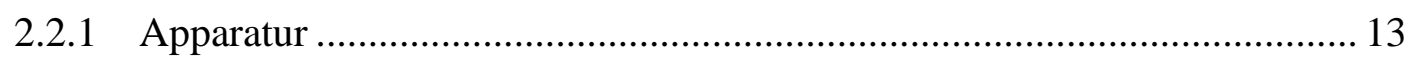

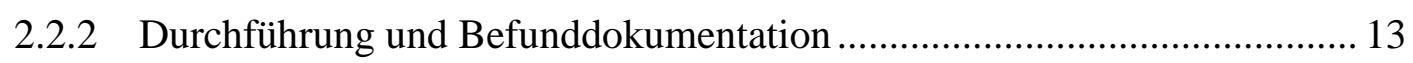

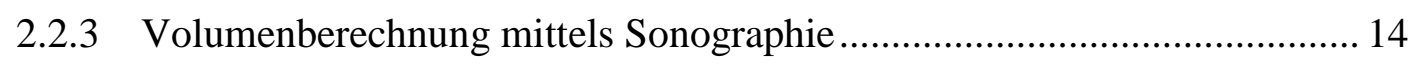

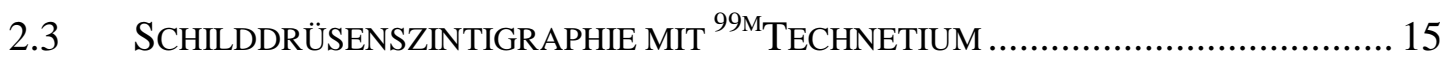

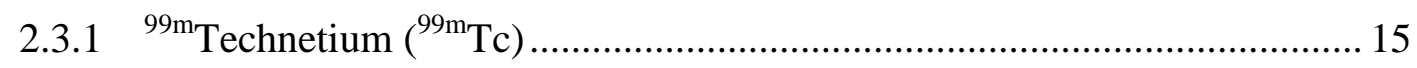

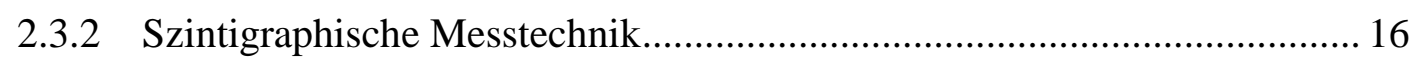

2.3.3 Durchführung und Befunddokumentation ............................................... 18

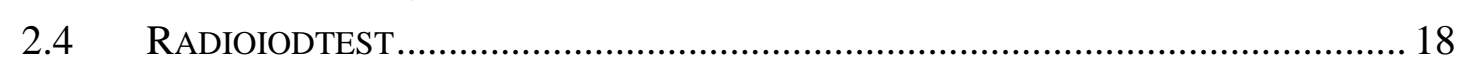

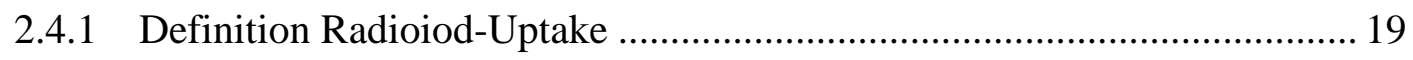

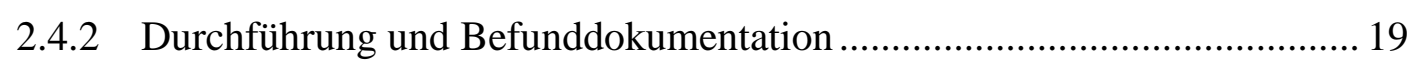

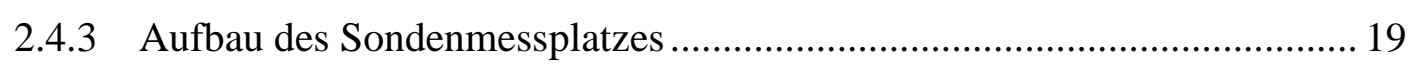

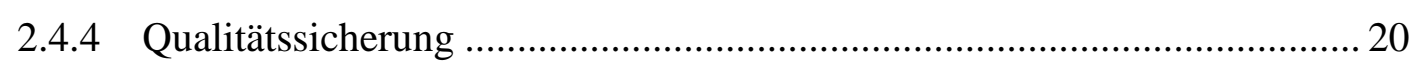

2.4.5 Bestimmung der effektiven Halbwertszeit ............................................. 22 


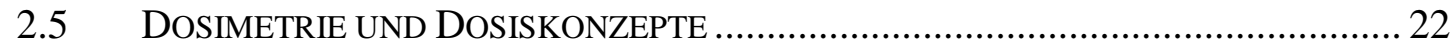

2.5.1 Dosiskonzepte - fixe Aktivität und individuelle Berechnung .................... 23

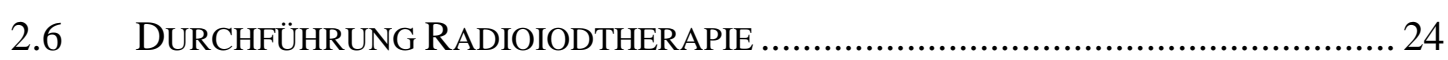

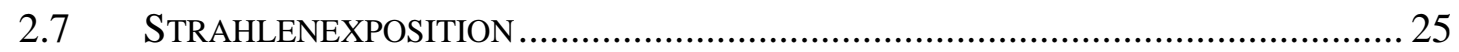

2.8 DATENAUSWERTUNG UND STATISTISCHE METHODEN .................................... 26

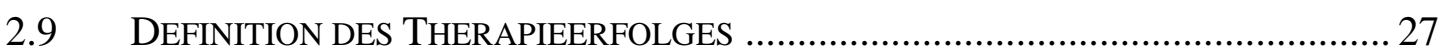

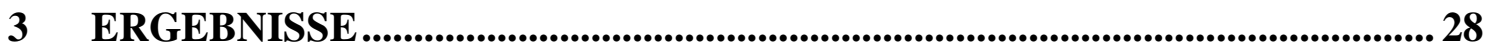

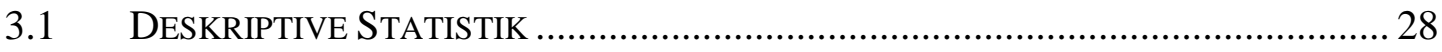

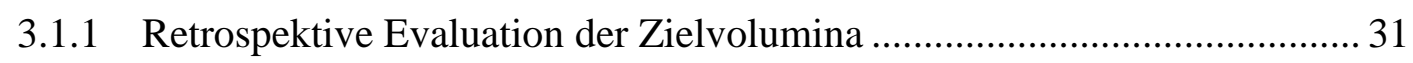

3.2 UNIVARIATE ANALYSE MÖGLICHER EINFLUSSFAKTOREN.............................. 31

3.2.1 Allgemeine Betrachtung ................................................................... 31

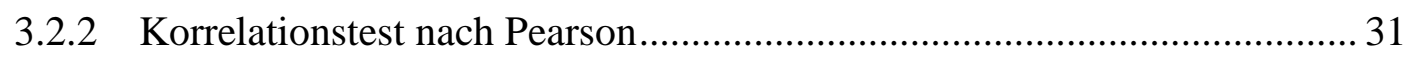

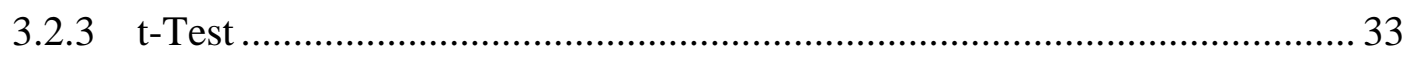

3.2.4 Vergleich der prä- und posttherapeutischen effektiven Halbwertszeiten und

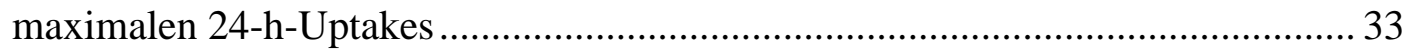

3.3 KORRELATION DER PRÄ- UND POSTTHERAPEUTISCHEN HALBWERTSZEIT BZW. DES 24-H-UPTAKES UND DEM VERFEHLEN DER VERSCHRIEBENEN DOSIS ...................... 38

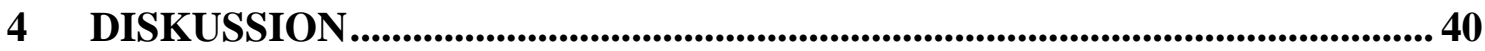

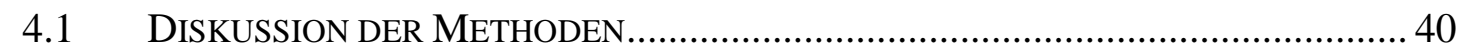

4.1.1 Eichung des Sondenmessplatzes und Messgeometrie .............................. 40

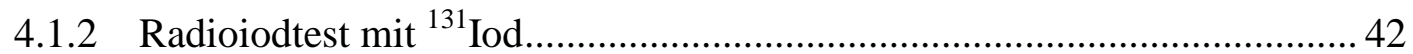

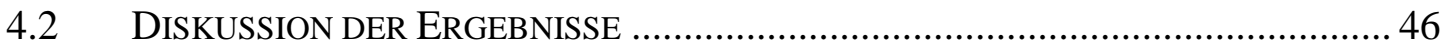

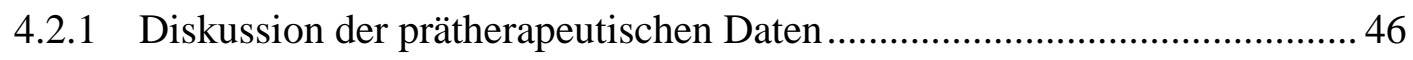

4.2.2 Diskussion der posttherapeutischen Daten ............................................. 53

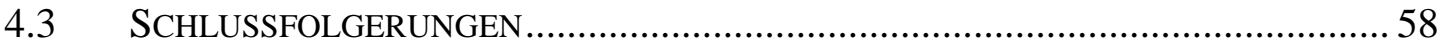

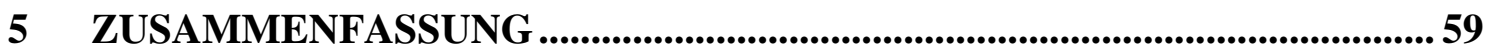

6 LITERATURVERZEICHNIS................................................................................... 60

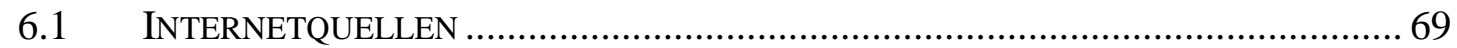

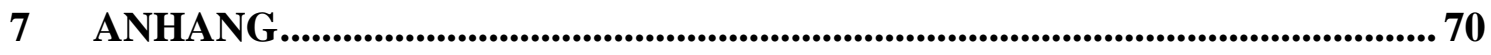

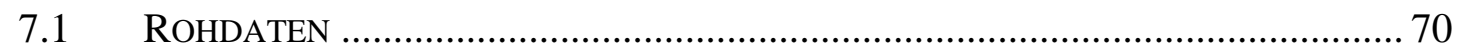

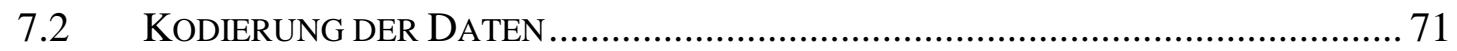




\section{Abbildungsverzeichnis}

Abbildung 1: Iodstoffwechsel in der Schilddrüse, Quelle: Meller, Psychiatrie und Autoimmunerkrankungen (AITD) der Schilddrüse, MVZ Endokrinologikum, 2015, mit freundlicher Genehmigung der Autoren

Abbildung 2: Pathogenese des Morbus Basedow, Quelle: Bouter 2015, Psychiatrie und Autoimmunerkrankungen (AITD) der Schilddrüse, MVZ Endokrinologikum, 2015, mit freundlicher Genehmigung der Autoren .5

Abbildung 3: Zerfallsreaktionen Molybdän (vereinfacht) 16

Abbildung 4: Sondenmessplatz in der nuklearmedizinischen Abteilung der UMG....... 20 Abbildung 5 Aufbau der Referenzmessung, Messungen am Patienten finden mit identischem Aufbau statt 21

Abbildung 6: Linearitätsmessung des Sondenmessplatzes der UMG im August 2014, Quelle: Pröhl 2014, mit freundlicher Genehmigung des Autors ................................. 22

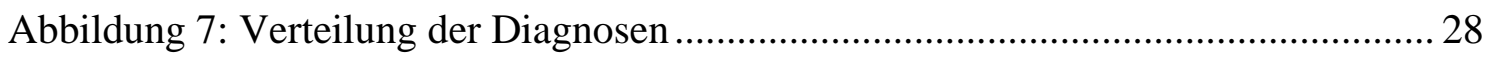

Abbildung 8: posttherapeutische Stoffwechsellage .................................................. 29

Abbildung 9: TSH-Spiegel zum Zeitpunkt des Radioiodtest ...................................... 29

Abbildung 10: TSH-Spiegel zum Zeitpunkt der RIT ............................................... 30

Abbildung 11: Abweichung der Dosis kategorisiert nach Diagnose ............................. 30

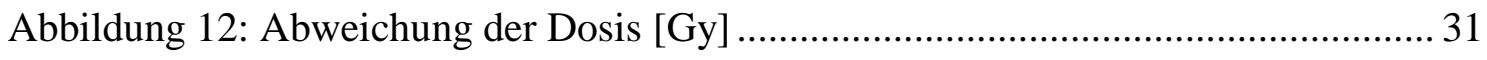

Abbildung 13: Vergleich der prä- und posttherapeutischen effektiven HWZ ................ 34

Abbildung 14: Vergleich der prä- und posttherapeutischen eff. HWZ, kategorisiert nach

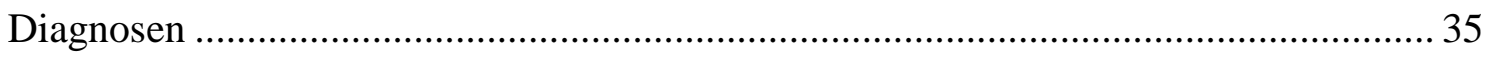

Abbildung 15: Vergleich des prä- und posttherapeutischen max. 24-h-Uptakes ............ 36

Abbildung 16: Vergleich des prä- und posttherapeutischen max. 24-h-Uptakes,

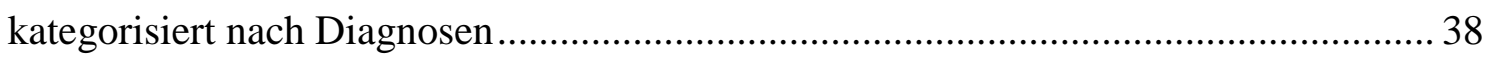

Abbildung 17: Korrelation zwischen prä- und posttherapeutischem 24-h-Uptake,

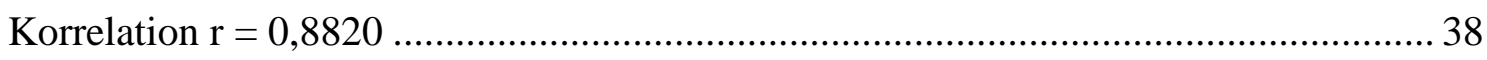




\section{Tabellenverzeichnis}

Tabelle 1: Indikationen und Kontraindikationen zur RIT bei MB / funktioneller Autonomie, (mod. nach Hotze u. Schumm-Draeger 2003) .......................................... 9

Tabelle 2: Obere Grenzwerte für physiologische Schilddrüsenvolumina (Dietlein et al. 2003)

Tabelle 3: Vergleich der prä- und posttherapeutischen eff. HWZ [Tage], kategorisiert nach Diagnosen, Differenz des Mittelwerts. 35

Tabelle 4: krankheitsspezifische HWZ auf Basis der radioiodtherapeutischen Daten... 36

Tabelle 5: Vergleich des prä- und posttherapeutischen maximalen 24-h-Uptakes [Prozent], kategorisiert nach Diagnosen, Differenz des Mittelwerts 37

Tabelle 6: krankheitsspezifische HWZ auf Basis der radioiodtherapeutischen Daten ... 57 


\section{Formelverzeichnis}

Formel 1: Ellipsoidformel zur Berechnung des Schilddrüsenvolumens ........................ 14

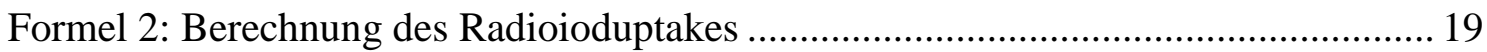

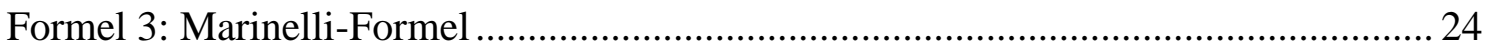




\section{Abkürzungsverzeichnis}

\begin{tabular}{|c|c|}
\hline ALARA & As Low As Reasonably Achievable \\
\hline cAMP & zyklisches Adenosinmonophosphat \\
\hline $\mathrm{CT}$ & Computertomographie \\
\hline $\mathrm{D}$ & Energiedosis \\
\hline DA & disseminierte Autonomie \\
\hline DGN & Deutsche Gesellschaft für Nuklearmedizin e.V. \\
\hline eff. HWZ & effektive Halbwertszeit \\
\hline (f)T3 & (freies) Triiodthyronin \\
\hline (f)T4 & (freies) Thyroxin \\
\hline HLA & humanes Leukozyten-Antigen \\
\hline hTG & humanes Thyreoglobulin \\
\hline HWZ & Halbwertszeit \\
\hline $\mathrm{I}^{-}$ & Iodid \\
\hline IHT & immunogene Hyperthyreose \\
\hline i.v. & intravenös \\
\hline MB & Morbus Basedow \\
\hline MFA & multifokale Autonomie \\
\hline MRT & Magnetresonanztomogramm \\
\hline $\mathrm{n}$ & Patientenzahl \\
\hline $\mathrm{NaI}$ & Natrium-Iodid \\
\hline NIS & Natrium-Iodid-Symporter \\
\hline NS & Nachsorgeuntersuchung \\
\hline p.i. & post injectionem \\
\hline p.o. & per os \\
\hline RIT & Radioiodtherapie \\
\hline RIU & Radioioduptake \\
\hline ROI & Region of Interest \\
\hline SD & Schilddrüse \\
\hline SD-Vol. & Schilddrüsenvolumen \\
\hline SPECT & Single-Photon-Emissions-Computertomographie \\
\hline StrlSchV & Strahlenschutzverordnung \\
\hline TcTU & 99mTc-Pertechnetat-Uptake \\
\hline TcTUs & 99mTc-Pertechnetat-Uptake unter Suppressionsbedingungen \\
\hline TPO & Thyreoperoxidase-Antikörper \\
\hline TRAK & TSH-Rezeptor-Antikörper \\
\hline TSH & Thyroidea-stimulierendes Hormon \\
\hline $\mathrm{TSHb}$ & basales TSH \\
\hline
\end{tabular}


Abkürzungsverzeichnis

$\mathrm{U}$

Unit (Enzymeinheit)

UFA

unifokale Autonomie

UMG

Universitätsmedizin Göttingen

$\mathrm{Xe}$

Xenon 


\section{Einleitung}

\subsection{Radioiodtherapie}

Das erste radioaktive Isotop von Iod, ${ }^{128}$ Iod mit einer Halbwertszeit von 26 Minuten, wurde im Jahr 1938 von Hertz et al. synthetisiert. Hertz beobachtete im Tierversuch eine präferentielle Speicherung dieses Elements in der Schilddrüse (Hertz und Roberts 1946; Sawin und Becker 1997). Im Laufe der Zeit wurden weitere Iodisotope hergestellt, unter anderem das heute therapeutisch überwiegend eingesetzte Isotop ${ }^{131}$ Iod. Eine Hyperthyreose wurde in den Vereinigten Staaten von Amerika im Jahr 1942 erstmalig mit ${ }^{131}$ Iod therapiert, ein Jahr später folgte die erfolgreiche Behandlung eines Schilddrüsenkarzinoms (Beierwaltes 1979; Chapman 1983). In Europa verzögerte sich bedingt durch die Wirren des Krieges die Erprobung dieser neuen Methode um einige Zeit. In den Jahren 1949 und 1951 wurden erste Schilddrüsenkarzinome und benigne Schilddrüsenerkrankungen mit ${ }^{131}$ Iod in Deutschland behandelt (Winkler 1950).

Mittlerweile ist die RIT (Radioiodtherapie mit ${ }^{131}$ Iod) bei benignen und malignen Schilddrüsenerkrankungen weltweit eine etablierte Therapieform. In Deutschland werden zur Zeit ca. 50.000 Patienten wegen einer Thyreopathie mit Radioiod behandelt (Lorenz et al. 2015). Im Vordergrund stehen hierbei die Behandlungen von Hyperthyreosen, bei denen eine Operation nicht indiziert ist.

\subsection{Hyperthyreose}

Eine Indikation für eine Behandlung mit Radioiod ist die Hyperthyreose. Sie ist definiert als ein Überangebot von freien Schilddrüsenhormonen mit konsekutivem Überangebot an freiem Triiodthyronin (fT3) an den entsprechenden intrazellulären T3 - Rezeptoren. Circa $2 \%$ der weiblichen und 0,2 \% der männlichen Bevölkerung entwickeln eine Hyperthyreose (Cooper 2003; Gurgul und Sowinski 2011). Die immunogene Hyperthyreose, auch Morbus Basedow genannt, und die Schilddrüsenautonomie stellen mit über $95 \%$ aller Ursachen die Hauptgründe für eine Hyperthyreose dar (Allolio 2010). Bei diesen Krankheitsbildern handelt es sich um Bildungshyperthyreosen. Das heißt, sie entstehen durch eine Überproduktion von Schilddrüsenhormonen. Die Patienten zeigen häufig klinische Symptome wie Tachykardie, Gewichtsverlust, Reizbarkeit, motorische Unruhe und Schlafstörungen (Schott 2013). Stammen die überschüssigen Schilddrüsenhormone aus einer exogenen Zufuhr, zum Beispiel in Tablettenform, handelt es sich um eine Hyperthyreosis factitia (Marischler 2007). Bei entzündlichen intrathyreoidalen Prozessen kann es außerdem zu einer Freisetzungshyperthyreose kommen. 
Im Unterschied zum Morbus Basedow ist die Schilddrüsenautonomie eine typische Iodmangelerkrankung, wie sie gehäuft in Iodmangelstrumen zu finden ist. Per definitionem ist eine Struma jede Vergrößerung der Schilddrüse über eine Volumenobergrenze eines altersund geschlechtsspezifischen Referenzbereiches von $18 \mathrm{ml}$ bei Frauen und über $25 \mathrm{ml}$ bei Männern sowie knotige Veränderungen bei einer in der Größe unveränderten Schilddrüse (Marischler 2007). Deutschland ist ein ehemaliges Iodmangelgebiet. Die laut WHO (World Health Organisation) empfohlene tägliche Zufuhr von $100-200 \mu \mathrm{g}$ Iodid ist durch Iodierung von Fertiglebensmitteln durch die Lebensmittelindustrie flächendeckend umgesetzt worden (Hampel et al. 1995; Thamm et al. 2007). Knotenstruma sind dennoch deutschlandweit mit etwa 20 - $30 \%$ betroffenen Erwachsenen häufig (Schicha et al. 2013). Eine reine Vergrößerung der Schilddrüse ist sogar bei der Hälfte der deutschen Bevölkerung zu beobachten (Hampel et al. 1995).

Die Schilddrüse ist aus Follikeln aufgebaut. Die Follikel haben eine durchschnittliche Größe von 0,5 mm. Sie bestehen aus einem einschichtigen Epithel und im Zentrum aus Kolloid. Das Kolloid besteht größtenteils aus Thyreoglobulin (TG), einem Makroglobulin. Thyreoglobulin ist ein ausschließlich durch Thyreozyten synthetisiertes Glykoprotein mit einem Molekulargewicht von $660 \mathrm{kDa}$. An der Basis des Thyreozyten befindet sich der Natrium-Iodid-Symporter (NIS), über den das Iodid in das Zytosol transportiert wird. Es handelt sich um ein Glykoprotein aus 618 Aminosäuren, mit einem Molekulargewicht von 65,2 kDa und 13 Transmembrandomänen. An der apikalen Seite des Thyreozyten befindet sich Pendrin als weiterer aktiver Transportmechanismus, der Iodid in das Follikellumen transportiert. Es besteht aus 780 Aminosäuren und einem Molekulargewicht von 86 kDa (Löffler et al. 2006).

Im Follikellumen findet dann unter dem Einfluss der thyreoidalen Peroxidase eine Umwandlung von Iodid in organisches Iod und eine Iodierung von Thyrosylresten des Thyreoglobulins statt. Jedes Thyreoglobulinmolekül hat ungefähr 120 bis 140 Thyrosylreste. Aus diesen iodierten Thyrosylresten entstehen durch enzymatische Kopplung schließlich Triiodthyronin (T3) und Tetraiodthyronin (T4). Diese Schilddrüsenhormone werden über Pinozytose aus den Thyreozyten in den Intravasalraum gebracht. Das meiste T3 in der Zirkulation entsteht aus T4 in der Leber mittels einer enzymatischen Umwandlung durch die Diiodinase-1. Die normale Schilddrüse unterliegt einer Rückkopplung durch das Thyroidea-stimulierende Hormon (TSH) aus dem Hypophysenvorderlappen, das mit dem TSHRezeptor, einem membranständigen G-protein-gekoppelten Rezeptor, zusammenwirkt. Eine Aktivierung des Rezeptors bewirkt eine Erhöhung von cAMP und weiterer sekundärer Transduktionskaskaden, die unter anderem auch mit einer erhöhten NIS-Expression, TG-Expression und Thyreoperoxidase-Antikörper (TPO)-Expression einhergehen (Löffler et al. 2006; Klinke et al. 2010). 
Bei den Hyperthyreosen besteht entweder im Rahmen der Autonomie eine monoklonale Gain-of-Function-Mutation am TSH-Rezeptor, die dann zu einer vermehrten Aufnahme von Iod und einer vermehrten, ungeregelten Produktion von Schilddrüsenhormonen führt oder im Rahmen einer immunogenen Hyperthyreose das Vorliegen von TSHRezeptorautoantikörpern, die den TSH-Rezeptor stärker und länger stimulieren als das TSH selbst (Paschke 2011; Sancak et al. 2011). Ein dritter Mechanismus ist die Freisetzungshyperthyreose, bei der Follikel destruiert werden und Schilddrüsenhormonvorstufen in den Intravasalraum entweichen.

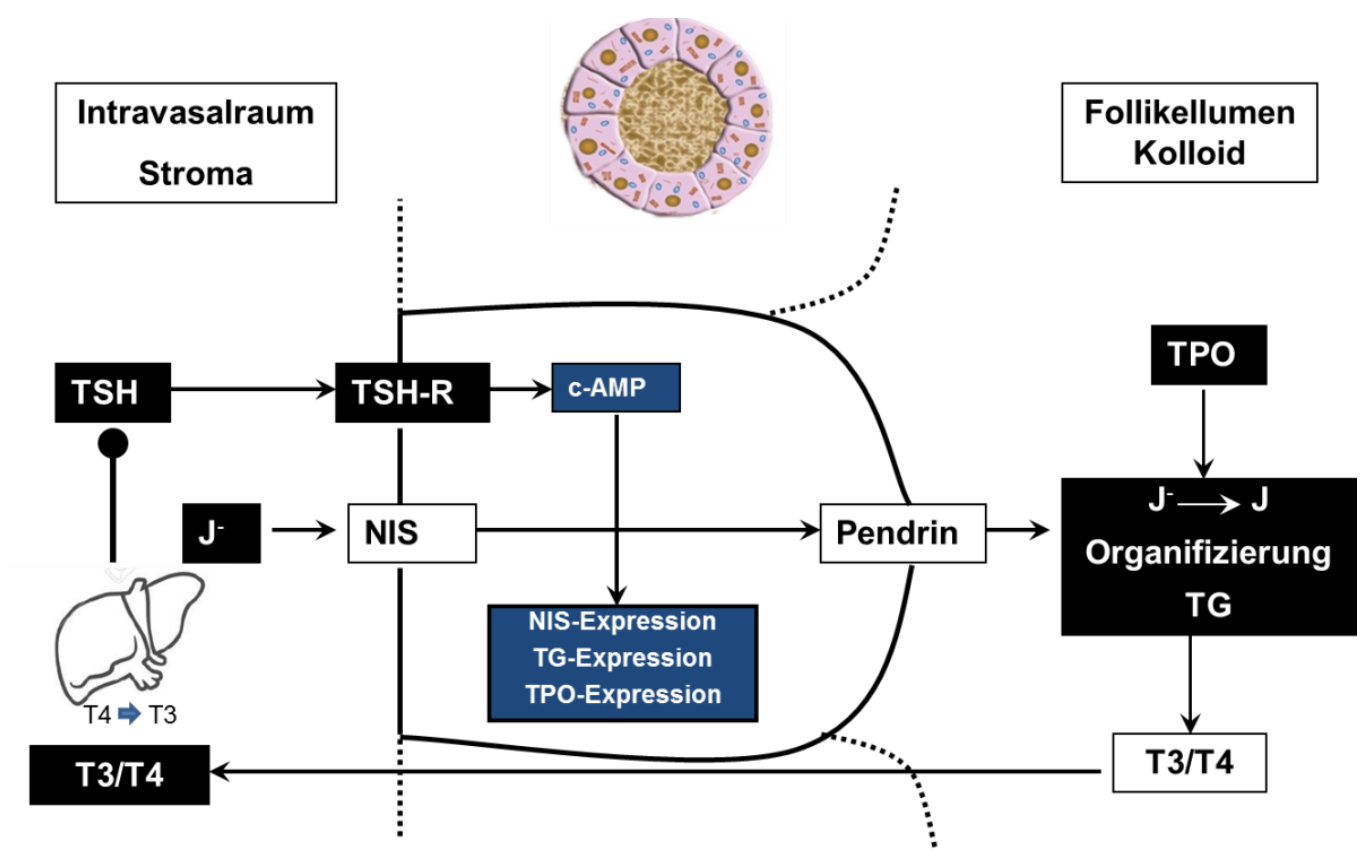

Abbildung 1: Iodstoffwechsel in der Schilddrüse, Quelle: Meller, Psychiatrie und Autoimmunerkrankungen (AITD) der Schilddrüse, MVZ Endokrinologikum, 2015, mit freundlicher Genehmigung der Autoren

\subsubsection{Funktionelle Schilddrüsenautonomie}

Bei der funktionellen Autonomie entzieht sich die Funktion der Schilddrüse der Regulation durch den TSH-Rezeptor und dem zugehörigen Hormon (Thyroidea-stimulierendesHormon). Der thyreotrope Regelkreis ist somit gestört. Diese Autonomie des Gewebes kann in unterschiedlichen Variationen auftreten. Szintigraphisch unterscheidet man rein deskriptiv das autonome Adenom (unifokale Autonomie, ca. $25 \%$ der Fälle), eine multifokale Autonomie (ca. $50 \%$ der Fälle) oder eine disseminierte Autonomie. Die autonomen Gewebeanteile führen jedoch nicht zwangsläufig zu einer signifikanten Verschiebung des Schilddrüsenhormonspiegels im Serum (Pfannenstiel 1990; Schott 2013). Erst wenn die Autonomie eine gewisse funktionelle Relevanz erreicht hat, kommt es zunächst zu einer Erniedrigung, später zu einer völligen Suppression des TSH und im weiteren Verlauf auch zu einem Anstieg der peripheren Hormonkonzentration im Serum. Eine Autonomie kann zurzeit nur szintigraphisch diagnostiziert werden, andere bildgebende Verfahren sind zur Diagnosesicherung nicht geeignet. Ursprünglich dachte man, dass für die Entstehung einer 
Hyperthyreose bei Autonomie vor allem die Masse des autonomen Gewebes entscheidend ist, dass es sich also um ein quantitatives Problem handelt. Mittlerweile hat sich gezeigt, dass ca. $80 \%$ aller unifokalen Autonomien aus einer einzelnen mutierten Zelle hervorgehen. Sie sind somit monoklonalen Ursprungs. Bei 80 \% dieser Genveränderung besteht sie in einer aktivierenden, somatischen Mutation am TSH-Rezeptor. Der Rezeptor besteht aus zwei Untereinheiten (alpha / beta), aufgebaut aus 743 Aminosäuren und steuert die Expression des Natrium-Iodid-Symporters, die Iodierung von Thyreoglobulin und die Ausschleusung von Triiodthyronin und Thyroxin. Bei den erwähnten aktivierenden Mutationen handelt es sich um Punktmutationen in heterozygoter Form, dass mutierte Allel ist gegenüber dem Wildtyp-Allel dominant. Die Veränderungen bestehen in Aminosäurensubstitutionen oder Deletionen. Solche Mutationen führen zu einer Fixierung der Primärstruktur des TSHRezeptors in seiner aktiven Konformation, unabhängig von einer TSH-Stimulation. Der derartig veränderte Rezeptor zeigt eine erhöhte Affinität zum TSH, seine Expression ist aber insgesamt verringert. Nach einer Selbst-Aktivierung folgt größtenteils eine G-Protein 5- $\alpha$-s gekoppelte cAMP-Kaskade, seltener eine Signaltransduktion mittels Phospholipase C 2 (Parma et al. 1993; Krohn et al. 1998; Krohn et al. 2000). Dabei ist die rezeptormutationsvermittelte cAMP-Stimulation etwa 2 - 10-fach höher, als beim Wildtyp. Die beschriebenen autonomen Thyreozyten haben zudem einen Wachstumsvorteil gegenüber unveränderten Zellen zu haben. Mittlerweile gelang es unterschiedliche Rezeptor-Mutationen auch bei multifokalen Autonomien mittels Mikrodissektion autonomen Gewebes und anschlieBender genetischer Analyse nachzuweisen (Parma et al. 1993).

\subsubsection{Immunhyperthyreose vom Typ Morbus Basedow}

Im Jahr 1840 wurde vom deutschen Arzt Carl von Basedow (28. März 1799 - 11. April 1854) erstmalig die Symptomatik des Morbus Basedow beschrieben. Basedow beschreibt in dieser Publikation, welche unter dem Namen „Exophthalmos durch Hypertrophie des Zellgewebes in der Augenhöhle“ in „Caspers Wochenschrift für die gesamte Heilkunde“ erschien, die klassischen Symptome (Meng 2004). Der irische Arzt Robert James Graves (27. März 1797 - 20. März 1853) hatte diesen Symptomkomplex fünf Jahre zuvor bereits beschrieben, sie aber einem Herzleiden zugeordnet. Im englischen Sprachraum ist daher auch der Name Grave's Disease gebräuchlich. Der Zusammenhang mit der Schilddrüse wurde erst Jahrzehnte später durch Paul Justus Möbius (24. Januar 1853 - 8. Januar 1907) 1886 nachgewiesen (Gerabek et al. 2005).

Die Erkrankung ist autoimmuner Genese mit einer globalen Stimulation des Schilddrüsenparenchyms mittels TRAKs, hierbei handelt es sich um TSH-Rezeptorautoantikörper vom Typ IgG (Weetman 2000). Virale und bakterielle Infektionen (Yersinien, Retroviren), ein Iodexzess, genetische Disposition, aber auch psychosoziale Faktoren können eine immunogene Hyperthyreose (IHT) auslösen. Dies führt zu einer HLA DR3 - assoziierten Auf- 
hebung der Immuntoleranz (Hotze und Schumm-Draeger 2003; Strieder et al. 2003). Immunologisch liegt folglich dieser Autoimmunreaktion eine IFN $\gamma$-induzierte Expression eines HLA-Klasse II-Moleküls (MHC-II-Rezeptor, sogenannte humane Leukozytenantigene) auf der Thyreozytenoberfläche und auch auf Zellen im retroorbitalen Gewebe zugrunde. Der Thyreozyt fungiert fortan als antigenpräsentierende Zelle (Heufelder et al. 1991). Dieser Reaktion schließt sich die Kaskade einer Entzündung an. Spezialisierte CD4+ und CD8+ T-Lymphozyten wandern in das Schilddrüsengewebe ein, es kommt zu einer antigenabhängigen Proliferation von B-Lymphozyten und zur Bildung von Zytokinen wie IL1, IL-6, IL-8 oder TNF $\alpha$. Letztendlich werden Antikörper gegen den TSH-Rezeptor (TRAKs) gebildet, welche vornehmlich stimulierend wirken. Im Vergleich zum TSH selbst weisen TRAKs eine erhöhte Affinität zum Rezeptor und auch eine verlängerte Wirksamkeit auf. Es folgt eine unkontrollierte Überfunktion der Schilddrüse (Hotze und SchummDraeger 2003; Kohn und Harii 2003).

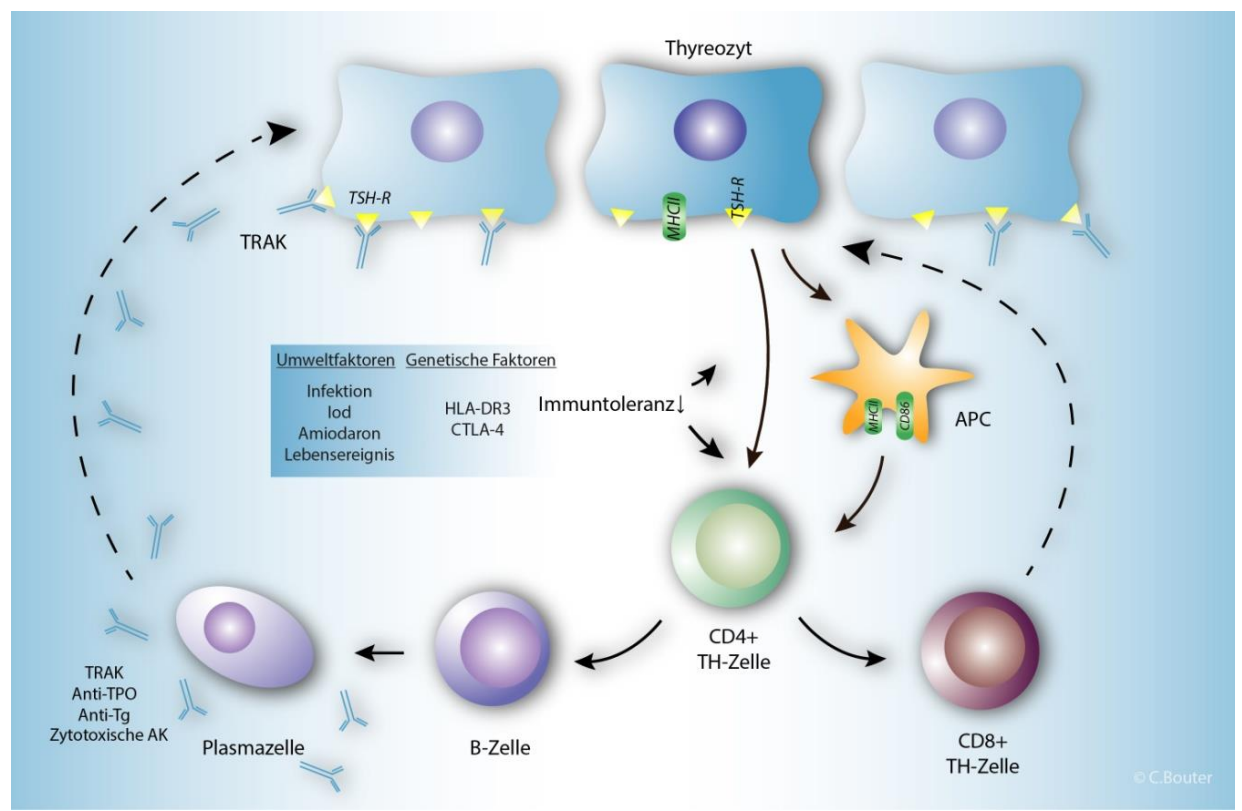

Abbildung 2: Pathogenese des Morbus Basedow, Quelle: Bouter 2015, Psychiatrie und Autoimmunerkrankungen (AITD) der Schilddrüse, MVZ Endokrinologikum, 2015, mit freundlicher Genehmigung der Autoren

\subsection{Therapie}

\subsubsection{Medikamentöse Therapie}

\subsubsection{Funktionelle Schilddrüsenautonomie}

Bei dem Krankheitsbild der Schilddrüsenautonomie handelt es sich um einen oder mehrere benigne Tumore. Eine relevante Autonomie mit latenter oder manifester Hyperthyreose muss nach medikamentöser Stabilisierung immer definitiv behandelt werden, da nicht mit 
Spontanremissionen zu rechnen ist. Thyreostatika können nichtsdestoweniger vorübergehend den Allgemeinzustand verbessern. Eventuell sind auch durch den entgleisten Hormonhaushalt entstandene Begleiterscheinungen (z. B. Herzrhythmusstörungen) medikamentös (Betablocker) zu behandeln (Als et al. 1997). Eine unbehandelte Hyperthyreose kann eine thyreotoxische Krise mit kardialen und metabolischen Beeinträchtigungen induzieren, dieses in bis zu 10 \% der Fälle mit einem letalen Verlauf (Scholz et al. 2003).

\subsubsection{Immunhyperthyreose}

Die Therapie einer Autoimmunkrankheit ist stets rein symptomatisch, da der ursächliche Prozess nicht beeinflusst werden kann. Zudem sind bei einer IHT nicht nur TRAK mit stimulierender Wirkung nachweisbar, sondern zusätzlich Autoantikörper mit blockierender Wirkung auf den TSH-Rezeptor. Eine spontane Remission ist daher nicht selten zu beobachten. Folglich ist bei einer Erstmanifestation anfänglich eine Behandlung mit Thyreostatika indiziert. Aktuell am häufigsten verabreicht werden die Präparate Propylthiouracil (Propycil ®) und Thiamazol (Favistan ${ }^{\circledR}$ ). Dies geschieht über einen Zeitraum von neun bis zwölf Monaten. In Einzelfällen, vor allem bei Kindern und Jugendlichen, erfolgt die Medikamentengabe über eine Dauer von 24 Monaten. Die Dosierung ist in dieser Periode stetig zu verringern, bis im Idealfall nach vier bis sechs Wochen ein euthyreoter Zustand erreicht wird. Bei $50 \%$ der rein thyreostatisch behandelten Patienten zeigte sich eine anhaltende Remission (Prasek et al. 2015).

Die Dosis der Schilddrüsenmedikamente wurde in den vergangenen Jahren kontinuierlich verringert, da bei höheren Dosen zwar schneller ein euthyreoter Zustand erreicht wird, aber Nebenwirkungen häufiger auftreten (Meyer-Gessner et al. 1989). Als Langzeittherapeutikum sollten thyreostatische Medikamente aufgrund schwerwiegender Nebenwirkungen wie der Agranulozytose, Hepatotoxizität und gesteigerten Schilddrüsenwachstums nicht verabreicht werden (Otsuka et al. 2012). Davon ausgenommen sind multimorbide Patienten, bei denen eine definitive Therapie unmöglich durchführbar ist, nicht hospitalisierbare Patienten und bei Patienten, die eine definitive Therapie ablehnen (Hotze und SchummDraeger 2003).

\subsubsection{Definitive Therapie}

Bei Hyperthyreosen ergeben sich folgende Situationen, die einer definitiven Therapie (Thyreoidektomie oder RIT) bedürfen. Einerseits, wenn eine funktionell relevante Autonomie vorliegt, das heißt der Patient ist persistierend latent oder subklinisch hyperthyreot. Die latente Hyperthyreose stellt lediglich eine leichte Form der Hyperthyreose dar, dennoch gilt sie als behandlungsbedürftig. Das supprimierte periphere TSH (>0,1 mU / 1) stellt einen unabhängigen Risikofaktor für linksventrikuläre Hypertrophie, supraventrikuläre tachykarde Herzrhythmusstörungen und Osteoporose dar. Andererseits wird beim Mor- 
bus Basedow eine definitive Therapie notwendig, wenn es nach einjähriger thyereostatischer Therapie zu einer Rezidivhyperthyreose kommt, da eine erneute einjährige thyreostatische Therapie nur noch zu geringen Remissionsraten von unter $10 \%$ führen würde. (Meng und Schmidt 1998, Meller, persönliche Kommunikation 2016).

Des Weiteren empfiehlt sich eine RIT bereits bei der Erstmanifestation eines Morbus Basedow, wenn das Risiko eines Rezidivs voraussehbar groß ist. Dies ist zum Beispiel bei Schilddrüsenvolumina größer als 40 Milliliter, sehr hohem Serumspiegel von TSHRezeptorautoantikörpern (> $10 \mathrm{mIU} / \mathrm{l}$ ) nach sechs Monaten Behandlung oder bei Auftreten einer floriden endokrinen Orbitopathie der Fall (Hurley und Gharib 1996; Garber et al. 2011).

\subsubsection{Thyreoidektomie oder Resektion}

Ein chirurgisches Vorgehen ermöglicht einen raschen und vergleichsweise sicheren Erfolg und ist besonders bei relativ großer Struma, Karzinomverdacht, Persistenz oder Rezidiv oder bei jungen Frauen mit Kinderwunsch oder Gravidität sowie während der Laktation indiziert (Gurgul und Sowinski 2011). Eine euthyreote Stoffwechsellage ist präoperativ unbedingt medikamentös einzustellen, um perioperative Komplikationen zu vermeiden (Meng und Schmidt 1998). Zur Wahl stehen verschiedene Operationsmethoden und Therapieansätze, welche sich unter anderem auch nach dem Erkrankungsbild richten.

Im Falle einer multifokalen funktionellen Autonomie bietet sich eine bilaterale subtotale Resektion an. Bei dieser Technik werden beidseits große Teile des Schilddrüsenparenchyms unter Belassung von ca. 3 - 6 g dorsalen Restgewebes entfernt. In $72-87 \%$ der Fälle verläuft die bilaterale subtotale Resektion erfolgreich. Genovese stellte in einer Übersichtsarbeit Wahrscheinlichkeiten für eine transiente bzw. permanente Rekurrensparese unter Anwendung dieser Operationsmethode von 1,3 - 11,1\% bzw. 0 - 1,9\% heraus (Genovese et al. 2013).

Eine weitere Operationstechnik ist die Dunhill-Operation. Sie beinhaltet eine Kombination aus einer unilateralen Hemithyreoidektomie und einer subtotalen Resektion des zweiten Lobus unter Schonung von ca. 2 - 5 ml Restvolumen. Auf diesem Weg kann in 40 - 57 \% der Fälle eine lebenslange Hormonsubstitution umgangen und Nervläsionen sowie Verletzungen der Nebenschilddrüsen vermieden werden (Moreno et al. 2006). Die DunhillVariante wird vornehmlich zur Therapie des Morbus Basedow eingesetzt. Trotz Belassen von möglicherweise autonomem Restgewebe zeigt eine Untersuchung der Arbeitsgruppe um Moreno aus Barcelona, dass erst ab einem Restvolumen von mehr als $5 \mathrm{ml}$ das Rezidivrisiko, also eine postoperative Hyperthyreose, signifikant ansteigt (Moreno et al. 2006). 
Auch die vollständige Resektion, die Thyreoidektomie, ist eine gängige Operationstechnik. Sie führt zwar in jedem Fall zu einer substitutionsbedürftigen Hormonsituation, doch liegt die Erfolgsquote bei 100 \% (im Vergleich: Rezidivrate bei subtotaler Resektion 7,9 \%). Sofern die Operation durch eine/n erfahrene/n Chirurgen/in in einem spezialisierten Zentrum durchgeführt wird, können mittels kapselnaher Dissektion nach dorsal die empfindlichen Strukturen N. laryngeus recurrens und die Nebenschilddrüsen geschont werden (Delbridge 2003; Sosa et al. 2008).

\subsubsection{Radioiodtherapie}

Die Schilddrüse benötigt zur Hormonbiosynthese Iodid. Dieses gelangt gegen ein Konzentrationsgefälle, wie bereits beschrieben, über aktiven Transport mittels des NIS über die basolaterale Plasmamembran in die Follikelepithelzellen. Das NIS-Protein erreicht auf diese Weise eine 20 - 40-fach höhere Konzentration des Iodids intrafollikulär als extrafollikulär. Dieser spezielle Transportmechanismus begründet die selektive Iodid-Aufnahme ausschließlich im Schilddrüsenparenchym. Andere Organe verfügen ebenfalls über die Expression des NIS, beispielsweise die Parietalzellen des Magens oder die der Speicheldrüsen. Die Schilddrüse ist jedoch das einzige Organ, welches radioaktives Iod auch organifizieren kann. Das heißt, die Schilddrüse kann das Iod in Schilddrüsenhormonvorstufen einbauen und es retiniert somit länger im Parenchym (Köhrle und Schmutzler 1998). Die Radioiodtherapie nutzt diese Besonderheit für die interne Bestrahlung mit dem radioaktiven Isotop ${ }^{131}$ Iod. Zudem begünstigt der anatomische Aufbau der Schilddrüse die Wirksamkeit der RIT. Das Isotop ${ }^{131}$ Iod ist überwiegend ein Beta-Strahler mit einer mittleren Reichweite von 0,44 mm und einer maximalen Reichweite von 2,2 $\mathrm{mm}$. In einer gesunden Schilddrüse misst eine Follikelepithelzelle im Durchmesser 0,05 - 0,5 mm. Somit korreliert die Reichweite der therapeutisch wirksamen $\beta$-Strahlung optimal mit der Größe der Follikel. Die umliegende vaskularisierte Struma wird mit ausreichender Dosis erreicht, dagegen werden angrenzende extrathyroidale, zu schonende Strukturen nahezu keiner Strahlung ausgesetzt (Bell und Grünwald 2000). Bezüglich der Indikation und Differentialindikation sowie zu den Kontraindikationen wird auf die Tabelle 1 verwiesen.

Um die individuelle Iodkinetik und die effektive Halbwertszeit des ${ }^{131}$ Iod zu ermitteln, wird ein Radioiodtest vor einer RIT durchgeführt. Genauere Erläuterungen dieses Vorgehens siehe weiter unten (siehe 2.4 Radioiodtest). 


\begin{tabular}{|c|c|c|}
\hline Indikationen & Absolute Kontraindikation (KI) & Relative KI. \\
\hline 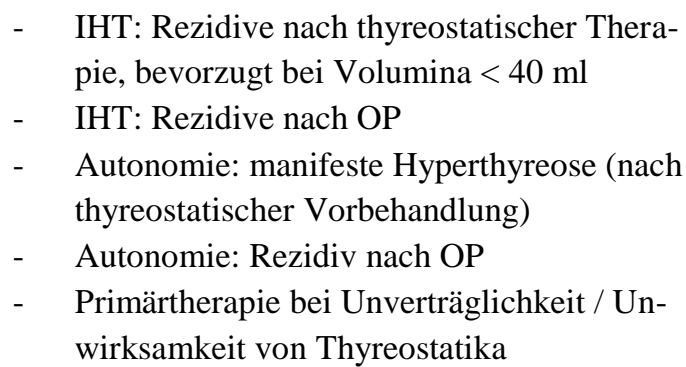 & $\begin{array}{ll}\text { - } & \text { Gravidität / Laktation } \\
- & \text { Malignomverdacht } \\
- & \text { Niedrige Radioiodaufnah- } \\
& \text { me im Radioiodtest } \\
& (<10 \%) \\
- & \text { Kinderwunsch in 6 Mona- } \\
& \text { ten nach RIT }\end{array}$ & $\begin{array}{ll}\text { - } & \text { Jugendliches } \\
& \text { Alter } \\
\text { - } & \text { Große Strumen } \\
& (>60 \mathrm{ml})\end{array}$ \\
\hline
\end{tabular}

Tabelle 1: Indikationen und Kontraindikationen zur RIT bei MB / funktioneller Autonomie, (mod. nach Hotze u. Schumm-Draeger 2003)

\subsection{Gesetzeslage in Deutschland}

Der Umgang mit offenen radioaktiven Stoffen unterliegt in Deutschland dem Atomgesetz. Das maßgebliche Dokument für die Anwendung in der Nuklearmedizin ist die „Richtlinie Strahlenschutz der Medizin“, zu finden in der „Richtlinie zur Verordnung über den Schutz vor Schäden durch ionisierende Strahlen“ der Strahlenschutzverordnung (StrlSchV) (Bundesministerium für Umwelt, Naturschutz, Bau und Reaktorsicherheit 2011). In dieser Verordnung ist der regelgerechte Umgang mit radioaktiven Materialien genauestens beschrieben und reglementiert. Zudem existiert eine Richtlinie des Länderausschusses für Atomkernenergie (LAA), welche sich explizit mit dem „Strahlenschutz in der Medizin“ beschäftigt. So ist nach den $\S \S 4-6$ StrlSchuV und der Vorschiften $\S \S 80-81$ StrlSchuV im Vorfeld jedweder Anwendung radioaktiver Stoffe in der Diagnostik und Therapie die rechtfertigende Indikation zu stellen und schriftlich zu dokumentieren. Dies erfolgt durch den behandelnden Mediziner mit entsprechender Sach- und Fachkunde. Nach $§ 81$ Abs. 3 StrlSchuV muss vor geplanter Therapie oder Diagnostik ein individuell angepasster Bestrahlungsplan von einem Arzt mit Fachkunde im Strahlenschutz in Zusammenarbeit mit einem Medizinphysikexperten ebenfalls schriftlich festgelegt werden. Der Plan beinhaltet eine exakte Dosiskalkulation für das Zielvolumen, mit möglichst niedriger Strahlenbelastung der umliegenden Organe und Körperteile (Bundesministerium für Umwelt, Naturschutz, Bau und Reaktorsicherheit 2011).

Eine Therapie mit ${ }^{131}$ Iod ist in Deutschland nur mit einem stationären Mindestaufenthalt von 48 Stunden möglich. Die nuklearmedizinische Abteilung muss in ihrer Einrichtung und Ausstattung den Richtlinien vom Deutschen Institut für Normung entsprechen (DIN 6844-1:2005-01; DIN 6844-2:2005-01). Nur so ist gewährleistet, dass der Großteil des nicht in der Schilddrüse aufgenommen Radioiods ausgeschieden und regelgerecht entsorgt wird. Zudem ist die Entlassungsaktivität mit $250 \mathrm{MBq}$ festgelegt, beziehungsweise muss die Dosisleistung in Abstand von zwei Metern vom bestrahlten Patienten unter 3,5 $\mu \mathrm{Sv} / \mathrm{h}$ liegen (Bell und Grünwald 2000). 
Nach 1990 wurden 32 ostdeutsche nuklearmedizinische Zentren nach Umbau nach den atomgesetzlichen Bestimmungen zugänglich, folglich stieg die Bettenkapazität für Radioiodpatienten (Deckart et al. 1999). Zusätzlich verbesserten sich durch die Erhöhung der Entlassungsaktivität in den Strahlenschutzvoraussetzungen die Behandlungskapazitäten in Deutschland im Vergleich zu den vergangenen Jahren. Nichtsdestoweniger ist infolge der optimierten alimentären Iodversorgung und der damit einhergehenden Abnahme der Autonomieinzidenz bei stationären nuklearmedizinischen Behandlungsfällen ein Rückgang um 17,5 \% in den Jahren 2004 bis 2012 zu verzeichnen. Im Jahr 2012 fand sich bei 114 von insgesamt 2017 Krankenhäusern in Deutschland eine nuklearmedizinische Station, dies ist eine Verringerung um drei Einrichtungen im Vergleich zur letzten Erhebung (Lorenz et al. 2015).

\subsection{Ziel und Hintergrund der Arbeit}

\subsubsection{Abteilungsspezifischer Hintergrund der Arbeit}

Bis in die späten 90er Jahre wurde ein sehr aufwendiger Radioiodtest mit Uptakemessungen nach 24, 48, 72, 96 Stunden durchgeführt. Ein solches Vorgehen birgt logistische Probleme. Vor allem älteren Patienten sowie Patienten mit weiteren Anreisewegen scheint ein solch extensiver Test nicht zumutbar. Aufgrund theoretischer Überlegung wurde durch die Arbeitsgruppe um Prof. Dr. Luig (damalige Arbeitsgruppe Medizinphysik in der Abteilung Nuklearmedizin der UMG) eine späte Ein-Punkt-Messung zur Berechnung der zu applizierenden Aktivität etabliert. Der Uptake zu einem späten Zeitpunkt, z. B. sieben Tage nach Applikation lässt nur eine geringe Streubreite der theoretisch möglichen Kurven der intrathyreoidalen Iodkinetik zu. Gleichzeitig wurden in diesem Ansatz krankheitsspezifische Halbwertszeiten in die Modellierung der frühen Iodkinetik mit eingerechnet, die aus Krankheitsverläufen der Abteilung selbst generiert wurden. Diese Methode wurde nach der Pensionierung von Prof. Dr. Luig aufgegeben und den aktuellen Empfehlungen der DGN angepasst. In diesen Empfehlungen wurde zwar eine späte Ein-Punkt-Messung empfohlen, krankheitsspezifische Halbwertszeiten wurden hingegen nicht berücksichtigt.

Seit Einführung der postradioiodtherapeutischen Dosimetrie im März 2013 mit dem System der Firma Medsystem GmbH Hospitaltechnik in der Abteilung Nuklearmedizin fiel unterdies eine erhebliche Diskrepanz zwischen den geplanten und erreichten Herddosen im Rahmen der Radioiodtherapie gutartiger Schilddrüsenerkrankungen auf. Zunächst wurde angenommen, dass sich diese Diskrepanz durch die Verwendung eines Radioiodtests mit einer Ein-Punkt-Messung erklärt. Infolgedessen wurde im Juli 2013 auf eine Adaptation mit einer Zwei-Punkt-Messung unter Annahme eines Maximal-Uptakes nach 24 Stunden 
übergegangen. Unter diesen Bedingungen waren die Diskrepanzen nicht mehr so hervorgehoben, blieben aber dennoch bestehen.

\subsubsection{Ziel der Arbeit}

Ziel dieser Studie ist eine Überprüfung, ob die geplante Herddosis unter Verwendung einer präradioiodtherapeutischen Dosimetrie mit einer Zwei-Punkt-Messung unter Annahme eines Maximal-Uptakes nach 24 Stunden erreicht wurde. Diese Überprüfung erfolgt über die postradioiodtherapeutische Dosimetrie als Referenz.

Im Anschluss soll die präradioiodtherapeutische Dosimetrie auf etwaige Fehlerquellen bzw. Einflussfaktoren auf das Erreichen bzw. Nicht-Erreichen der geplanten Herddosen untersucht werden.

In einer weiteren Analyse werden die prä- und postradioiodtherapeutische intrathyreoidale Iodkinetik verglichen. Bei Auftreten von Abweichungen soll eine stimmige Erklärung für diese erarbeitet werden.

Aus den gewonnenen Daten sollen gegebenenfalls Empfehlungen für ein zukünftiges therapeutisches Vorgehen entwickelt werden.

\section{Patienten und Methoden}

\subsection{Patienten}

Diese retrospektive Analyse bezieht sich auf konsekutive Patienten, die in der Abteilung Nuklearmedizin des Universitätsklinikums Göttingen im Zeitraum zwischen März 2013 und Juli 2014 eine Radioiodtherapie zur Behandlung einer Hyperthyreose aufgrund einer funktionell relevanten Schilddrüsenautonomie oder Immunthyreopathie erhalten haben. Von anfänglich 183 Patienten waren abschließend nur 49 Datensätze vollständig zu recherchieren. Diese Datensätze bilden die Grundlage der Analyse. Hauptgründe für den Ausschluss der 134 Patienten waren zum einen, dass die Messungen im Rahmen des Radioiodtest nicht in der Universitätsmedizin Göttingen (UMG) stattgefunden haben $(\mathrm{n}=40)$, zum anderen fanden in 90 Fällen die Kontrolluntersuchungen nach drei bis sechs Monaten nicht in der Universitätsmedizin statt. In einem Fall fand sich ein nicht für die Studie geeignetes Krankheitsbild $(\mathrm{n}=1)$.

Die Patienten mussten folgende Kriterien erfüllen:

- Erkrankung: Morbus Basedow, unifokale Autonomie, multifokale Autonomie, disseminierte Autonomie

- Mindestens einen Nachsorgetermin drei bis sechs Monate nach Radioiodtherapie im Endokrinologikum Göttingen oder in der Universitätsklinik Göttingen 
- Radioiodtest mit mindestens zwei Uptake-Messungen unter Zugrundelegung des 24-hUptakes als Speichermaximum

Folgende Parameter wurden prätherapeutisch erhoben:

- Alter

- Geschlecht

- Erkrankung

- Schilddrüsenspezifische Medikation, zum Zeitpunkt des Radioiodtests und der RIT

- Sonographisch bestimmtes Schilddrüsenvolumen (gesamt und autonom, dies entspricht dem Zielvolumen)

- Schilddrüsen-in-vitro-Parameter (TSHb, fT3, fT4) zum Zeitpunkt des Radioiodtests und der -therapie

- Fallweise Schilddrüsen-Autoantikörper (TPO, TRAK)

- Radioiodtest mit Dosiskonzept, effektiver Halbwertszeit, Aktivität (mittels einer Uptake-Messung nach 24 Stunden und einer Messung nach sieben Tagen)

Folgende Parameter wurden posttherapeutisch erhoben:

- Erreichte Herddosis

- Schilddrüsenspezifische Medikation

- Schilddrüsen-in-vitro-Parameter (TSHb, fT3, fT4)

- Fallweise Schilddrüsen-Autoantikörper (TPO, TRAK)

\subsection{Schilddrüsensonographie}

Kaum ein anderes diagnostisches Mittel in der Medizin ist vergleichbar nebenwirkungsfrei, schmerzlos, wirtschaftlich und einfach in der Durchführung wie die Sonographie. Die anatomische Lage der Schilddrüse begünstigt diese Untersuchungsmethode in der Endokrinologie zusätzlich. Herdbefunde ab einem Millimeter Durchmesser können mit modernen Sonographiegeräten zuverlässig und in Echtzeit diagnostiziert werden, Mikrokalk bereits im Mikrometerbereich (Schmidt und Görg 2015). So ist nach der Leitlinie der Deutschen Gesellschaft für Nuklearmedizin e.V. (DGN) die Schilddrüsensonographie bei jeder Schilddrüsenerstdiagnostik obligat und Mittel der Wahl bei einer erstmaligen Bildgebung (Hotze und Schumm-Draeger 2003).

Grundlegendes Prinzip einer Ultraschalluntersuchung ist die Interaktion des Schalls mit dem Gewebe. Diese Wechselwirkungen bestehen im Wesentlichen aus Absorption, Reflexion, Brechung und Streuung. Jedes beschallte Gewebe erzeugt auf diese Weise ein individuelles Echo, welches mit einer Ultraschallsonde erfasst wird (Morneburg 1995). Einziges Defizit der Methode ist die interindividuelle Varianz bzw. die mäßige Reproduzierbarkeit. Demzufolge ist für ein verlässliches Ergebnis ein erfahrener Mediziner erforderlich, laut 
DGN wird eine Interobserver-Varianz bei der sonographischen Volumetrie (untersucherabhängiger Fehler) von $10-30 \%$ beobachtet (Dietlein et al. 2003).

\subsubsection{Apparatur}

Für die Anwendung in der Schilddrüsendiagnostik eignen sich alle modernen B-ModeUltraschallgeräte mit Linear- oder Sektorschallkopf. Die Schallfrequenz neuster Geräte liegt bei 7,5 bis $13 \mathrm{MHz}$, wobei die Wahl des Schallkopfes und der Frequenz dem zu untersuchenden Gewebe angepasst wird. Niedrige Sendefrequenzen erhöhen, sofern nötig, die Eindringtiefe, aber immer auf Kosten der Feinauflösung. Besonders große Strumen bedürfen darüber hinaus gegebenenfalls zur präzisen Vermessung zusätzlich zum Linearschallkopf (Länge nicht unter $6 \mathrm{~cm}$ ) die Verwendung eines Sektorschallkopfs mit 3,5 - 5 MHz (Hotze und Schumm-Draeger 2003; Schmidt und Görg 2015).

In der Abteilung Nuklearmedizin der Universität Göttingen werden die sonographischen Untersuchungen entweder mit dem Ultraschallgerät HD 11 XE der Firma PHILIPS (Amsterdam, Niederlande) mit einem Linearschallkopf zwischen 5 und $12 \mathrm{MHz}$ durchgeführt oder mit dem Gerät Acuson Antares der Firma SIEMENS (Erlangen, Deutschland). Das Fabrikat von Philips ist nicht mit Schallköpfen ausgestattet, die eine adäquate Erfassung der Längsachse bei Strumen über ca. $60 \mathrm{ml}$ möglich machen. Um den wahren Längsdurchmesser zu erfassen, werden verschiedene Extrapolationsmöglichkeiten von den Untersuchern wahrgenommen (z. B. Zusammensetzen mehrerer Teilbilder bzw. digitales Abfahren des Längsdurchmessers und Erstellung eines virtuellen Längsdurchmessers). Das Gerät der Firma Siemens hat neben den Hochfrequenzschallköpfen, die für eine hohe Auflösung wichtig sind (VTX 13-6, hochauflösend, Linearschallkopf), auch einen Abdominalschallkopf mit 3,5 MHz Frequenz (CH6-2, niedrigauflösend zur Volumetrie, Sektorschallkopf). Die Anwendung dieses Schallkopfes ermöglicht es, auch sehr große Strumen bis ca. $150 \mathrm{ml}$, zum Teil in sub- oder retrosternaler Lage, optimal in ihrer Längsausdehnung zu erfassen (Goretzki 2004, Meller, persönliche Kommunikation 2016).

\subsubsection{Durchführung und Befunddokumentation}

Die Sonographie der Schilddrüse kann ohne vorbereitende Maßnahmen am liegenden Patienten durchgeführt werden. Um eine leichte Überstreckung der Halswirbelsäule zu erzeugen, wird im Schulterbereich des auf dem Rücken liegenden Patienten ein Kissen positioniert. Der Schallkopf wird von der Höhe des Ringknorpels sanft und ohne Druck in horizontaler Ebene nach kaudal bewegt. Sofern die Schilddrüse nicht vergrößert ist, lassen sich auf diese Weise beide Lappen parallel im Querschnitt darstellen. Eine Darstellung im Längsschnitt wird mittels schrägen Aufsetzens des Schallkopfes und einer Führung von kraniolateral nach mediokaudal erreicht. Referenzpunkte zur Befundung (Anatomie und Echogenität) bieten angrenzende Strukturen wie Gefäße und Muskelgruppen (Arteriae 
carotides, Venae jugulares, Musculi sternothyroidei, sternohyoidei und sternocleidomastoidei) (Hotze und Schumm-Draeger 2003; Schmidt und Görg 2015).

Zur sicheren Diagnosestellung ist ein Sonogramm jedoch nicht ausreichend, demnach ist die Befundung rein deskriptiv. Erfasst werden Angaben über das Schilddrüsenvolumen (sofern erkennbar unter Berücksichtigung aller drei Ebenen) für jeden der zwei Schilddrüsenlappen, Besonderheiten der Lage und der Form, eine Beschreibung der Binnenstruktur (z. B. Mikrokalk), Schilderung der Lokalisation, Echogenität und Begrenzung etwaiger Herde und auch die angrenzenden Strukturen (oben beschrieben, aber auch die zervikalen Lymphknoten, Nebenschilddrüsen etc.) werden beurteilt. Wie bereits erwähnt, dient das umliegende Gewebe als Referenzwert hinsichtlich des Echoverhaltens und der Homogenität der Drüse. Abweichungen zu gesundem, echonormalem Schilddrüsenparenchym (normal große Follikel) können eine verminderte oder vermehrte Echogenität sein. Umschriebene Herdbefunde werden in gleichem Maße bezüglich ihres Echoverhaltens befundet (Hotze und Schumm-Draeger 2003).

Zur Sicherung einer Verdachtsdiagnose sind weitere Untersuchungen wie eine Feinnadelpunktion (histologische Beurteilung) oder ein Szintigramm (Aktivitätszustand) erforderlich. Eine Studie der Universität Würzburg zeigt, dass bei unter dreißigjährigen Patienten ein Sonogramm ohne Herdbefunde mit Gewissheit gegen eine Schilddrüsenautonomie spricht, bei Älteren aber eine Autonomie in keinem Fall durch eine rein sonographische Untersuchung ausgeschlossen werden kann (Becker et al. 1986).

\subsubsection{Volumenberechnung mittels Sonographie}

Die Größen- bzw. Volumenbestimmung der Gesamtdrüse und eventuell vorhandener Läsionen erfolgt in der Schilddrüsendiagnostik routinemäßig mithilfe einer abgewandelten Form der Volumenformel für ein Rotationsellipsoid. Die zwei Schilddrüsenlappen werden getrennt voneinander betrachtet und summiert. Das Volumen des Isthmus ist meist marginal und wird außer Acht gelassen.

$$
\begin{gathered}
\text { Vol. }[\mathrm{ml}] \text { eines Lappens }=\text { Länge }[\mathrm{cm}] * \text { Breite }[\mathrm{cm}] * \text { Tiefe }[\mathrm{cm}] * 0,5 \\
\text { Gesamtvolumen =Vol.re.Lappen +Vol.li.Lappen }
\end{gathered}
$$

Formel 1: Ellipsoidformel zur Berechnung des Schilddrüsenvolumens $0,5=$ Vereinfachung, statt korrekterweise $\frac{\pi}{6}=0,524 \mathrm{~s}$. Ellipsoidformel

Zusätzlich beeinflussen Alter und Geschlecht das Volumen. In Tabelle 2 werden die aktuellen Grenzwerte der DGN aufgeführt. Diese Daten entsprechen dem Mittelwert von 
Schilddrüsenvolumina aus einem ausreichend mit Iod versorgtem Gebiet. Sie können lediglich als Referenzbereiche und nicht als festgelegte Grenzen betrachtet werden.

\begin{tabular}{|l|l|}
\hline Alter / Geschlecht & Volumen in ml \\
\hline 6 Jahre & $4 \mathrm{ml}$ \\
12 Jahre & $8 \mathrm{ml}$ \\
$15-18$ Jahre & $15 \mathrm{ml}$ \\
Erwachsene Frauen & $18 \mathrm{ml}$ \\
Erwachsene Männer & $25 \mathrm{ml}$ \\
\hline
\end{tabular}

Tabelle 2: Obere Grenzwerte für physiologische Schilddrüsenvolumina (Dietlein et al. 2003)

\subsection{Schilddrüsenszintigraphie mit ${ }^{99 \mathrm{~m}}$ Technetium}

Ergänzend zur morphologischen Beurteilung mittels Sonographie gestattet die szintigraphische Untersuchung eine Bewertung des globalen und lokalen Funktionszustandes der Schilddrüse. Dieser wird an der Farbgebung im Szintigramm, welche sich proportional zum Ausmaß der Iodkinetik verhält, ablesbar. Grundprinzip dieser Methodik ist demnach die Tatsache, dass die Hauptiodaufnahme speziell in funktionell aktiven Follikelepithelzellen der Schilddrüse (s. 1.3.2.2. Radioiodtherapie) stattfindet. Die quantitative Schilddrüsenszintigraphie demonstriert folglich bildlich die globale und lokale Aktivität der thyreoidalen Iodaufnahme (Bähre et al. 1988).

\subsection{1 ${ }^{99}{ }^{9}$ Technetium $\left({ }^{99} \mathrm{~m} \mathrm{Tc}\right)$}

Neben ${ }^{123}$ Iod und unter speziellen Umständen auch ${ }^{131}$ Iod ist das bei der Szintigraphie am häufigsten verwendete Radionuklid ${ }^{99 \mathrm{~m}}$ Tc. Das erste Isotop des Technetiums wurde von Emilio Segrè und Carlo Perrier an der Universität Palermo 1937 nach dem Beschuss von Molybdänfolie mit Deuteronen nachgewiesen. Bereits 66 Jahre zuvor hatte Mendelejew die Eigenschaften des Technetiums vorhergesagt. Segrè und Perrier benannten es nach dem griechischen Wort $\tau \varepsilon \chi v \eta \tau o ́ \varsigma$ für künstlich, da keine natürlichen stabilen Isotope des Elementes bekannt sind. Es wird rein synthetisch hergestellt (Neumüller 1972).

${ }^{99}$ Molybdän $\left({ }^{99} \mathrm{Mo}\right)$ zerfällt über einen $\beta^{-}$-Zerfall in das ${ }^{99 \mathrm{~m}}$ Technetium. Dieser Übergang findet bei ca. $20 \%$ der Kerne unmittelbar statt, bei ca. $80 \%$ der Kerne befindet sich das ${ }^{99 \mathrm{~m}}$ Technetium noch in einem angeregten Kernzustand, mit einer physikalischen HWZ von etwa sechs Stunden. Wenn der angeregte Kernzustand in den Grundzustand zurückfällt, wird Energie in Form von Gammaquanten mit einer Energie von $140 \mathrm{keV}$ freigesetzt. Diese zweite Reaktion ist die entscheidende Kernreaktion für die Szintigraphie, da der 140 keV-Peak für die Bildgebung maßgeblich ist (Krieger 2009; Krieger 2013). 


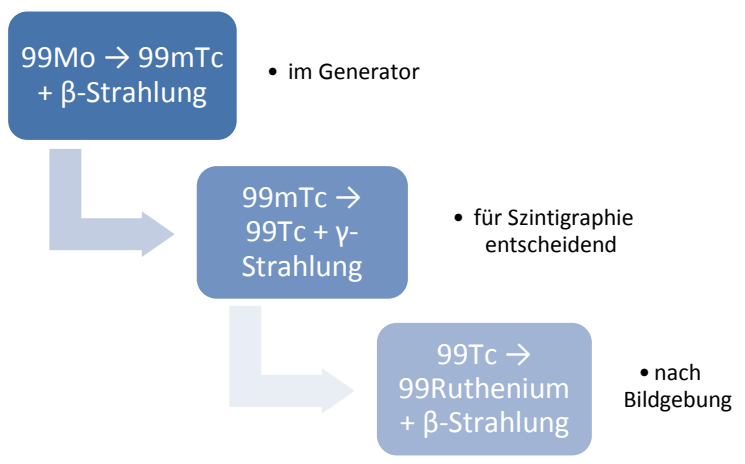

Abbildung 3: Zerfallsreaktionen Molybdän (vereinfacht)

${ }^{99}$ Tc zerfällt letztendlich bei einer $\mathrm{HWZ}$ von $2 * 10^{5}$ Jahren zu stabilem Ruthenium (Haïssinsky und Adloff 1968; Hotze und Schumm-Draeger 2003).

Gewonnen wird das nur in verschwindend geringen Mengen natürlich vorkommende ${ }^{99 \mathrm{~m}} \mathrm{Tc}$ in einem Radionuklidgenerator. In diesem Gerät liegt das Mutternuklid ${ }^{99}$ Mo an eine Anionenaustauschersäule gebunden vor. Diese chromatographische Säule ist mit Aluminiumoxid gefüllt, an welchem das ${ }^{99} \mathrm{Mo}$ in Form von Molybdat $\left(\mathrm{MoO}_{4}{ }^{2-}\right)$ fest haftet und eine Wanderung im wässrigen Elutionsmittel (NaCl-Lösung) ausgeschlossen ist. Das Zerfallsprodukt ${ }^{99 \mathrm{~m}} \mathrm{Tc}$ hingegen, vorliegend als Pertechnetat $\left(\mathrm{TcO}_{4}{ }^{-}\right)$, kann leicht herausgelöst werden. Die so geschaffene Natriumpertechnetatlösung kann dem Patienten zur szintigraphischen Untersuchung injiziert werden. Die Generatoren sind mit Blei abgeschirmt und kommerziell verfügbar. Nach Lieferung lassen sie sich in etwa 14 Tage lang eluieren (Kauffmann et al. 1996).

Warum bei der Szintigraphie ${ }^{99 \mathrm{~m}} \mathrm{Tc}$ bevorzugt wird, ist unter anderem in der relativ kurzen physikalischen HWZ und der folglich verringerten Strahlenbelastung der Patienten begründet. Zudem weist ${ }^{99 \mathrm{~m}}$ Tc (Pertechnetat: Atomradius $=136 \mathrm{pm}$ ) eine dem Iodid (Atomradius $=133 \mathrm{pm}$ ) ähnliche Molekulargröße auf und wird aktiv über den NIS aufgenommen. Dies geschieht jedoch in einer 15-fach geringeren Menge, als für Iodid üblich. Intrazellulär unterscheiden sich die beiden Stoffe zusätzlich in ihrer Kinetik. Während Iod rasch in den Thyreoglobulinverbund eingebaut wird (Iodisation), verlässt ${ }^{99 \mathrm{~m}}$ Tc per Diffusion die Zelle unverändert. Diese Bewegung ist 20 - 30 min. p. i. von klinischer Bedeutung (Haïssinsky und Adloff 1968; Burke et al. 1972; Krieger 2013).

\subsubsection{Szintigraphische Messtechnik}

Die nuklearmedizinische Messtechnik beruht auf der Möglichkeit, Gammastrahlen mit einer Gammakamera, nachweisen zu können. Unter Einsatz dieses Gerätes kann die räumliche Verteilung des ${ }^{99 \mathrm{~m}} \mathrm{Tc}$ in der Schilddrüse sichtbar gemacht werden. Dieses radioaktive 
Verteilungsmuster ist der Istzustand zum Zeitpunkt der Messung. Zentrales Bauteil der Kamera ist ein großer NaI(TI)-Szintillationskristall, welcher die emittierten Gammaquanten absorbiert. Durch einen vorgeschalteten Parallellochkollimator aus Blei ist gewährleistet, dass nur senkrecht auftreffende Photonen und keine gestreuten einfallen können. Alle gestreuten Quanten werden von den Kollimatorwänden aufgenommen. Bei der Anwendung von ${ }^{99} \mathrm{~m}$ Tc in der Endokrinologie werden Schilddrüsen-Spezialkollimatoren mit schmalen Löchern und dünnen Septen eingesetzt. Stärkere Bleistege werden nur bei Nukliden mit höherer Gammaenergie benötigt. Beim Gebrauch von ${ }^{99 \mathrm{~m}} \mathrm{Tc}$ würde eine derartige Abschirmung lediglich die Auflösung verschlechtern. Im Kristall erzeugen die gefilterten Quanten ein ihrer Energie entsprechendes Lichtsignal, welches wiederum mithilfe von Photomultipliern (PM) und einer Software detektiert und analysiert wird. Liegt die Energie des Lichtquants in einem zuvor festgelegten Energiefenster, wird ein Bildpunkt im späteren Szintigramm diesem Zerfall im Patienten zugeordnet. Dies passiert im sogenannten Diskriminator (Emrich und Bitter 1979; Morneburg 1995; Schicha et al. 2013).

In der Schilddrüsendiagnostik wird eine statische Form der Szintigraphie angewandt. Hier differenziert man zwischen der Cold-Spot-Szintigraphie (nuklidarmer Bereich, negativer Kontrast) und der Hot-Spot-Szintigraphie (nuklidreicher Bereich, positiver Kontrast). Zwischen diesen Befunden ist jedoch keine strikte Abgrenzung möglich. Es können sowohl szintigraphisch aktive als auch passive Areale gemeinsam auftreten. Die gesammelten Rohdaten werden digital gespeichert und auffällige Areale (Region of Interest (ROI)) können anschließend eingehender betrachtet werden (Schicha et al. 2013).

Zu Beginn der Untersuchung wird die Aktivität der Injektionslösung in der Spritze gemessen und nach Applikation findet eine Rückmessung statt. Mit dem Wissen über die zuvor applizierte Aktivitätsmenge und der in der Spritze verbliebenen Aktivität, kann nach der quantitativen Bestimmung der lokalen und globalen ${ }^{99 \mathrm{~m}}$ Tc-Aufnahme in die Follikelepithelzellen der prozentuale Anteil dieser Radioaktivitätsmenge an der Spritzenaktivität ermittelt werden. Dieser Wert, der ${ }^{99 \mathrm{~m}} \mathrm{Tc}$-Uptake (TcTU $={ }^{99 m}$ Tc thyroid uptake), ist von entscheidender diagnostischer Bedeutung, da der Uptake von $\mathrm{TcO}_{4}{ }^{-}$und die Clearance von Iodid gut korrelieren (Büll und Hör 1990). In ausreichend mit Iod versorgten Gebieten liegt physiologisch ein ${ }^{99 \mathrm{~m}}$ Tc-Uptake von $0,5-2 \%$ vor (Gotthardt et al. 2006).

Nach etwa 15 Minuten ist der maximale Uptake erreicht. Wie oben bereits beschrieben, unterscheiden sich die beiden betrachteten Stoffe in ihrer intrazellulären Kinetik (siehe 2.3.1 99mTechnetium). Mit dieser Tatsache lässt sich auch die Plateauphase in der Aufnahme von ${ }^{99 \mathrm{~m}} \mathrm{Tc}$-Pertechnetat zwischen der 15 . und 30 . Minute p.i. erklären. ${ }^{99 \mathrm{~m}} \mathrm{Tc}$ Pertechnetat verlässt die Schilddrüse wieder, während die Aufnahmekurve von Iodid kontinuierlich ansteigt. Folglich sollte die Bestimmung des TcTU frühzeitig (vor der Plateauphase) stattfinden. In dieser Zeitspanne ist der TcTU am ehesten mit der Radioiodclearance gleichzusetzen (Meller und Becker 2002). 


\subsubsection{Durchführung und Befunddokumentation}

Den Leitlinien der DGN zufolge wird Erwachsenen intravenös eine Menge von 37 - 75 $\mathrm{MBq}{ }^{99 \mathrm{~m}} \mathrm{Tc}$ verabreicht. Bei Einnahme von Schilddrüsenhormonen sollten diese Präparate vorher abgesetzt werden (Triiodthyronin (T3)-Präparate zehn Tage vor der Untersuchung, Levothyroxin (T4)-Präparate vier Wochen vor der Untersuchung), zudem sollten im Vorhinein keine stark iodhaltigen Medikamente verabreicht werden (Vermeidung kompetitiver Hemmung des NIS). Zwecks Eichung wird die exakte Aktivität des Spritzeninhaltes vor Applikation gemessen und dokumentiert. Beginn der eigentlichen Szintigraphie ist 15 - 25 Minuten nach der Injektion, mit anschließenden Messungen über einen Zeitraum von fünf bis zehn Minuten. Bei allen Messungen muss die Gammakamera identisch justiert werden, dies ist insbesondere bei Lage und Breite des Energiefensters von Bedeutung. In der nuklearmedizinischen Abteilung der UMG wird eine 1-Kopf-Gammakamera, Modell CX250Mini-Cam, der Firma Intermedical eingesetzt. In der schriftlichen Befunddokumentation muss unter anderem das Szintigramm als Papierausdruck oder Röntgenfilm vorliegen. Die Bezeichnung des verwendeten Radiopharmakons, die verabreichte Aktivität und der errechnete TcTU müssen ebenso vermerkt sein (Deutsche Gesellschaft für Nuklearmedizin e.V.).

\subsection{Radioiodtest}

Die patientenspezifische Dosisbestimmung ist in Deutschland in den Strahlenschutzbestimmungen gesetzlich geregelt. Eine Über- bzw. Unterdosierung soll auf diese Weise vermieden werden. Dies geschieht unter Berücksichtigung der ALARA-Leitlinie (As Low As Reasonably Achievable) des Strahlenschutzes. Das heißt, die Strahlenbelastung mit ionisierenden Strahlen ist so gering wie möglich zu halten (Berkhout 2015). Eine Kalkulation der zu applizierenden Aktivität zum Erreichen der geplanten Herddosis gelingt potentiell über die Erfassung des individuellen Iodstoffwechsels mittels Uptaketests mit einem Radionuklid des Iods. Sofern möglich, sollte dieser Radioiodtest in kurzem Abstand zur eigentlichen RIT terminiert werden. So ist es wahrscheinlicher, dass die Iodkinetik zum Therapiezeitpunkt in etwa die Verhaltensweise während der Testphase widerspiegelt. In der UMG wird für den Test das gleiche Nuklid wie für die Therapie eingesetzt. Es handelt sich hierbei um ${ }^{131}$ Iod mit einer Aktivität der Testkapsel von 1,11 MBq. Diese Aktivität wird annähernd quantitativ im nüchternen Zustand beim Patienten im oberen Dünndarm vollständig resorbiert.

Wie zuvor unter 1.3.2.2 Radioiodtherapie beschrieben, handelt es sich bei ${ }^{131}$ Iod in erster Linie um einen Beta-Strahler, der von einem Gamma-Zerfall von unter anderem $364 \mathrm{keV}$ begleitet wird. Diese Strahlung kann nun extrakorporal gemessen werden. Es wird vereinfachend angenommen, dass nach 24 Stunden bei der Mehrheit der Patienten das Speicher- 
maximum erreicht ist. Zudem ist nach 24 Stunden der Anteil des sich im Blutkreislauf befindlichen ${ }^{131}$ Iod an der gemessenen Zählrate kleiner als $1 \%$ und kann vernachlässigt werden (Hänscheid et al. 2013). Aus diesem Grund kommt der ersten Messung besondere Bedeutung zu. Allerdings kann bei ausgeprägten Hyperthyreosen das Maximum bereits nach deutlich kürzerer Zeit erlangt werden. In diesem Fall sind eventuell frühere Messungen angezeigt (Bogner und Czempiel 1993).

\subsubsection{Definition Radioiod-Uptake}

Der Radioioduptake (RIU) ergibt sich durch die Erfassung der Aktivität im Schilddrüsengewebe zum gewählten Zeitpunkt t. Der Uptake ist demnach die prozentual zur applizierten Aktivität aufgenommene Menge ${ }^{131}$ Iod zum Zeitpunkt der Messung ( $\mathrm{t}$ ). Der AktivitätsZeit-Integral wird bestimmt. Je mehr Messpunkte vorhanden sind, desto genauer kann die Area under the curve (AUC) ermittelt werden.

$$
R I U(t)=\frac{\text { Aktivität in der Schilddrüse }(t)}{\text { Applizierte Aktivität }} * 100
$$

Formel 2: Berechnung des Radioioduptakes

\subsubsection{Durchführung und Befunddokumentation}

Die ${ }^{131}$ Iod-Testkapsel mit 1,1 MBq wird nach der Kalibrierungsmessung im Phantom dem Patienten oral verabreicht. Der Patient muss hierzu nüchtern sein und zusätzlich eine zweistündige Nahrungskarenz nach Darreichung einhalten. Die Menge der aufgenommenen Aktivität wird anschließend nach 24 Stunden und nach fünf bis sieben Tagen für die Dauer von fünf Minuten gemessen und in Prozent der Kapselaktivität angegeben. Entscheidend ist, dass die Messgeometrie der Phantommessung und der eigentlichen Uptake-Messung am Patienten identisch sind.

\subsubsection{Aufbau des Sondenmessplatzes}

Im Gegensatz zur Szintigraphie werden die Aktivitätsmessungen beim Radioiodtest nicht mit einer Gammakamera, sondern an einem Sondenmessplatz vorgenommen. Dieser besteht aus einer Einkristallsonde mit vorgeschaltetem trichterförmigem Kollimator aus Blei (Dicke $2 \mathrm{~cm}$ ) zur Abschirmung gegen die Hintergrundaktivität.

Das Prinzip ist eine möglichst hohe Impulsausbeute zu erzielen, bei Verzicht auf eine szintigraphische Bildgebung. Dieses Prinzip gilt als die effektivste in-vivo-Methode zum Nachweis radioaktiver Aktivität in einem ausgewählten Volumen (Schicha et al. 2013).

Messsonde und Kollimator sind über ein Stativ in zwei Ebenen auf die Schilddrüse einstellbar (siehe Abb. 4). Der Abstand zwischen Detektor und Patientenhals sollte $30 \mathrm{~cm}$ betragen, mindestens jedoch $25 \mathrm{~cm}$. Der Messfehler nimmt mit zunehmender Entfernung 
des Detektors stark zu. Verschiedene Phantommessungen zeigten, dass es zu einer Erhöhung der Abweichung von 1,5\% pro Millimeter Mehrabstand kommt. Dem zugrunde liegt das Abstandsquadrat-Gesetz (Hänscheid et al. 2013).

Der Kristall besteht, ähnlich dem der Gammakamera, aus Natriumiodid dotiert mit $1 \%$ Thallium (die hohe Dichte sichert eine ausreichende Gammaquant-Zählausbeute) und ist ebenfalls mit einem Photomultiplier (Sekundär-Elektronen-Vervielfacher (SEV)) verbunden. Die beim Zerfall des ${ }^{131}$ Iod zu ${ }^{131}$ Xenon emittierten Gammaquanten erzeugen im Kristall Lichtblitze (Szintillationen). Diese werden im SEV auf das $10^{9}$-Fache verstärkt (mittels Hochspannung von 3000 - 5000 Volt erfolgt eine Vervielfachung und Beschleunigung der Elektronen) und in einen Spannungsimpuls umgewandelt. Anschließend findet eine elektronische Weiterverarbeitung und Überprüfung dieser Signale statt. Ist die Prüfung positiv, kommt es zu einem Zählereignis (Emrich und Bitter 1979).

In der UMG wird das ISOMED 2101 - Gerät der Firma MED Nuklear-Medizintechnik Dresden $\mathrm{GmbH}$ für die Uptake-Messungen eingesetzt.

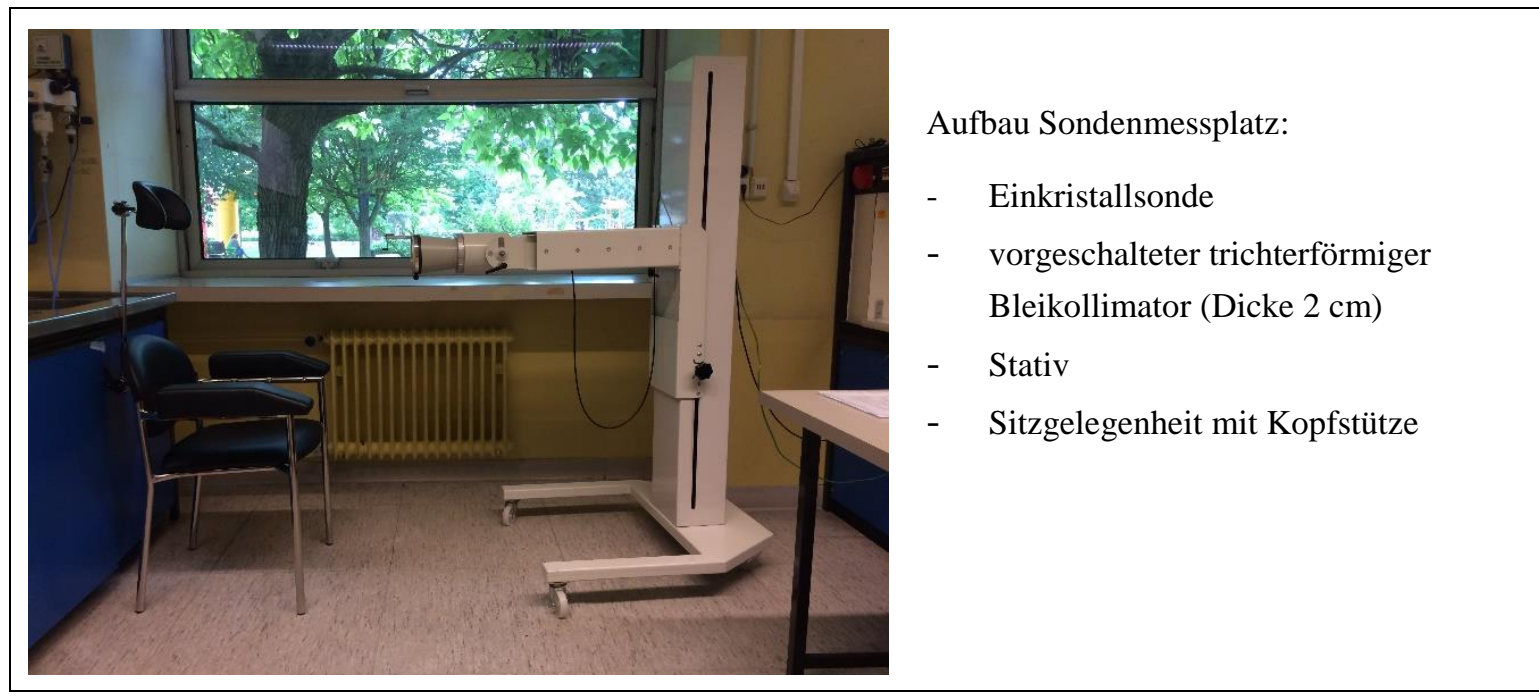

Abbildung 4: Sondenmessplatz in der nuklearmedizinischen Abteilung der UMG

\subsubsection{Qualitätssicherung}

Gesetzlich vorgeschriebene Qualitätskontrollen und die im Rahmen dieser Doktorarbeit zusätzlich durchgeführte Linearitätskontrolle dienen dazu, Messfehler frühzeitig zu erkennen und entsprechende Gegenmaßnahmen zu ergreifen.

\subsubsection{Kontrolle des Sondenmessplatzes}

Arbeitstäglich wird der Leerwert, d. h. die Untergrundzählrate bestimmt. Die Untergrundzählrate, auch Nulleffekt genannt, ist die Zählrate, die ohne eine bewusst platzierte Strahlenquelle (z. B. Kapsel, Patient) durch die Sonde gemessen wird. Die so ermittelte Menge 
der Hintergrundstrahlung wird später bei der Patientenmessung abgezogen. Ebenfalls täglich wird die Einstellung des Energiefensters überprüft. Es muss gewährleistet sein, dass der Peak in seiner Energie der Nuklidenergie entspricht und mittig im Energiefenster liegt. Als Phantom dient hier eine aktivitätsgefüllte Spritze. Mittels Caesium $\left({ }^{137} \mathrm{Cs}\right)$ als Standardwert wird zudem täglich (laut DNG wöchentlich) die Konstanz der Ausbeute kontrolliert. Caesium 137 weist eine HWZ von 30,17 Jahren auf, eine gleichbleibende Zerfallsrate ist somit über einen langen Zeitraum gewährleistet (Eckardt et al. 2009).

Eine Kontrollmessung findet halbjährlich oder gegebenenfalls aus aktuellem Anlass (plötzliche Veränderungen in der Zählrate, plötzliche Veränderungen im Peak des Diskriminators) statt. Im Rahmen dieser Überprüfung wird eine Kalibrierung des gesamten Messsystems mit einer Testkapsel vorgenommen. Diese Kalibrierung erfolgt mittels eines Schilddrüsenphantoms dessen nähere Beschreibung in Abbildung 5 gegeben ist.

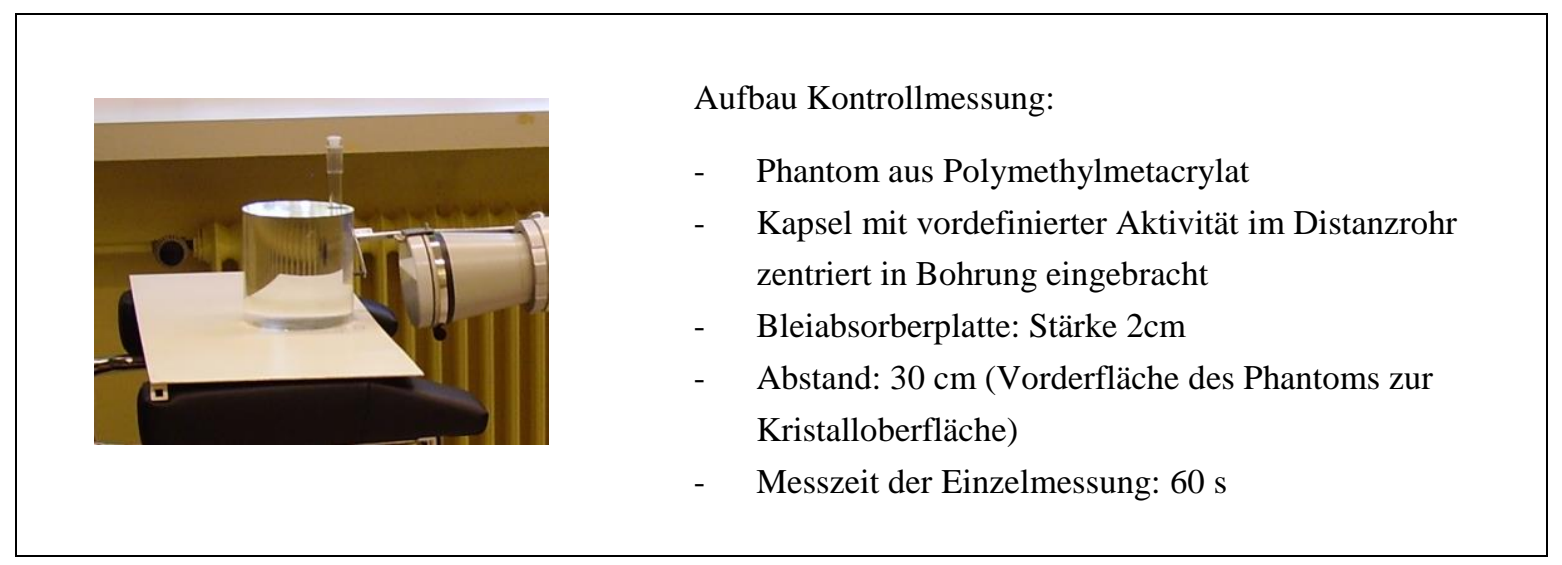

Abbildung 5 Aufbau der Referenzmessung, Messungen am Patienten finden mit identischem Aufbau statt

\subsubsection{Linearitätsmessung im Rahmen dieser Dissertation}

Im August 2014 wurde vom Medizinphysikexperten der nuklearmedizinischen Abteilung der UMG, Herrn Thomas Pröhl, zudem eine Linearitätsmessung zur Qualitätssicherung durchgeführt. Es sollte ausgeschlossen werden, dass die Uptakemesssonde bei hohen Aktivitäten keine lineare Messung durchführen kann. Es wurden Wertepaare verglichen, bestehend aus der Aktivität einer Testkapsel ${ }^{131}$ Iod, gemessen im Aktivimeter in der Abteilung Nuklearmedizin radiochemisches Labor, und die Aktivität einer Testkapsel, gemessen mit einer Sonde mit einer reproduzierbaren, konstanten Messgeometrie. Dabei wird an aufeinander folgenden Tagen eine Ausgangsaktivität, die im Verlauf zerfällt, mit beiden Messgeometrien gemessen und die Ergebnisse auf Linearität überprüft. 


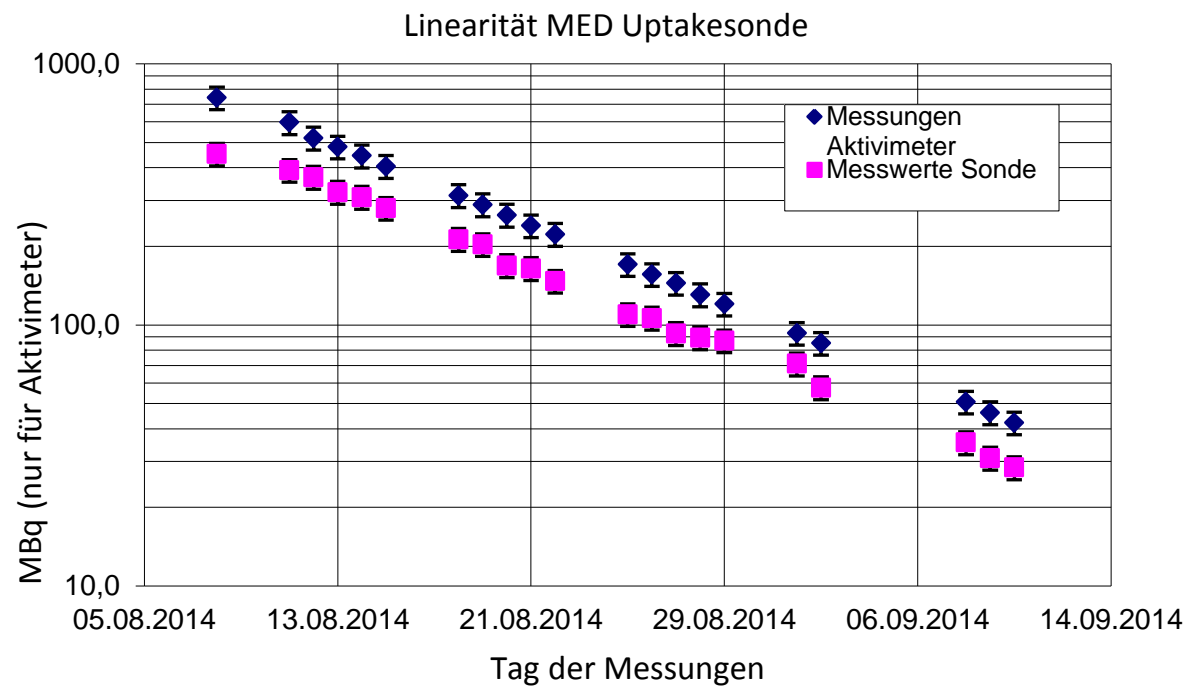

Abbildung 6: Linearitätsmessung des Sondenmessplatzes der UMG im August 2014, Quelle: Pröhl 2014, mit freundlicher Genehmigung des Autors

\subsubsection{Bestimmung der effektiven Halbwertszeit}

Die effektive Halbwertszeit ließ sich genaugenommen nur durch möglichst engmaschige, mehrtägige Uptakemessungen mit dem Sondenmessplatz ermitteln. Nicht nur die Messdaten, sondern auch Modelle zur Nuklidkinetik spielen bei der Bestimmung der effektiven HWZ eine Rolle. So ergeben sich durchaus unterschiedliche Messdaten, wenn von einem mono-, bi- oder multiexponentiellen Abfall der Zeit-Aktivitätskurve ausgegangen wird.

Aufgrund logistischer Probleme ist der reale Testablauf immer ein Kompromiss zwischen der wünschenswerten Dichte der Uptakemessungen und den in der klinischen Routine erreichbaren Messungen. In vielen Einrichtungen ist man daher dazu übergangen, mit nur wenigen Uptakemessungen auszukommen. Als Extrem ist hier das Verfahren einer einmaligen Uptakemessung nach sieben bis zehn Tagen zu nennen, welches auch von der DGN in den Leitlinien favorisiert wird. Dieses Verfahren kann durch empirische Werte für verschiedene Krankheitsbilder und eine begleitende Therapie weiter modifiziert werden (Bell und Grünwald 2000).

\subsection{Dosimetrie und Dosiskonzepte}

Im Prinzip unterscheidet man bei der RIT ein ablatives Konzept, bei dem bewusst eine Hypothyreose in Kauf genommen wird, von einem konservativen Therapiekonzept.

Beim Morbus Basedow hat sich gezeigt, dass ein konservatives Therapiekonzept nicht erfolgreich durchführbar ist. Bei Verwendung von Herddosen zwischen 100 und 200 Gy sind nach durchgeführter RIT bis zu ein Drittel der Patienten nach wie vor hyperthyreot. Bei Verwendung höherer Dosen, wie zum Beispiel 300 Gy, sind zwar über 90 \% der Patienten 
von ihrer Erkrankung geheilt, aber über $70 \%$ der Patienten hypothyreot. Diese Ergebnisse erklären sich durch die Tatsache, dass die TSH-Rezeptorautoantikörper, die intrathyreoidal wirksam sind, nicht beeinflusst werden können. Unter Umständen reicht so ein kleines postradioiodtherapeutisches Volumen aus, um bei hohen TRAK-Werten eine persistierende Hyperthyreose herbeizuführen. Aus diesem Grunde wird in Deutschland bei der RIT des Morbus Basedow überwiegend ein ablatives Dosiskonzept vertreten (Bell und Grünwald 2000, Meller, persönliche Kommunikation 2016).

Bei der Autonomie besteht zumindest theoretisch die Möglichkeit, ein konservatives Therapiekonzept mit Erreichen einer stabilen Euthyreose anzuwenden, indem man für thyreosuppressive Bedingungen während der RIT sorgt. Diese führen dazu, dass nicht autonomes Gewebe nur in geringem Ausmaß bestrahlt wird. Allerdings hängt es auch hier vom Verhältnis zwischen autonomem Volumen und noch gesunden Schilddrüsenanteilen ab, ob der Patient letztendlich hypothyreot wird oder euthyreot bleibt (Meller, persönliche Kommunikation 2016).

\subsubsection{Dosiskonzepte - fixe Aktivität und individuelle Berechnung}

Man unterscheidet zwei Dosiskonzepte. Erstens die Gabe einer fixen Aktivität, die unter Umständen noch modifiziert wird (z. B. höhere Aktivitäten bei größeren Schilddrüsenvolumen), sowie zweitens ein Dosiskonzept, das auf eine individuelle Dosimetrie gegründet ist. Weltweit wird hierzu das Verfahren von Marinelli verwendet.

Leonidas D. Marinelli (28. November 1906 - 13. September 1974) prägte die moderne Dosiskalkulation mit seinen 1948 veröffentlichten Verfahrensanweisungen zu Dosisdetermination, die eine beachtliche Zahl von Uptakemessungen (nach 4, 24, 48, 72 und 96 Stunden) beinhalten. So wollte Marinelli sichergehen, dass die patientenindividuelle Iodkinetik nahezu exakt ermittelt wird und folglich auch die effektive Halbwertszeit und das Uptake-Maximum genau bestimmt werden können. Gängige Praxis ist heute, wie oben beschrieben, ein zweizeitiges Messen der Radioiodaufnahme. Eine erste Messung nach 24 Stunden, hier ist erwartungsgemäß der Zeitpunkt des maximalen Uptakes, und eine zweite Messung nach fünf bis sieben Tagen. Mittels der Marinelli-Formel kann nun nach Erhebung aller erforderlichen Daten, wie sonographisch oder szintigraphisch ermitteltem Zielvolumen, Uptake, effektiver Halbwertszeit und erwünschter Herddosis, die nötige Aktivitätsmenge errechnet werden (Marinelli et al. 1948). Die erwünschte Herddosis ist dem Dosiskonzept der DGN zu entnehmen (unifokale Autonomie: 300 - $400 \mathrm{~Gy}$, multifokale / disseminierte Autonomie: 150 - 200 Gy, IHT: 200 - 300 Gy bei einem ablativen Konzept) (Eckardt et al. 2009; Deutsche Gesellschaft für Nuklearmedizin e.V.). 


$$
\text { Aktivität }[M B q]=\frac{\text { Herddosis }[G y] * S D V o l .[m l] * \text { Konstante }}{\text { Uptake }[\%] * \text { eff.HWZ }}
$$

Formel 3: Marinelli-Formel

Aktivität $=\mathrm{zu}$ verabreichende Aktivität, Herddosis $=$ erwünschte Zieldosis nach DGN, SDVol. = Volumen der gesamten Schilddrüse, Konstante $=24,7$, empirisch ermittelt, Uptake $=$ Maximum ermittelt im Radioiodtest, eff. HWZ $=$ effektive Halbwertszeit (Marinelli et al. 1948)

\subsection{Durchführung Radioiodtherapie}

Nach abgeschlossenem Radioiodtest und anschließender Aktivitätsermittlung über die Marinelli-Formel folgt die eigentliche definitive Therapie mit Radioiod. Bei entsprechenden Herstellern kann nun eine Kapsel mit der individuellen Aktivitätsmenge geordert werden, jedoch muss diese mit einem abteilungsinternen Aktivimeter aus Strahlenschutzgründen vom Empfänger nochmals überprüft werden. Das Kalibrierungsdatum muss ebenfalls vom Produzenten mit angegeben werden. Sofern nun die Indikationsstellung gegeben ist und alle Kontraindikationen (z. B.: Gravidität) ausgeschlossen sind, wird die Kapsel oral appliziert. Dies hat unter Umständen aus Sicherheitsgründen mit einem speziellen Applikator zu erfolgen und ist zwingend stationär auf einer geeigneten nuklearmedizinischen Fachabteilung durchzuführen. Die Verhaltensregeln sind denen des Radioiodtests sehr ähnlich, da die Iodkinetik zum Therapiezeitpunkt möglichst kongruent zu der Situation des Tests sein soll. Die Kapsel wird nüchtern (> $4 \mathrm{~h}$ nüchtern) eingenommen und auch nach Verabreichung muss eine einstündige Nahrungskarenz eingehalten werden, zudem sind ein Absetzten der thyreostatischen Medikation zwei bis drei Tage vor Therapiebeginn und eine Ioddiät sinnvoll. Eine ausreichende Flüssigkeitszufuhr zur Unterstützung der renalen Clearance muss gewährleistet sein. Zusätzlich kann ab einem gewissen Aktivitätsmaß die Gabe von Zitronensaft zum Schutz der Magenschleimhaut angezeigt sein (Bell und Grünwald 2000; Deutsche Gesellschaft für Nuklearmedizin e.V.).

Bei manchen Fällen des Morbus Basedow und bei bereits bestehender endokriner Orbitopathie (eO) werden therapiebegleitend Glukokortikoide (pro Tag 0,4-0,5 mg Prednisolon / kg Körpergewicht, ab Gabe Radioiod für vier bis sechs Wochen) empfohlen, um eine mögliche therapiebedingte Verschlechterung zu verhindern (Eckardt et al. 2009). Wie beim Radioiodtest schließen sich nun regelmäßige (mindestens einmal täglich) Uptakemessungen an, um die erzielte Strahlendosis erfassen zu können und die effektive HWZ zu bestimmen.

Ein besonderer Strahlenschutzplan beinhaltet unter anderem Vorgaben über die bauliche Gestaltung einer nuklearmedizinischen Station. So gehören Ein- oder Zweibettzimmer, Baryt-Betonwände, Raumluftwechsler und Sammlung der Abwässer in Abklinganlagen 
zum Standard. Durch die Atemluft der Patienten innerhalb der ersten 48 Stunden werden zirka 0,05 - 0,1\% der applizierten Dosis ausgeschieden (Bell und Grünwald 2000).

\subsection{Strahlenexposition}

Die erwünschte oder auch die erreichte Dosis (D) ist kein Parameter zur Quantifizierung möglicher Schäden durch die ionisierende Strahlung. Die Dosis erfasst lediglich die reine Energieabsorbtion pro kg Masse in Gray $(1 \mathrm{~Gy}=1 \mathrm{~J} / \mathrm{kg})$. So werden die unterschiedlichen Wirksamkeiten der Strahlenarten und die verschiedenen Empfindlichkeitsstufen der Gewebe außer Acht gelassen. Mithilfe eines Wichtungsfaktors (WR oder q) wird die unterschiedliche biologische Wirksamkeit von Alpha-, Beta- und Gammastrahlung bewertet und als Aquivalentdosis $\mathrm{H}\left(\mathrm{H}=\mathrm{q}^{*} \mathrm{D}\right)$ in der SI-Einheit Sievert (Sv) angegeben (Photonen, Elektronen und Röntgenstrahlen WR $=1$, Neutronen WR $=10$, Alphastrahlen WR = 20). Neben diesem Strahlen-Wichtungsfaktor existiert noch der Gewebe-Wichtungsfaktor WT. Dieser Faktor beinhaltet zusätzlich noch die Strahlenempfindlichkeit der unterschiedlichen Gewebe und definiert die effektive Dosis (E in Sv) als stochastisches Maß für die Krebsletalität nach Exposition. Beispielsweise erweisen sich die Gonaden deutlich strahlungssensitiver als die Schilddrüse oder die Haut (Berberich et al. 1980).

Die gesamte Strahlenexposition bei einer Schilddrüsenszintigraphie mit 99mTc (Referenzaktivität $70 \mathrm{MBq}$ ) liegt bei unter $1 \mathrm{mSv}$, wobei der Dickdarm das am meisten bestrahlte Organ darstellt. Bei der Untersuchung mit dem Radiopharmakon ${ }^{131}$ Iod (Referenz $3 \mathrm{MBq}$ ) ist eine effektive Dosis von $72 \mathrm{mSv}$ möglich (Schicha et al. 2013). Die Strahlenexposition des Körpers ist demnach etwa dreifach so ausgeprägt wie bei röntgendiagnostischen Maßnahmen. Zum Vergleich: eine Computertomographie (CT) des Abdomen weist eine mittlere Dosis (Standardpatient $70 \pm 5 \mathrm{~kg}$ ) von $25 \mathrm{mSv}$ auf (Bauer und Veit 2003). Eine Studie der Universität Birmingham zeigte in einer methodisch sehr guten case control study, dass eine Therapie mit ${ }^{131}$ Iod bei benignen Schilddrüsenerkrankungen zu keiner erhöhten Krebsletalität führt (Franklyn et al. 1999). Dies gilt insbesondere für die Organe, bei denen man theoretisch eine solche erwarten könnte (Colon, Magen, Niere, Harnblase, Knochenmark).

Sawka et al. verglichen ebenfalls in einer case control study Patienten, die aufgrund eines Schilddrüsenkarzinoms mit Radioiod oder ohne Anwendung eines Radionuklids behandelt wurden. Sawka et al. fanden im Langzeitverlauf die zu erwartende erhöhte Krebsmortalität in den Aufnahme- und Ausscheideorganen sowie im Knochenmark (Leukämie, myelodysplastisches Syndrom). Allerdings fand sich statistisch ein „quasi Schwellenwert“ von 7,4 GBq ${ }^{131}$ Iod, unter dem statistisch keine erhöhte Krebsletalität nachweisbar war. Auch genetische Schäden konnten nicht in Zusammenhang mit therapeutischen ${ }^{131}$ Iod-Dosen gebracht werden. Aktivitäten wie in der Therapie von Schilddrüsenkarzinomen werden in der 
RIT von benignen Schilddrüsenerkrankungen nicht erreicht, sodass die Ergebnisse von Sawka lediglich auf eine Dosis-Wirkungsbeziehung bei sehr hohen Aktivitäten hindeuten, die bei der RIT gutartiger Schilddrüsenerkrankungen nicht nachweisbar ist (Franklyn et al. 1999; Sawka et al. 2009).

Die Expression des NIS bei Zellen der Keim- und Speicheldrüsen und Zellen der Magenmukosa führen zu einer Aufnahme des radioaktiven Iods auch in diese Zellen, dennoch sind bisher keine teratogenen Folgen dokumentiert. Im Einzelnen werden im Rahmen einer RIT nur geringe Belastungen beobachtet (bei $185 \mathrm{MBq}$ : bei männlichen Patienten 0,01 Gy, bei weiblichen Patienten 2,0 Gy) (Spitzweg 2004). Die engeren Familienangehörigen werden in Folge einer Radioiodbehandlung eines Familienmitgliedes auch keiner nennenswerten Mehrstrahlung ausgesetzt. Bei Ehepartnern mit getrennten Schlafstätten wurde eine Dosis über einen Zeitraum von zwei Wochen von 0,17 mSv (bei einer Spanne von 0,02 $0,49 \mathrm{mSv}$ ) gemessen, bei nicht getrennten Schlafzimmern lag die Dosis bei 0,24 mSv ( $0,05-0,53 \mathrm{mSv}$ ) (Mathieu et al. 1997). Zum Vergleich: die effektive Dosis an kosmischer Strahlung bei einem Hin- und Rückflug von Frankfurt nach New York liegt bei ca. 0,1 mSv (Weber 2010).

Durch regelmäßige Belehrungen über potentielle Gefahren und Schulungen im Umgang mit ionisierender Strahlung und kontaminierten Patienten des Stationspersonals in der nuklearmedizinischen Abteilung der UMG ist die jährliche Dosis mit durchschnittlich $1 \mathrm{mSv}$ sehr gering. Durch das ständige Tragen eines Dosimeters wird dieser Wert überwacht. Es erfolgt eine monatliche Auswertung durch eine zentrale Auswertungsstelle (Büll und Hör 1990).

\subsection{Datenauswertung und statistische Methoden}

Unter Einhaltung der Datenschutzrichtlinien wurden die gesammelten Daten auf einem Laptop-PC anonymisiert gespeichert und verarbeitet. Dies erfolgte zunächst mit dem Windows-eigenen Tabellenkalkulationsprogramm Microsoft Office Excel 2016.

Zu Beginn wurden die Daten über Box-Whisker-Plots graphisch auf eine Normalverteilung hin geprüft (mittels Median, oberes und unteres Quartil und beiden Extremwerten). Dies sowie die nachfolgenden Analysen wurden mit der Software Statistica, Version 12 2015, von der Firma StatSoft gerechnet.

Das Signifikanzniveau wurde auf $\alpha=5 \%$ bestimmt und für die Signifikanz p gelten folgende Regeln:

p > 0,05 nicht signifikant, d. h. die jeweilige Variable hat keinen Einfluss

$\mathrm{p}<0,05$ signifikant, d. h. die jeweilige Variable hat Einfluss 
Der Chi-Quadrat-Test wurde bei der stochastischen Unabhängigkeitsprüfung einzelner Variablen eingesetzt.

Ziel dieser Promotionsarbeit war es, einflussübende Faktoren auf Erreichen oder Verfehlen der angestrebten Herddosis zu finden. Für diese Untersuchung wurden die erhobenen Daten mittels zweier verschiedener Verfahren überprüft. Alle metrischen Variablen konnten durch die Korrelationsanalyse nach Pearson auf mögliche Zusammenhänge evaluiert werden, bei allen restlichen nicht metrischen, dichotomen Variablen erfolgte die Überprüfung über eine Testung der Null-Hypothese mit dem t-Test.

\subsection{Definition des Therapieerfolges}

Ziel der RIT ist die Beseitigung der Hyperthyreose. Dies gilt sowohl für Patienten mit Morbus Basedow als auch für Patienten mit Autonomien. Als erfolgreich wurde in dieser Studie eine Behandlung definiert, bei der ca. sechs Monate nach RIT eine Hyperthyreose nicht mehr nachweisbar war.

Die Beurteilung erfolgte über den Nachweis einer Euthyreose (TSH im Normbereich mit oder ohne L-Thyroxin-Gabe). 


\section{Ergebnisse}

\subsection{Deskriptive Statistik}

Die Gesamtkohorte der letztendlich für diese Studie geeigneten Patienten bestand aus 14 männlichen und 35 weiblichen Kandidaten. Das durchschnittliche Alter lag bei 63,53 \pm 15,47 Jahren, bei einer Spannbreite des Alters zwischen 24 bis 93 Jahren.

13 Patienten (26,53\%) litten an Morbus Basedow, alle übrigen an einer funktionellen Autonomie (36 Patienten, 73,47 \%). Die Verteilung der unterschiedlichen Autonomieformen stellte sich wie folgt dar: zehn Fälle von disseminierter Autonomie (20,41\%), 16 Fälle von unifokaler Autonomie $(32,65 \%)$ und nochmals zehn Patienten litten unter einer multifokalen Autonomie $(20,41 \%)$. Demnach trat die unifokale Autonomie anteilig an den autonomiebedingten Hyperthyreosen mit 44,44 \% am häufigsten auf.

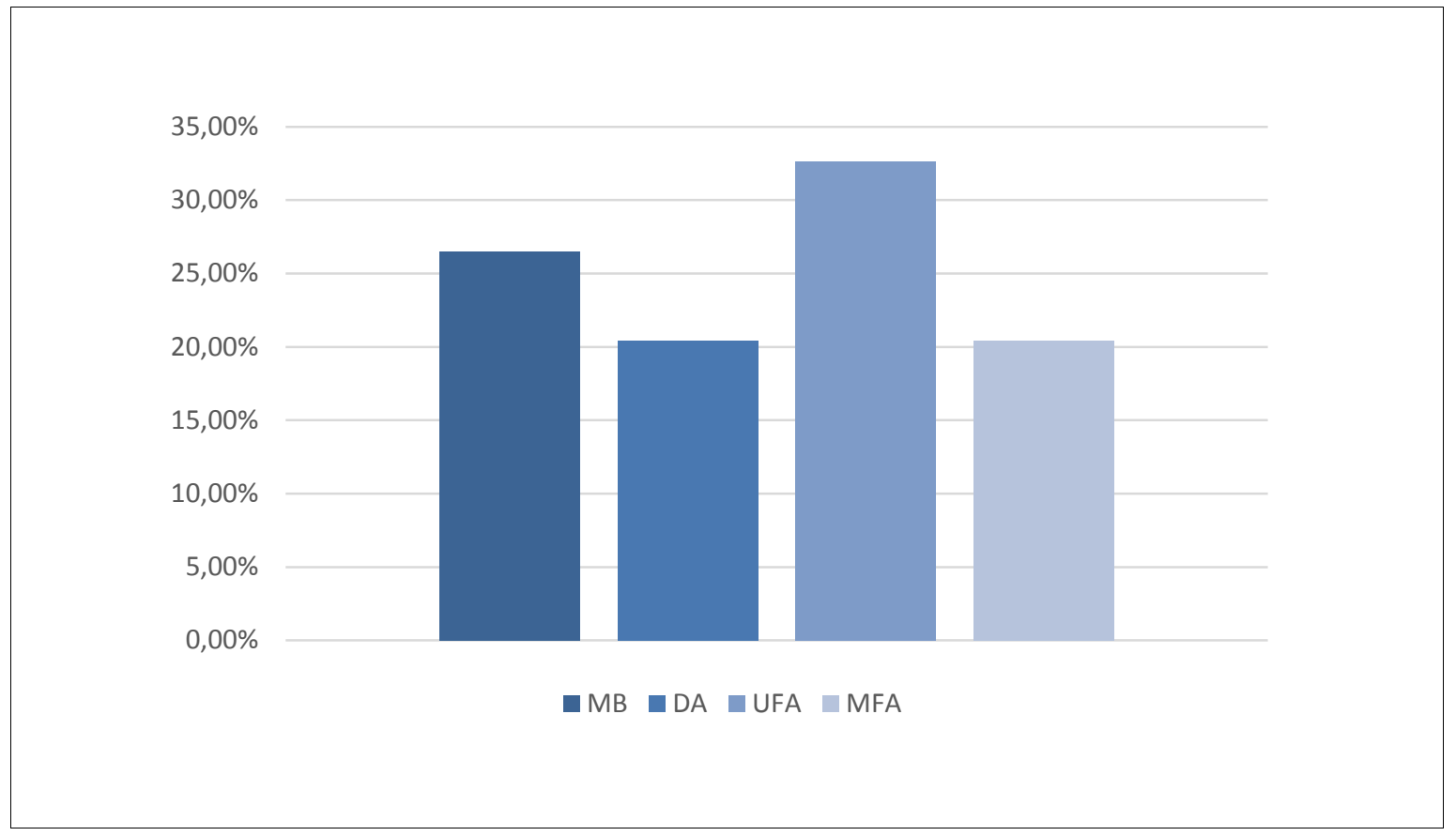

Abbildung 7: Verteilung der Diagnosen

Alle Patienten unterzogen sich einer Nachuntersuchung in einem Zeitraum von ca. drei bis sechs Monaten nach Durchführung der RIT. Insgesamt wurden 46 (93,88 \%) von 49 Patienten erfolgreich mit Radioiod therapiert, nur drei $(6,12 \%)$ Patienten zeigten auch nach erfolgter Therapie eine hyperthyreote Stoffwechsellage. 


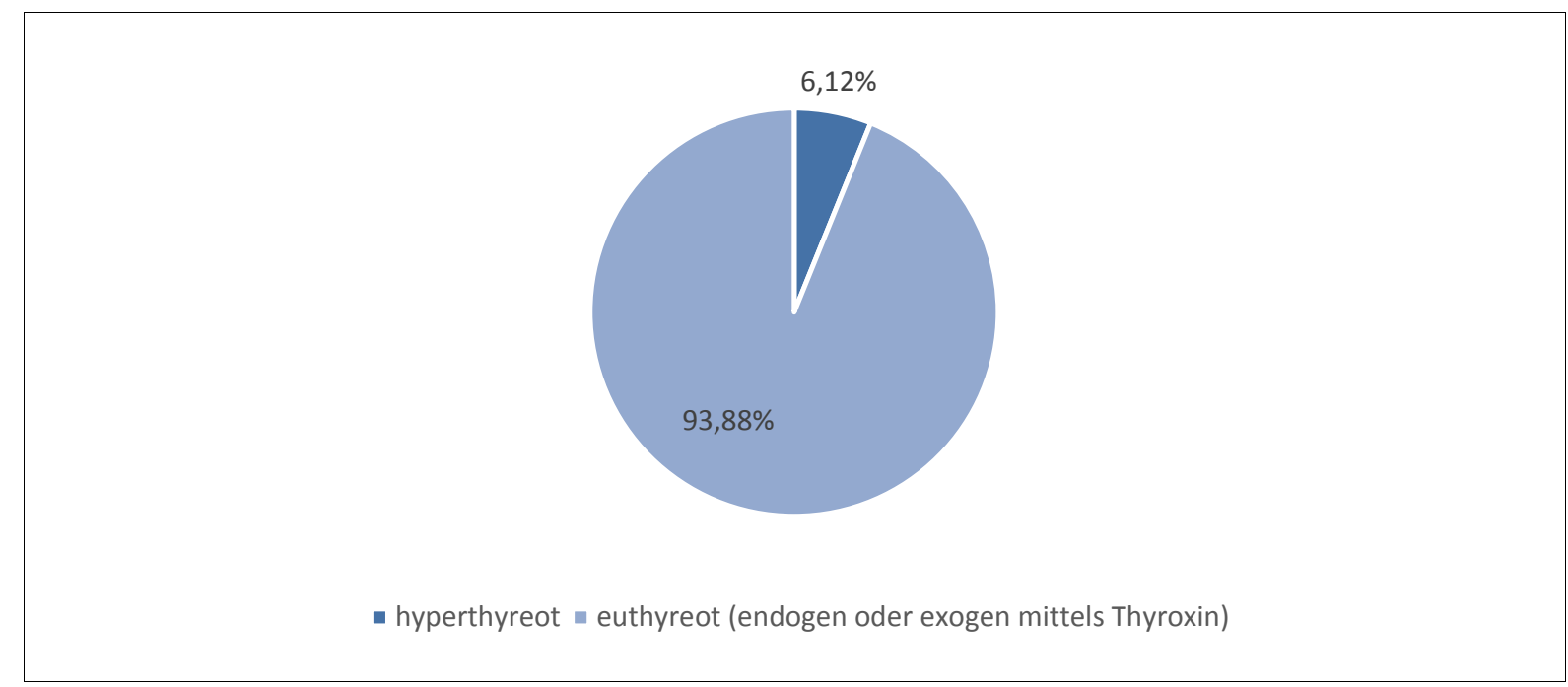

Abbildung 8: posttherapeutische Stoffwechsellage

Zum Zeitpunkt des Radioiodtests wurden neun Patienten (18,37 \%) mit Thyreostatika behandelt, während der RIT waren es nur noch fünf Patienten $(10,20 \%)$, demnach wurden bei der Mehrheit der Teilnehmer keine thyreostatischen Medikamente bei Test und Therapie verabreicht. Während des Radioiodtests war bei 14 Patienten $(28,57 \%)$ der TSHSpiegel exogen supprimiert, zum Zeitpunkt der RIT bei 18 Patienten $(36,73 \%)$.

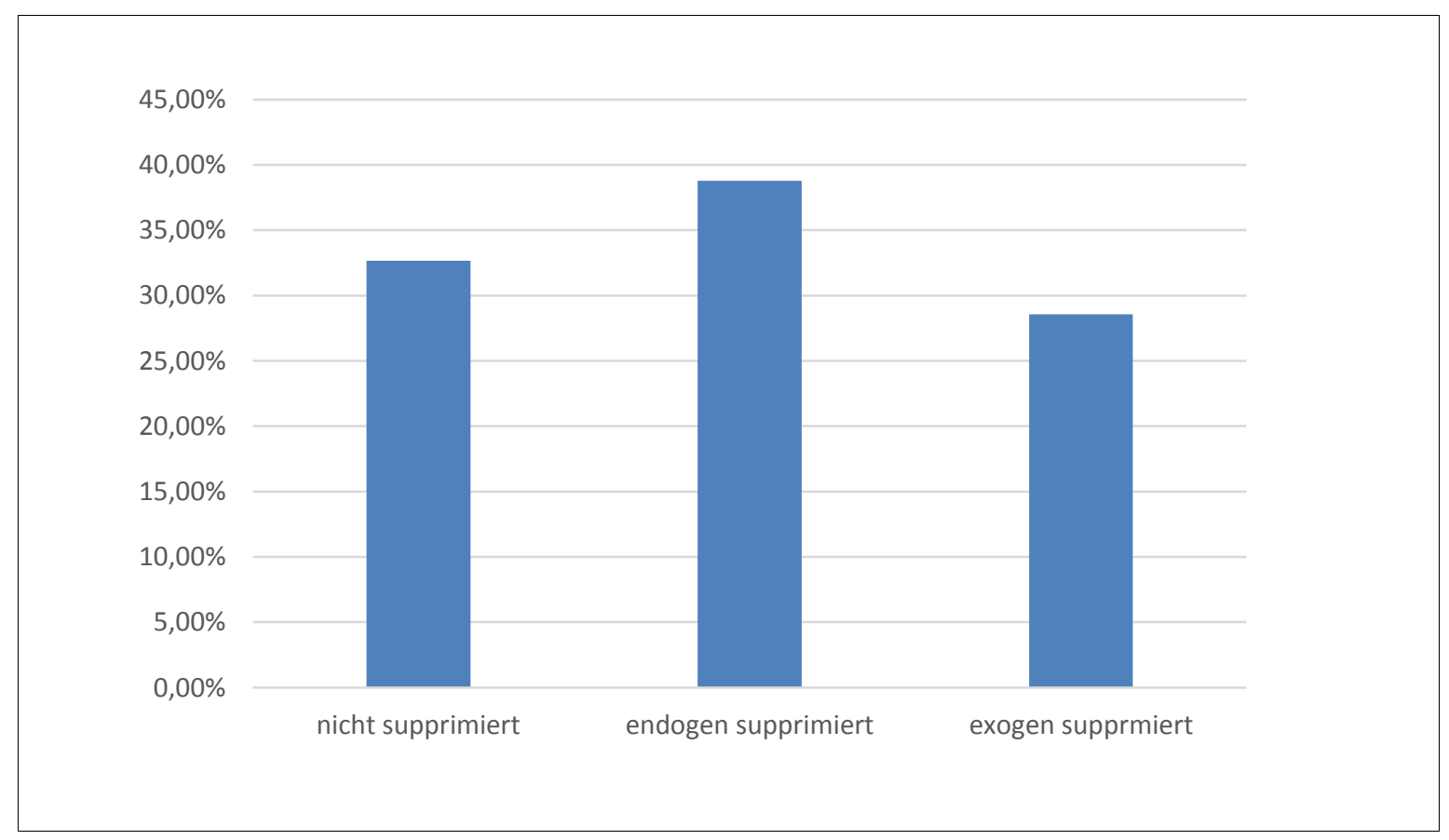

Abbildung 9: TSH-Spiegel zum Zeitpunkt des Radioiodtest 


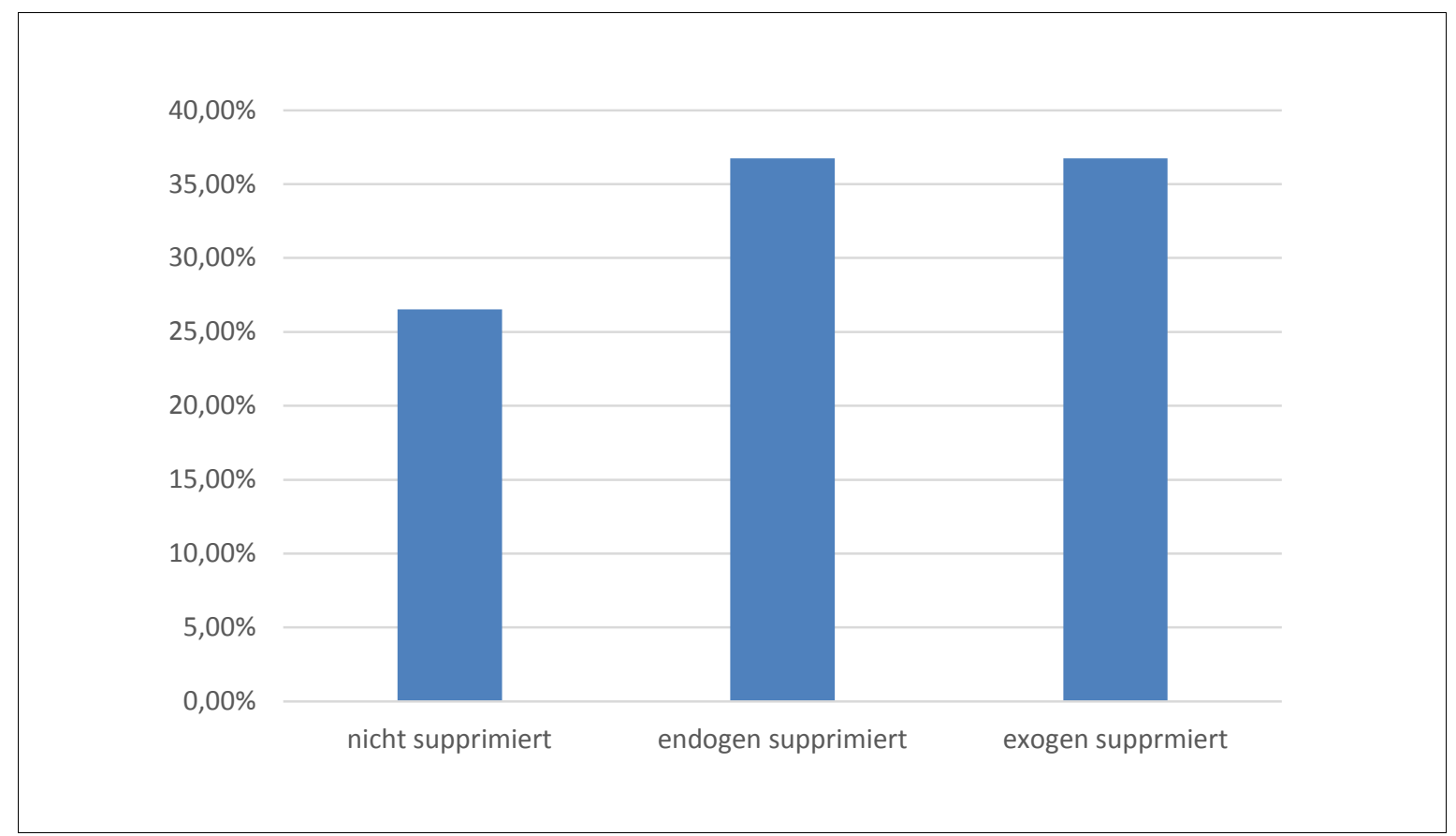

Abbildung 10: TSH-Spiegel zum Zeitpunkt der RIT

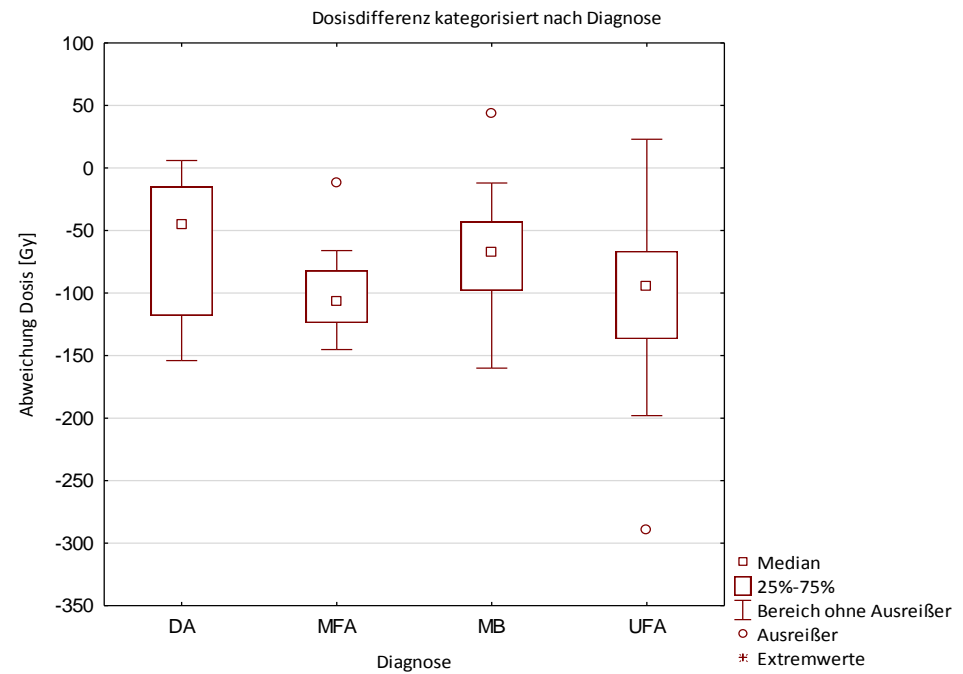

Abbildung 11: Abweichung der Dosis kategorisiert nach Diagnose

Die geplanten Herddosen wurden bei allen Diagnosegruppen deutlich unterschritten. In der obenstehenden Graphik (Abb. 11) sind die Abweichungen nach den vier unterschiedlichen Diagnosen rubriziert. Abbildung 12 zeigt nochmals graphisch die generalisierte Unterdosierung nahezu aller Patienten in dieser Studie. Von 49 analysierten Datensätze erreichten 43 die erstrebte Dosis nicht, d. h. 87,76 \% der Patienten sind unterdosiert. Die Erfolgsquote der untersuchten Patienten liegt nichtsdestoweniger bei 93,88\%. 


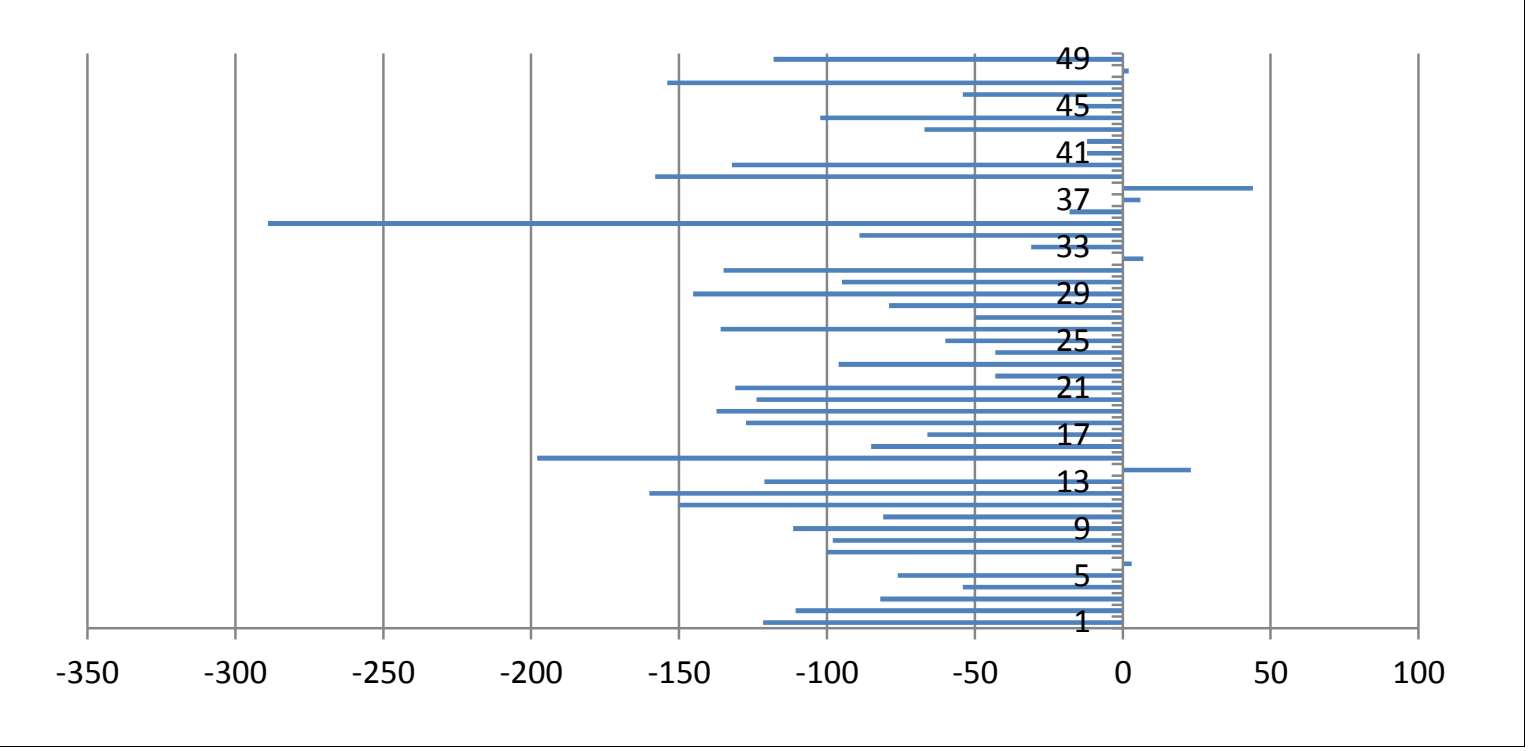

Abbildung 12: Abweichung der Dosis [Gy]

\subsubsection{Retrospektive Evaluation der Zielvolumina}

Bei der Definition des Zielvolumens wurde bei den unifokalen Autonomien das Knotenvolumen verwendet, bei sämtlichen anderen Erkrankungen hingegen das gesamte Schilddrüsenvolumen. Wie bereits im Methodenteil beschrieben, standen zwei Ultraschallgeräte zur Verfügung, wobei insbesondere bei großen Volumina der 3,5 MHz-Abdomenschallkopf zur Anwendung kam, um die Längsachse ausreichend genau zu definieren. Insgesamt wurden 28 Patienten mit dem Philips-Gerät untersucht, acht Patienten selektiv mit dem Siemens-Gerät (inkl. 3,5 MHz-Abdomenschallkopf) sowie 13 Patienten mit beiden Geräten. In diesen Fällen wurde jeweils das größer ausgemessene Volumen, aufgrund der Unterschätzung der Werte bei größeren Strumen, in die Berechnung eingesetzt.

\subsection{Univariate Analyse möglicher Einflussfaktoren}

\subsubsection{Allgemeine Betrachtung}

Ziel dieser Promotionsarbeit war es, einflussübende Faktoren auf das Erreichen oder Verfehlen der angestrebten Herddosis zu evaluieren. Zu diesem Zweck wurden die postradioiodtherapeutischen Herddosen mit den angestrebten Herddosen verglichen.

\subsubsection{Korrelationstest nach Pearson}

Alle metrischen Variablen wie Alter, zeitlicher Abstand zwischen Test und Therapie, Schilddrüsenvolumen, zu bestrahlendes Volumen, Uptake nach 24 Stunden und nach sieben Tagen, effektive Halbwertszeit, Aktivität, gewünschte und erreichte Dosis konnten per Korrelationsanalyse evaluiert werden. 


\subsubsection{Alter}

Das Lebensalter der erkrankten Patienten zum Therapiezeitpunkt zeigt keine Auswirkungen auf die beobachtete Dosisdifferenz $(\mathrm{p}=0,943)$.

\subsubsection{Zeitlicher Abstand zwischen Radioiodtest und -therapie}

Der Abstand zwischen der Durchführung des Radioiodtests und der RIT nahm keinen signifikanten Einfluss auf die Abweichung der erreichten Dosis $(\mathrm{p}=0,423)$. Der zeitliche Abstand zwischen Test und Therapie betrug durchschnittlich 12,84 Tage \pm 5,92 Tage, mit einem Minimum von acht Tagen und einem maximalen Abstand von 31 Tagen.

\subsubsection{Schilddrüsenvolumen}

Erhöhte Schilddrüsenvolumina erwiesen sich ebenfalls nicht als ausschlaggebend für die Differenz zwischen erwünschter und therapeutisch erreichter Dosis $(p=0,685)$. Die Patienten wiesen im Mittel ein Schilddrüsenvolumen von 45,87 $\mathrm{ml}$ auf.

Bei Morbus Basedow, disseminierter Autonomie und multifokaler Autonomie entsprach das Schilddrüsenvolumen dem Zielvolumen. Bei der unifokalen Autonomie wurde aus strahlenbiologischen Gründen ebenfalls nach einer Korrelation zwischen Gesamtvolumen und der Dosisdifferenz gesucht.

\subsubsection{Zielvolumen}

Bei der unifokalen Autonomie sind Gesamtvolumen und Zielvolumen nicht identisch. Das Zielvolumen entspricht dem Knotenvolumen. Wie das Gesamtvolumen wirkt sich auch das reine Knotenvolumen nicht auf die beobachtete Differenz der Dosis aus ( $p=0,367$ ). In dieser Untersuchung maß das größte Zielvolumen $120 \mathrm{ml}$ und das kleinste Zielvolumen 2,3 $\mathrm{ml}$.

\subsubsection{Uptake in der RIT}

Die Höhe des posttherapeutischen 24-h-Uptakes $(\mathrm{p}=0,160)$ und auch des Uptakes nach sieben Tagen $(\mathrm{p}=0,813)$ zeigte keine Korrelation mit einer Dosisdifferenz.

\subsubsection{Effektive Halbwertszeit im Radioiodtest}

Die effektive Halbwertszeit im Radioiodtest nahm keinen signifikanten Einfluss auf die Dosisdifferenz $(\mathrm{p}=0,250)$.

\subsubsection{Aktivität}

Die Höhe der therapeutisch applizierten Aktivität an ${ }^{131}$ Iod hatte keinen Einfluss auf die Dosisdifferenz $(\mathrm{p}=0,550)$. 


\subsection{3 t-Test}

Alle dichotomen Variablen wurden mithilfe eines t-Testes für unabhängige Stichproben auf einen Zusammenhang mit der Dosisdifferenz beobachtet.

\subsubsection{Geschlecht}

Das Geschlecht der therapierten Patienten zeigte keine Korrelation mit der Dosisdifferenz $(\mathrm{p}=0,219)$.

\subsubsection{Diagnose}

Die Art der Erkrankung zeigte keinen signifikanten Einfluss auf die Dosisdifferenz ( $\mathrm{p}=$ $0,112)$.

\subsubsection{TSH-Suppression während des Radioiodtests und der RIT}

Ein supprimierter oder nicht supprimierter TSH-Spiegel im Serum zeigte keinen signifikanten Einfluss auf die Dosisdifferenz (während Radioiodtest: $p=0,972$, während RIT: $p$ $=0,895)$.

\subsubsection{Thyreostase während des Radioiodtests und der RIT}

Eine Medikamenteneinnahme in Form von thyreostatischen Präparaten zeigte ebenfalls keinen signifikanten Einfluss auf die Dosisdifferenz (während Radioiodtest: p = 0,972, während RIT: $p=0,229)$.

\subsubsection{Einfluss der Dosisdifferenz auf den Erfolg der RIT nach 6 Monaten}

Eine Korrelation zwischen dem Erfolg der Therapie (Ausbleiben einer Hyperthyreose sechs Monate posttherapeutisch) und der Dosisdifferenz konnte ausgeschlossen werden ( $\mathrm{p}$ $=0,556)$. Von den 49 untersuchten Fällen wurden nur drei $(6,12 \%)$ nicht erfolgreich therapiert.

\subsubsection{Vergleich der prä- und posttherapeutischen effektiven Halbwertszeiten und maximalen 24-h-Uptakes}

Im Rahmen der Datenerhebung traten Abweichungen in den effektiven Halbwertszeiten sowie dem 24-h-Uptake zum Zeitpunkt des Radioiodtests und während der RIT hervor. Um diese Veränderung genauer zu beurteilen, wurden die prä- und posttherapeutischen Werte auf einen signifikanten Unterschied evaluiert. Zudem wurden die Werte auf diagnosespezifische Abweichungen untersucht. 


\subsubsection{Effektive Halbwertszeit}

Die prätherapeutische effektive Halbwertszeit lag im Median bei sieben Tagen, mit einem unterem (25\%) Quantil von sechs Tagen und einem oberen (75\%) Quantil von acht Tagen. Posttherapeutisch verkürzt sich die effektive Halbwertszeit im Median auf 5,7 Tage (25\%-Quantil: 4,4 Tage, $75 \%$-Quantil: 6,8 Tage).

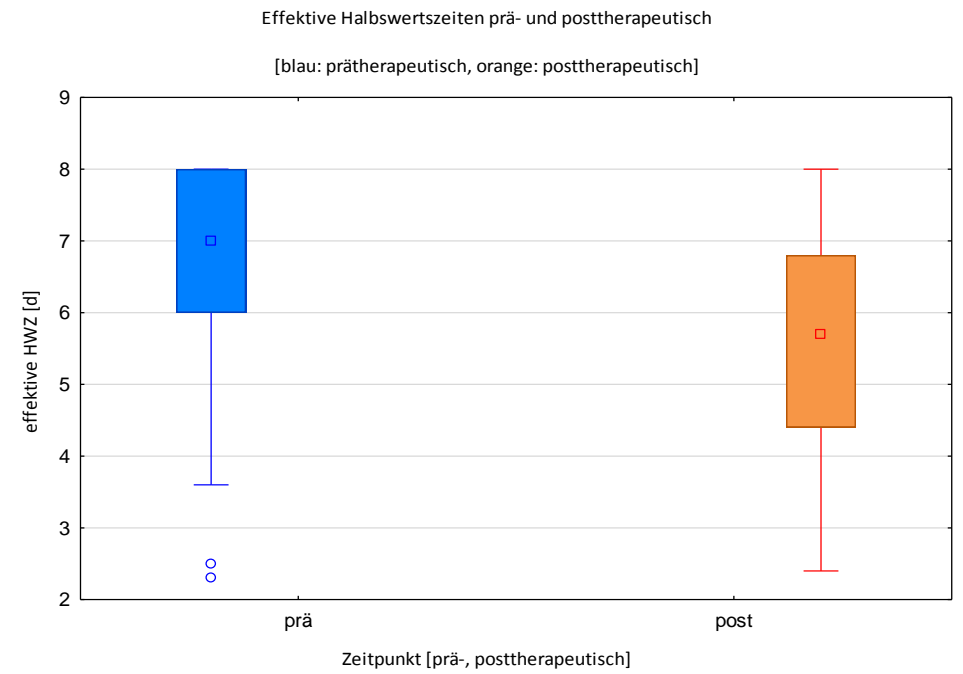

Abbildung 13: Vergleich der prä- und posttherapeutischen effektiven HWZ

Kategorisiert man nun nach den unterschiedlichen Diagnosen, weisen alle vier betrachteten Erkrankungen eine signifikante Veränderung der effektiven HWZ von prä- zu postradioiodtherapeutisch auf. Am deutlichsten wird dies bei der multifokalen Autonomie ( $\mathrm{p}=$ 0,004184).

Die MFA hat mit acht Tagen prätherapeutisch die höchste HWZ, gefolgt von der UFA mit knapp 7,6 Tagen. An dritter Stelle liegt die DA mit 7,4 Tagen, mit Abstand die kürzeste HWZ von nur 5,6 Tagen weist der Morbus Basedow auf. Die Abstufung der diagnosespezifischen HWZ ändert sich nicht posttherapeutisch, auch hier weist der MB die kürzeste HWZ mit 4,4 Tagen auf. Die stärkste Verringerung in Höhe von 1,86 Tagen zeigt die MFA. 


\begin{tabular}{|c|c|c|c|c|}
\hline Diagnose & prätherapeutisch & posttherapeutisch & Differenz & Abweichung \\
\hline DA & $\begin{array}{r}\text { Median: 7,4 } \\
\text { Mittelwert: 7,27 } \\
\text { 25\%-Quantil: 6,5 } \\
\text { 75\%-Quantil: 8,0 }\end{array}$ & $\begin{array}{r}\text { Median: 6,5 } \\
\text { Mittelwert: 6,53 } \\
\text { 25\%-Quantil: 5,7 } \\
\text { 75\%-Quantil: 6,9 }\end{array}$ & $-0,74$ & $\mathrm{p}=0,038507$ \\
\hline MFA & $\begin{array}{r}\text { Median: 8,0 } \\
\text { Mittelwert: 7,65 } \\
\text { 25\%-Quantil: } 8 \\
\text { 75\%-Quantil: } 8\end{array}$ & $\begin{array}{r}\text { Median: 6,0 } \\
\text { Mittelwert: 5,79 } \\
\text { 25\%-Quantil: 5,4 } \\
\text { 75\%-Quantil: 6,8 }\end{array}$ & $-1,86$ & $\mathrm{p}=0,004184$ \\
\hline UFA & $\begin{array}{r}\text { Median: 7,6 } \\
\text { Mittelwert: 7,0 } \\
\text { 25\%-Quantil: 6,25 } \\
\text { 75\%-Quantil: } 8\end{array}$ & $\begin{array}{r}\text { Median: 5,7 } \\
\text { Mittelwert: 5,8 } \\
\text { 25\%-Quantil: 4,05 } \\
\text { 75\%-Quantil: } 8\end{array}$ & $-1,24$ & $\mathrm{p}=0,023353$ \\
\hline MB & $\begin{array}{r}\text { Median: 5,6 } \\
\text { Mittelwert: 5,16 } \\
\text { 25\%-Quantil: 4,2 } \\
\text { 75\%-Quantil: 6,8 }\end{array}$ & $\begin{array}{r}\text { Median: 4,4 } \\
\text { Mittelwert: 4,7 } \\
\text { 25\%-Quantil: 3,4 } \\
\text { 75\%-Quantil: 5,5 }\end{array}$ & $-0,46$ & $\mathrm{p}=0,294142$ \\
\hline
\end{tabular}

Tabelle 3: Vergleich der prä- und posttherapeutischen eff. HWZ [Tage], kategorisiert nach Diagnosen, Differenz des Mittelwerts

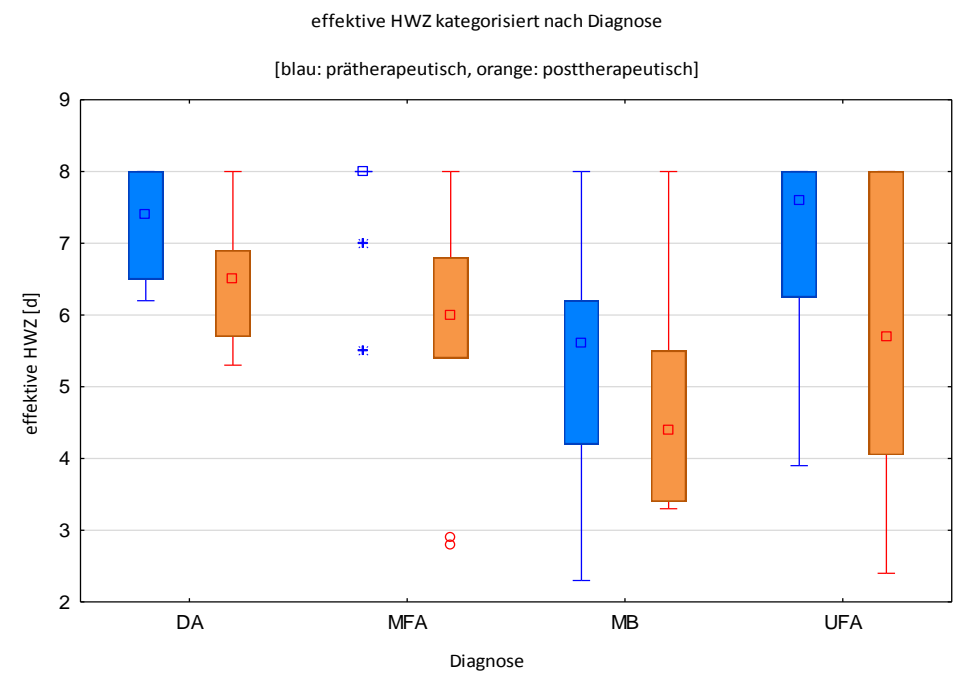

Abbildung 14: Vergleich der prä- und posttherapeutischen eff. HWZ, kategorisiert nach Diagnosen 
Sofern die Halbwertszeiten nicht im Rahmen des Radioiodtests ermittelt werden, kommen oft empirisch bestimmte krankheitsspezifische Halbwertszeiten zur Anwendung (Nüchel et al. 1993; Berg et al. 1996; Kobe et al. 2010).

Auf Basis der postradioiodtherapeutischen Daten der vorliegenden Studie ergeben sich folgende Werte für krankheitsspezifische Halbwertszeiten. Es handelt sich hierbei um die Median- und Mittelwerte.

\begin{tabular}{|l|l|}
\hline Diagnose & Effektive HWZ posttherapeutisch \\
\hline DA & Median: 6,5 \\
& Mittelwert: 6,53 \\
\hline MFA & Median: 6,0 \\
& Mittelwert: 5,79 \\
\hline UFA & Median: 5,7 \\
& Mittelwert: 5,8 \\
\hline MB & Median: 4,4 \\
& Mittelwert: 4,7 \\
\hline
\end{tabular}

Tabelle 4: krankheitsspezifische HWZ auf Basis der radioiodtherapeutischen Daten

\subsubsection{Maximaler 24-h-Uptake}

Der Median des maximalen 24-h-Uptakes lag prätherapeutisch bei $24 \%$, mit einem unteren Quantil von 18,3\% und einem oberen von 36,5 \%. Posttherapeutisch beträgt der Median des maximalen Uptakes 23,3 \% (25\%-Quantil: 16,6 \%, 75\%-Quantil: 30,7 \%).

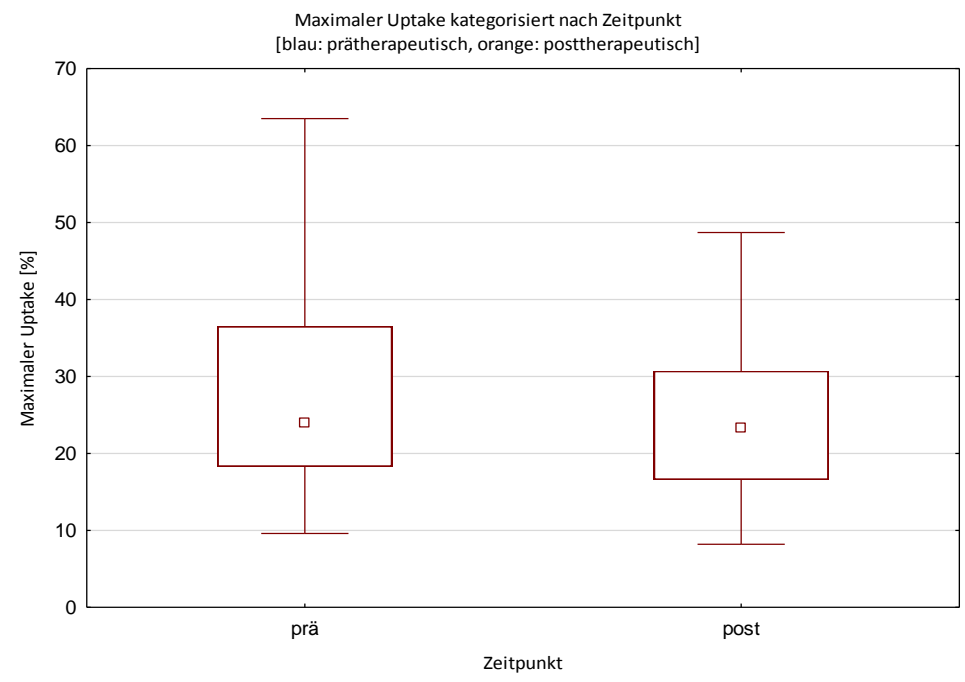

Abbildung 15: Vergleich des prä- und posttherapeutischen max. 24-h-Uptakes 
Die Werte des maximalen 24-h-Uptakes wurden nun ebenfalls nach Diagnose rubriziert und auf eine signifikante Abweichung evaluiert. Am stärksten fällt die Erniedrigung im Uptake beim Morbus Basedow aus. Hier nimmt der Uptake im Mittel um 9,99 Prozentpunkte von prä- zu postradioiodtherapeutisch ab.

\begin{tabular}{|c|c|c|c|c|}
\hline Diagnose & prätherapeutisch & posttherapeutisch & Differenz & Abweichung \\
\hline \multirow[t]{4}{*}{ DA } & Median: 22,9 & Median: 20,35 & $-0,18$ & $\mathrm{p}=0,906728$ \\
\hline & Mittelwert: 23,2 & Mittelwert: 23,0 & & \\
\hline & 25\%-Quantil: 19,6 & 25\%-Quantil: 16,6 & & \\
\hline & 75\%-Quantil: 25,8 & 75\%-Quantil: 26,4 & & \\
\hline \multirow[t]{4}{*}{ MFA } & Median: 19,45 & Median: 17,2 & $-1,21$ & $\mathrm{p}=0,386383$ \\
\hline & Mittelwert: 21,2 & Mittelwert: 20,0 & & \\
\hline & 25\%-Quantil: 14,3 & 25\%-Quantil: 13,6 & & \\
\hline & 75\%-Quantil: 24,5 & 75\%-Quantil: 24 & & \\
\hline \multirow[t]{4}{*}{ UFA } & Median: 21,45 & Median: 20,25 & $-0,58$ & $\mathrm{p}=0,530003$ \\
\hline & Mittelwert: 20,6 & Mittelwert: 20,1 & & \\
\hline & 25\%-Quantil: 17,4 & 25\%-Quantil: 15,05 & & \\
\hline & 75\%-Quantil: 24,55 & 75\%-Quantil: 26,05 & & \\
\hline \multirow[t]{4}{*}{ MB } & Median: 45,6 & Median: 33 & $-9,99$ & $\mathrm{p}=0,000222$ \\
\hline & Mittelwert:46,4 & Mittelwert: 36,4 & & \\
\hline & 25\%-Quantil: 43,8 & 25\%-Quantil: 30,6 & & \\
\hline & 75\%-Quantil: 50,7 & 75\%-Quantil: 41,3 & & \\
\hline
\end{tabular}

Tabelle 5: Vergleich des prä- und posttherapeutischen maximalen 24-h-Uptakes [Prozent], kategorisiert nach Diagnosen, Differenz des Mittelwerts 


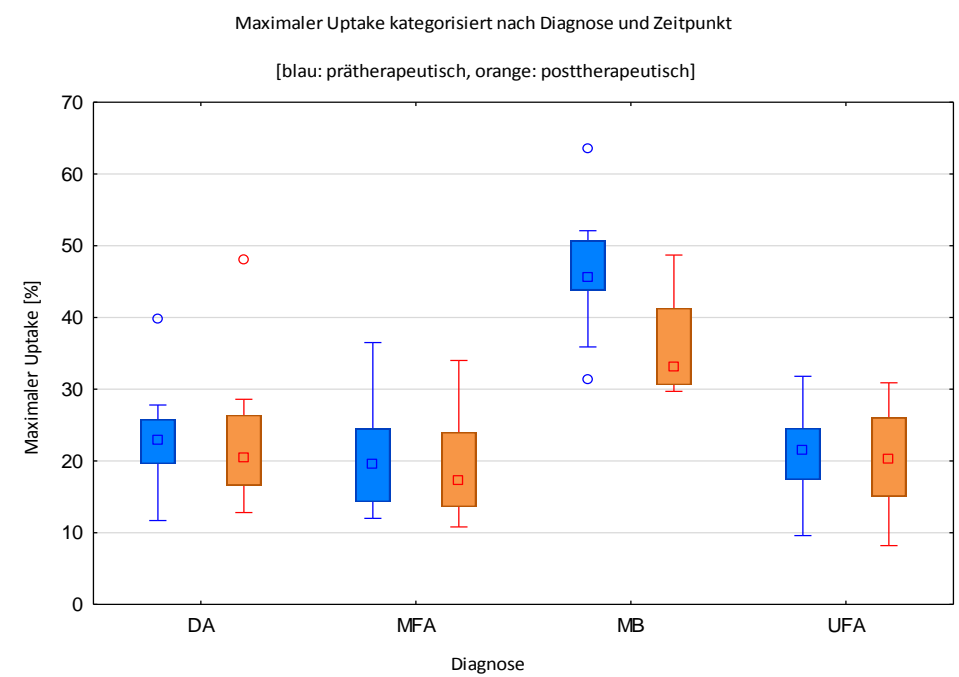

Abbildung 16: Vergleich des prä- und posttherapeutischen max. 24-h-Uptakes, kategorisiert nach Diagnosen

Im folgenden Diagramm ist jedoch ersichtlich, dass die prä- und posttherapeutisch gemessenen Werte dennoch sehr gut miteinander korrelieren. Die geschätzte Regressionsgerade folgt der Gleichung $\hat{y}=-0,0557+1,1272 * x$. Nach der Korrelationsanalyse nach Pearson beträgt der Korrelationskoeffizient 0,8820. In einer ähnlichen Studie von Reinartz et. al. aus dem Jahr 2003 wurde ein Korrelationskoeffizient von 0,91 ermittelt (Reinartz et al. 2003).

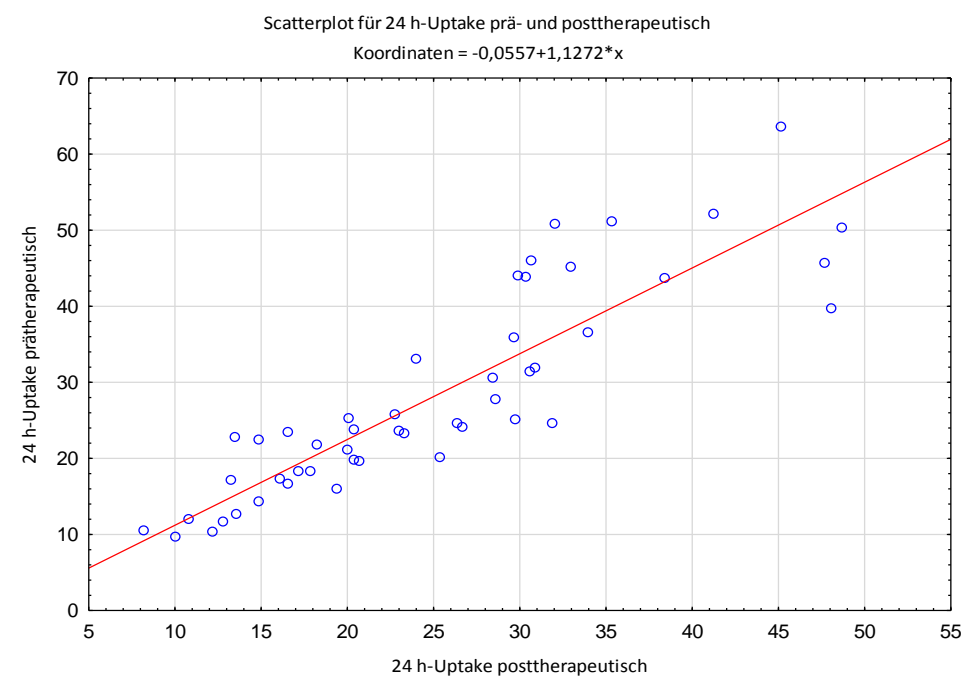

Abbildung 17: Korrelation zwischen prä- und posttherapeutischem 24-h-Uptake, Korrelation $r=0,8820$

\subsection{Korrelation der prä- und posttherapeutischen Halbwertszeit bzw. des 24-h-Uptakes und dem Verfehlen der verschriebenen Dosis}

Darüber hinaus wurde eine Korrelation zwischen den beobachteten Diskrepanzen zwischen prä- und postradioiodtherapeutisch bestimmten effektiven Halbwertszeiten bzw. Uptake- 
werten und dem Nicht-Erreichen der erwünschten Herddosis evaluiert. Mittels eines tTestes sind die Daten jeweils auf Einfluss auf eine Unterdosierung und ein Dosis-Erreichen überprüft worden. Fälle von Überdosierungen sind im Rahmen dieser Arbeit nicht aufgetreten und konnten somit nicht auf Korrelationen getestet werden.

Ein Erreichen der verschriebenen Dosis korreliert nicht mit Abweichungen zwischen präund posttherapeutischer effektiver HWZ. $\mathrm{p}=0,679887$

Ein Verfehlen der verschriebenen Dosis korreliert jedoch signifikant mit Abweichungen zwischen prä- und posttherapeutischer effektiver HWZ.

$$
p=0,000408
$$

Ein Erreichen der verschriebenen Dosis korreliert nicht mit einer Veränderung der Uptakewerte.

$$
\mathrm{p}=0,889110
$$

Ein Verfehlen der verschriebenen Dosis korreliert nicht mit einer Veränderung der Uptakewerte.

$$
\mathrm{p}=0,229251
$$




\section{Diskussion}

\subsection{Diskussion der Methoden}

Die vorliegenden Daten zeigen, dass die geplante Herddosis im Rahmen der RIT unter Verwendung einer präradioiodtherapeutischen Dosimetrie mit einer Zwei-Punkt-Messung unter Annahme eines Maximal-Uptakes nach 24 Stunden häufig nicht erreicht wurde. Es stellt sich die Frage, ob es sich bei den beobachteten Diskrepanzen um zufällige Fehler oder um einen systematischen Fehler in Durchführung und Planung des Radioiodtests oder der Radioiodtherapie handelt. Das Auftreten einer systematischen Unterdosierung bei allen untersuchten Patienten spricht für einen systematischen Fehler. Methodologisch können Fehlerquellen bei der Eichung des Sondenmessplatzes, bei der Performance des Sondenmessplatzes oder durch Variation in der Messgeometrie diskutiert werden.

\subsubsection{Eichung des Sondenmessplatzes und Messgeometrie}

Die Verlässlichkeit der Untersuchungsergebnisse hängt maßgeblich von der Funktionsfähigkeit des entsprechenden Messgerätes ab. In Deutschland sind Qualitätskontrollen nuklearmedizinischer Untersuchungsgeräte in der „Richtlinie Strahlenschutz in der Medizin“ in Ausführung der Strahlenschutzverordnung (Strahlenschutz in der Medizin - Richtlinie zur Verordnung über den Schutz vor Schäden durch ionisierende Strahlen (Strahlenschutzverordnung - StrlSchV)) gesetzlich verankert. Im Rahmen des Radioiodtests werden die Aktivitätsmessungen mit einem Sondenmessplatz durchgeführt. Im Gegensatz zur Gammakamera kann mit der Sonde - bei Verzichtbarkeit einer szintigraphischen Bildgebung - eine hohe Impulsausbeute erzielt werden. Bei den genannten Prüfungen werden Abnahmeprüfungen und Konstanzprüfungen unterschieden. Eine Abnahme findet bei Neuinstallation und nach Reparatur statt, die Konstanzprüfung hingegen soll sicherstellen, dass die Leistungsparameter unverändert sind und somit die Funktionstüchtigkeit der Messgeräte gewährleistet bleibt. Konkret bedeutet dies eine arbeitstägliche Bestimmung des Leerwertes, das heißt eine Messung der Untergrundstrahlung und eine Kontrolle des Energiefensters (siehe 2.4.4 Qualitätssicherung), zudem wird wöchentlich (in der Universitätsmedizin Göttingen sogar täglich) die Konstanz der Ausbeute mittels Caesium als langlebiger Prüfstrahler überprüft (Goretzki 2004).

Alle Messungen unterliegen Fehlern aufgrund von Aktivitätsschwankungen der Aktivität im Messobjekt, ausgelöst zum Beispiel durch Lageveränderungen oder Aktivitätsabnahme (insbesondere bei Nukliden mit kurzer Halbwertszeit). Der mittlere relative Fehler sollte aber $1 \%$ nicht überschreiten, um ein zufriedenstellendes Ergebnis zu erzielen (Hermann 2004). Je höher das Verhältnis der gemessenen Impulszahlen zur Untergrundstrahlung ist, desto kleiner ist der statistische Messfehler. Die Ergebnisse der Qualitätssicherungsmaß- 
nahmen sind drei Jahre aufzubewahren, und auch in der nuklearmedizinischen Abteilung der Universitätsmedizin Göttingen sind diese Messungen lückenlos dokumentiert (Deutsche Gesellschaft für Nuklearmedizin e.V.; Strahlenschutzverordnung - StrlSchV).

Darüber hinaus bieten zahlreiche weitere Umstände Fehlerpotential. Der Aufbau und die Messgeometrie können das Messergebnis stark beeinflussen. Die exakt gleiche Geometrie des Aufbaus stellt sicher, dass die Messung am Patienten den Kalibrierungsmessungen entspricht. So führt zum Beispiel ein erhöhter Abstand zwischen Szintillationsdetektor und Patientenhals zu einer Erhöhung der Messabweichung von 1,5 \% pro Millimeter Mehrabstand (Hänscheid et al. 2013). Der Abstand sollte demnach möglichst genau $30 \mathrm{~cm}$ betragen. SOPs (Standard Operating Procedure) und regelmäßige Schulungen der MedizinischTechnischen Radiologieassistenten (MTRA) der Abteilung Nuklearmedizin der UMG stellen dies sicher.

Dem Szintillationszähler ist ein Bleikollimator zur Verringerung der Streustrahlung vorgeschaltet, auch dieses Bauteil ist regelmäßig zu überprüfen. Allein durch das Gewicht der Blende kann es aufgrund von mechanischem Verschleiß der Befestigungsvorrichtung zu Abweichungen im Aufbau der Messeinheit kommen. Die penible Einhaltung der Messgeometrie ist demnach unabdingbar und muss regelmäßig kontrolliert werden (persönliche Kommunikation, Pröhl 2015).

Die individuelle Patientenanamnese sollte auch nicht unbeachtet bleiben. Vorerkrankungen, bereits erfolgte operative Eingriffe und Medikamenteneinnahme sind im Vorfeld des Radioiodtests zu evaluieren. Krankheiten und Medikamenteneinnahme können zu einer Beeinflussung des Ioduptakes führen (Büll et al. 1999). Sind die Rahmenbedingungen wie optimale Einstellung, reguläre Qualitäts- und Funktionsprobe und Kenntnis der einzelnen Fehlerquellen jedoch gegeben, kann das Verfahren als sehr zuverlässig betrachtet werden.

Alle mit der Messsonde umgehenden Mitarbeiter der Abteilung Nuklearmedizin sind gehalten, die Messegeometrie penibel einzuhalten. Es ergibt sich somit im Untersuchungszeitraum kein Hinweis auf Unregelmäßigkeiten, weder eine Missachtung der genauen Messgeometrie noch ein Wegdriften des Energiefensters oder ein abnorm hoher Hintergrund wurde beobachtet.

Potentielle Fehler können bei hohen intrathyreoidalen Aktivitäten durch die Totzeit des Messgeräts entstehen. Durch diese Totzeit, in der die Sonde keinen Zerfall registrieren kann, ist ab einer bestimmten Zählrate die Proportionalität zur gemessenen Aktivität nicht mehr gegeben (Goretzki 2004). Um einen derartigen Messfehler auszuschließen, wurde durch den Medizinphysikexperten der nuklearmedizinischen Abteilung der Universitätsmedizin Göttingen die bei der Radioiodtherapie üblich vorkommenden Aktivitätsmengen auf ein Erreichen dieser Totzeit evaluiert. Die Messungen ergaben, dass die verwendete Uptakemesssonde den Aktivitätsbereich zuverlässig linear messen kann (siehe 2.4.4.2 Li- 
nearitätsmessung im Rahmen dieser Dissertation). Alle bekannten möglichen Fehlerquellen im technischen Aufbau und Vorgehen können somit ausgeschlossen werden.

\subsubsection{Radioiodtest mit ${ }^{131}$ Iod}

Weitere Fehlerquellen birgt die Dosiskalkulation für die zu applizierende Aktivität im Radioiodtest. Im Rahmen des Radioiodtests wird mittels der Marinelli-Formel die Aktivität berechnet, welche benötigt wird, um die laut Dosiskonzept der Deutschen Gesellschaft für Nuklearmedizin empfohlene Herddosis intrathyreoidal zu erreichen (unifokale Autonomie: 300 - 400 Gy, multifokale / disseminierte Autonomie: 200 Gy, IHT: 300 Gy bei einem ablativen Konzept) (Eckardt et al. 2009).

Mögliche Einflüsse, die zu einer Beeinflussung des Ioduptakes führen, werden in „Diskussion der Ergebnisse“ (siehe 4.2) diskutiert. Letztendlich wurden die oben genannten Zieldosen in unserer Studie nicht erreicht, sodass zunächst eine Fehlersuche nach systematischen Fehlern in der Testsituation erfolgte.

In die Marinelli-Formel fließen das zuvor sonographisch bestimmte Schilddrüsenvolumen, die empfohlene Herddosis, eine empirisch ermittelte Konstante von 24,7, der 24-h-Uptake und die effektive Halbwertszeit mit ein (siehe Formel 3). Um also einen Fehler im Resultat der Formel zu finden, müssen vorab die einzelnen eingehenden Variablen untersucht werden. Da sowohl die Konstante, als auch die vorgegebene Herddosis keiner Variation unterliegen, werden sie in der weiteren Untersuchung nicht beachtet.

Das sonographisch ermittelte Schilddrüsenvolumen, das Volumen des gesamten Organs und falls abweichend das des Zielvolumens wurden auf einen möglichen Einfluss untersucht. Der Verdacht liegt nahe, dass ein frühzeitiger Messfehler aufgrund der Inter- und Intraobserver-Variabilität beim Ultraschallverfahren dem Fehlerfortpflanzungsgesetz folgend zu einer Fehlkalkulation der zu applizierenden Dosis führt. Eine Arbeitsgruppe der Universität Würzburg beziffert diese Variabilität zwischen den Untersuchern auf eine Varianz von $17 \%$ und auf eine 14-prozentige Abweichung in den Ergebnissen eines einzelnen Untersuchers. Das Schilddrüsenvolumen von zehn Probanden wurde in dieser prospektiven, verblindeten Studie mehrfach von neun erfahrenen Untersuchern mittels 2DUltraschall bestimmt. Anschließend wurde das Volumen erneut mittels multiplanarer 3DSonographie als Referenz bestimmt und mit den 2D-Werten verglichen. Der Mittelwert der Differenzen ergab in Bezug auf die Korrektheit eine signifikante Überschätzung des Volumens mit 2D-Sonographie um bis zu $17 \%$ (Andermann et al. 2007). Frühere Vergleichsstudien der nuklearmedizinischen Abteilung der UMG, die die Inter- und Intraobserver Variabilität berücksichtigen, zeigen im Gegensatz zu der Würzburger Studie, dass die Gefahr einer Unterschätzung des Schilddrüsenvolumens größer ist als die Gefahr einer Überschätzung (Meller, persönliche Kommunikation 2016). Würde das Schilddrüsenvolumen 
und somit das Zielvolumen überschätzt, wäre es bei unseren Patienten zu einer systematischen Überdosierung gekommen. Dies ist aber nicht der Fall. Würde es unterschätzt, könnte man die Unterdosierungen im Rahmen dieser Studie unter anderem durch eine systematische Unterschätzung des Schilddrüsenvolumens erklären. Das Problem der Messvariabilität wird in der Abteilung Nuklearmedizin dadurch minimiert, dass bei jedem einzelnen Patienten, oftmals unter Zuhilfenahme mehrerer Schallköpfe und Evaluation durch mehrere unabhängige Untersucher das Volumen möglichst genau bestimmt wird. Dies zeigte sich auch bei der retrospektiven Evaluation der Sonographie bei unseren Patienten, sodass Fehlmessungen kaum anzunehmen sind.

Die eigentliche Messung zur Berechnung des Volumens nach der Ellipsoidformel erfolgte in allen drei Ebenen für beide Schilddrüsenlappen getrennt, anschließend wurden beide Volumina unter Vernachlässigung des Isthmus addiert (siehe 2.2.3 Volumenberechnung mittels Sonographie).

Ein Ansatz, um genauere Ergebnisse zu erzielen, ist die Zuhilfenahme eines Korrekturfaktors. In Deutschland gebräuchlich ist die Verwendung eines Faktors von 0,479 (vereinfacht oft 0,5), eingeführt von Brunn et. al. (Brunn et al. 1981). Es besteht allerdings kein Konsens bei den Autoren, welcher Faktor die exaktesten Ergebnisse liefert oder ob Ultraschall generell zu ungenauen Resultaten führt, insbesondere sobald substernale Anteile der Schilddrüse vorhanden sind (Knudsen et al. 1999; Nygaard et al. 2002). An dieser Stelle ist zusätzlich die Problematik zu erwähnen, dass die meisten Ultraschalluntersuchungen der Schilddrüse mit einem Linearschallkopf mit beschränktem Sichtfeld von maximal $5 \mathrm{~cm}$ durchgeführt werden. Ein solcher Linearschallkopf ist nicht fähig, Strumen über ca. $60 \mathrm{ml}$ adäquat zu erfassen. So greift man auf verschiedene Extrapolationsmöglichkeiten zurück, welche wiederum Fehlerpotential bergen. Eine bessere Option bietet die Anwendung eines Abdominalschallkopfs bzw. eines Sektorschallkopfs. Die Anwendung dieses Schallkopfs ermöglicht es auch, sehr große Strumen bis ca. $150 \mathrm{ml}$, sogar bei retro- oder substernaler Lage, in der Längsausdehnung zu erfassen. In der Abteilung Nuklearmedizin ist man sich der Fehlkalkulationen im Ultraschallverfahren bewusst; deswegen wird vor einem Radioiodtest häufig mit zwei unterschiedlichen Geräten unter Verwendung multipler Schallköpfe, darunter auch ein Abdomenschallkopf, möglichst genau das Schilddrüsenvolumen erfasst.

Im Vergleich mit anderen Methoden, wie zum Beispiel der MRT oder Computertomographie, korreliert die Sonographie zufriedenstellend, auch wenn einige Verfahren in der Genauigkeit überlegen sind. So gilt die Volumenbestimmung mittels CT als die akkurateste Methode, insbesondere wenn substernale Anteile der Schilddrüse vorhanden sind (Nygaard et al. 2002; Lee et al. 2014). Das Verfahren der Computertomographie unterscheidet sich maßgeblich in der Art und Weise der Bildgenerierung von der Sonographie. Unter Anwendung der Ellipsoidformel (siehe 2.2.3 Volumenberechnung mittels Sonographie und For- 
mel 1) wird bei der Sonographie die Beschaffenheit der Schilddrüse als Ellipse vereinfacht. In der Realität ist dies, insbesondere bei großen Strumen, vielfach nicht zutreffend (Brunn et al. 1981; Shu et al. 2011). Beim CT wird eine zwei- oder dreidimensionale Darstellung des realen Volumens über das Schnittbildverfahren möglich. Hierzu werden eine große Anzahl eindimensionale Absorbtionsprofile erstellt und computergestützt zu einer zweioder dreidimensionalen Abbildung verrechnet (Kauffmann et al. 1996). Eine Arbeitsgruppe der Chung-Ang-Universität in Seoul verglich in einer prospektiven Studie bei 47 Patienten das sonographisch und das computertomographisch (zwei- und dreidimensional) ermittelte Schilddrüsenvolumen mit dem realen Volumen, welches nach totaler Thyreoidektomie über das archimedische Prinzip (Wasserverdrängungsmethode) berechnet wurde. Die Volumina der Sonographie $(p=0,937)$ und der 3D-CT $(p=0,999)$ wichen nicht signifikant vom realen Volumen ab. Die 2D-CT brachte jedoch signifikant abweichende Ergebnisse und ist somit der Sonographie nicht überlegen $(\mathrm{p}=0,016)$ (Lee et al. 2014). Für die klinische Routine eignet sich die 3D-CT jedoch nicht, sodass sie bei der Volumetrie der Schilddrüse keine weitere Verbreitung gefunden hat.

Van Isselt et al. verglichen die Sonographie mit der planaren Szintigraphie, der SinglePhoton-Emissions-Computertomographie (SPECT) und der Magnetresonanztomographie (MRT, Referenzverfahren) verglichen. Die Studie umfasste 25 Patienten (drei männliche und 22 weibliche Patienten) mit der Diagnose Morbus Basedow. Im Vergleich mit dem MRT korreliert das ermittelte Volumen in der Sonographie stärker $(r=0,97)$ als das Volumen in der planaren Szintigraphie $(r=0,61)$. Da es sich bei der Szintigraphie um eine eindimensionale Darstellung handelt, war eine adäquate Volumetrie nicht zu erwarten (van Isselt et al. 2003).

Aufgrund dieser Daten erscheint die Sonographie trotz ihrer bekannten Schwächen die praktikabelste Methode für die präradioiodtherapeutische Diagnostik zu sein (van Isselt et al. 2003; Lee et al. 2014).

Wie bereits erwähnt, fließen neben dem Volumen auch die effektive Halbwertszeit und der individuelle Uptake in die Dosisberechnung mit ein. Um präzise den Uptake zu bestimmen und die Halbwertszeit vorhersagen zu können, sind möglichst viele Uptakemessungen über den Zeitraum von mehreren Tagen nötig (Bockisch et al. 1993; Meier et al. 2002). Zwischen Radioiodtest und -therapie sollten nicht mehr als zwei Wochen Zeitabstand liegen und auch die Medikation zum Testzeitpunkt sollte der zum Therapiezeitpunkt entsprechen.

Manche Autoren plädieren für Uptakemessungen bereits am ersten Tag, da beim floriden untherapiertem Morbus Basedow, das Maximum bereits vier Stunden nach Verabreichen von ${ }^{131}$ Iod erreicht sein kann. Allerdings werden alle Patienten in der Abteilung Nuklearmedizin der UMG bei der immunogenen Hyperthyreose im euthyreoter Stoffwechsellage therapiert, sodass eine solche frühe Messung nicht notwendig erscheint. Patienten mit gut 
kompensierten Autonomien zeigen gelegentlich ein Speichermaximum nach 48 Stunden oder später (Schicha et al. 2013). In der nuklearmedizinischen Abteilung der Universitätsmedizin Göttingen findet als Kompromiss, wie in ähnlichen universitären Einrichtungen in Deutschland, die erste Messung nach 24 Stunden im Rahmen des Radioiodtests statt, die in aller Regel auch dem Speichermaximum entspricht.

Es wird kontrovers diskutiert, wie verlässlich dieses Verfahren zur Vorhersage von Uptake und effektiver Halbwertszeit zum Therapiezeitpunkt letztendlich ist, da es zumindest theoretisch zu Abweichungen von $100 \%$ zwischen kalkulierter und erreichter Herddosis kommen kann (Berberich et al. 1980; Bockisch et al. 1993; Dai et al. 1996). Einige Autoren sind der Meinung, dass ab drei Messungen suffiziente Daten ermittelt werden können (Berg et al. 1996), anderen zufolge erlauben erst Messungen über den Zeitraum von fünf Tagen verlässliche Aussagen (Meier et al. 2002). Einen gänzlich anderen Ansatz wählen Studien mit empirisch ermittelten teilweise krankheitsspezifischen Halbwertszeiten. Hier findet keine individuelle Ermittlung der Halbwertszeiten statt (Kobe et al. 2010). Aktuell gibt es zahlreiche Konzepte der verschiedenen Gesellschaften (z. B.: European Association of Nuclear Medicine (EANM), The American Association of Clinical Endocrinologists (AACE), American Thyroid Association (ATA), Deutsche Gesellschaft für Nuklearmedizin e.V. (DGN)), aber keinen Konsens, welches Verfahren laut heutigem Wissensstand zu empfehlen ist. In der nuklearmedizinischen Abteilung der Universitätsmedizin Göttingen wurden in der Vergangenheit ebenfalls mehrere Varianten des Radioiodtests erprobt. Aufgrund der auffälligen Häufung von Abweichungen der geplanten Herddosis soll an dieser Stelle auch das aktuell angewandte Verfahren in Frage gestellt werden.

In einer retrospektiven Studie der Universität Würzburg wurden die Daten von 126 Morbus Basedow-Patienten evaluiert. Mittels multivariater Analyse wurden unabhängige Einflussfaktoren für den Erfolg oder Misserfolg einer RIT evaluiert. Dabei zeigte sich statistisch kein Vorteil einer individuell ermittelten HWZ im Vergleich zur Verwendung einer gruppenspezifisch bestimmten effektiven HWZ. Die prätherapeutische Dosimetrie erfolgte aus logistischen Gründen uneinheitlich (Schneider et al. 2002).

Eine retrospektive Studie aus dem Jahr 2015, die nach Initiierung dieser Doktorarbeit publiziert wurde, zeigte anhand der retrospektiv ausgewerteten Daten von 1538 radioiodtherapierten Patienten, dass der Radioiodtest die intratherapeutische effektive HWZ nicht sicher voraussagt. Die Autoren plädieren daher für die Verwendung einer gruppenspezifischen HWZ und die Bestimmung lediglich eines einzigen Uptakewerts zum Beispiel zwischen 24 und 48 Stunden (Nüchel et al. 1993; Krohn et al. 2015). 


\subsection{Diskussion der Ergebnisse}

\subsubsection{Diskussion der prätherapeutischen Daten}

Die patientenspezifische Dosiskalkulation mittels präradioiodtherapeutischer Bestimmung des individuellen Iodstoffwechsels ist in Deutschland in den Strahlenschutzbestimmungen gesetzlich geregelt. Auf diese Weise soll eine Über-, aber auch eine Unterdosierung vermieden werden. Laut den aktuellen Empfehlungen der Deutschen Gesellschaft für Nuklearmedizin hinsichtlich des Radioiodtests ist für die Berechnung der zu applizierenden Aktivität eine einzelne Uptakemessung nach fünf bis acht Tagen ausreichend. Soll darüber hinaus die individuelle effektive HWZ bestimmt werden, so ist mindestens eine weitere Messung durchzuführen (Eckardt et al. 2009).

Weltweit werden sehr unterschiedliche Varianten der Radioiodtherapie verwendet, die von fixen Aktivitäten, fixen Aktivitäten bezogen auf das Schilddrüsengewicht, fixen Aktivitäten normiert auf den 24-h-Uptake bis hin zu einer präradioiodtherapeutischen dosimetrischen Abschätzung nach Marinelli mit Bestimmung der effektiven HWZ reichen. Insgesamt ist zurzeit noch nicht geklärt, ob die Radioiodtherapie mit errechneter Aktivität der Verwendung von Standardaktivitäten überlegen ist.

Eine erste Metaanalyse zu dieser Frage erschien 2009 und erfasste Daten die an BasedowPatienten und Patienten mit Autonomie erhoben worden waren. Die Datenanalyse konnte keine Überlegenheit für eine dosimetrisch gestützte Aktivitätskalkulation nachweisen (Rooij et al. 2009).

In einer methodologisch sehr validen Metaanalyse, die 2014 publiziert wurde, gingen zwei randomisierte und fünf nicht-randomisierte klinische Studien mit insgesamt 669 Patienten, die wegen einer Schilddrüsenautonomie mit Radioiod therapiert worden sind, ein (Rokni et al. 2014). In diesen Studien wurde der Therapieerfolg fixer Aktivitäten mit dem Therapieerfolg dosimetrisch ermittelter Aktivitäten verglichen. Dabei zeigte sich als Hauptaussage der Metaanalyse, dass Patienten, bei denen eine individuelle Dosimetrie, in welcher Form auch immer, erfolgte, insgesamt eine 9,6 \% höhere Erfolgsrate aufwiesen (risk-ratio 1,17) als die Patienten, bei denen eine Standartaktivität verabreicht worden ist. Patienten mit einer individuellen Dosimetrie wiesen zudem eine nur gering erhöhte Hypothyreoserate auf, die 0,3 \% über der Hypothyreoserate der mittels Standardaktivität behandelten Patienten lag. Die Autoren verweisen auf höchst heterogene Studiendesigns, die endgültige Schlüsse zurzeit nicht zulassen. Nur zwei Studien der Metaanalyse, die im Folgenden näher betrachtet werden sollen, weisen ein prospektiv randomisiertes Design auf (Jarløv et al. 1995; Zakavi et al. 2009).

Jarløv et al. analysierten prospektiv die Therapieergebnisse von 163 Patienten mit Hyperthyreose. Die Patienten wurden in eine Gruppe mit fixer (Gruppe $1, n=85$ ) und eine mit 
kalkulierter Aktivität (Gruppe 1, $\mathrm{n}=78$ ) eingeteilt. Die Kalkulation der Aktivität in Gruppe 1 erfolgte durch die Verschreibung einer vorgegebenen Aktivität abhängig vom Schilddrüsenvolumen (<30 ml: $185 \mathrm{MBq}, 30$ - $60 \mathrm{ml}: 379 \mathrm{MBq}$, > $60 \mathrm{ml}: 555 \mathrm{MBq}$ ). Die Berechnung der Aktivität in Gruppe 2 erfolgte durch die Verschreibung einer fixen Aktivität / g Gewebe geteilt durch den 24-h-Uptake. Das Schilddrüsengewicht wurde sonographisch ermittelt. Eine effektiven HWZ wurde bei diesem Vorgehen nicht errechnet. In $59-65 \%$ der Fälle konnte eine Hyperthyreose erfolgreich therapiert werden, ungeachtet mit welcher Therapievariante behandelt wurde. (Jarløv et al. 1995).

Zakavi publizierte eine prospektiv randomisierte Studie mit insgesamt vier gleichgroßen Vergleichsgruppen: Gruppe 1 mit fixer „,niedriger“ Aktivität (481 MBq), Gruppe 2 mit fixer „hoher“ Aktivität (832 MBq), Gruppe 3 und 4 mit Verschreibung einer fixen Aktivität (Gruppe 3: 3,33 - 3,7 MBq / g Gewebe; Gruppe 4: 6,66 - 7,4 MBq / g Gewebe) geteilt durch den 24-h-Uptake. Eine tendenziell höhere Erfolgsquote fand sich in Gruppe 4, während die anderen Gruppen keine signifikanten Unterschiede im Ansprechen auf die RIT zeigten (Zakavi et al. 2009).

Peters et al. führte eine prospektiv randomisierte Vergleichsstudie fixer Aktivitäten und dosimetrisch ermittelter Aktivitäten bei Patienten mit immunogener Hyperthyreose durch. Patienten der Gruppe $1(\mathrm{n}=98)$ erhielten eine Standardaktivität von $15 \mathrm{mCi}$ (555 $\mathrm{MBq}){ }^{131}$ Iod, Patienten der Gruppe $2(\mathrm{n}=107)$ erhielten eine Dosimetrie und Dosiskalkulation mit Verschreibung von 100 Gy nach der Marinelli-Formel. Die Erfolgsquote dieser Studie (Erfolg = Eu- oder Hypothyreose) lag bei $71 \%$ bei Verwendung einer Standardaktivität und bei $58 \%$ bei der individuell errechneten Aktivität. Allerdings muss hinzugefügt werden, dass eine Dosis von 100 Gy nicht den heute empfohlenen Herddosen der DGN entspricht, bei denen 300 Gy kalkuliert werden.

Leslie et al. untersuchten prospektiv die Therapieergebnisse von 88 Patienten mit Morbus Basedow, indem sie fixe mit kalkulierten Aktivitäten verglichen. Es erfolgte lediglich eine Uptakemessung nach 24 Stunden und das Schilddrüsenvolumen wurde bei 68 von $88 \mathrm{~Pa}$ tienten rein palpatorisch bestimmt. Zudem wurde während der RIT weder der Uptake noch die effektive HWZ bestimmt. Die Erfolgsrate lag bei allen Patienten bei 74 - $82 \%$, sodass sich die kalkulierte Dosis der fixen Dosis nicht als überlegen darstellte (Leslie et al. 2003).

Der zeitliche Abstand zwischen Durchführung des Radioiodtests und eigentlicher Therapie scheint bei der Verlässlichkeit der Vorhersage der Schilddrüsenkinetik zum Therapiezeitpunkt ebenfalls eine Rolle zu spielen. So sollen laut den Empfehlungen der DGN nicht mehr als zwei Wochen zwischen Test und Therapie liegen. Diese Empfehlung beruht auf der Tatsache, dass die individuelle Iodkinetik natürlicher Weise einer gewissen Variabilität unterliegt und sich unter bestimmten Bedingungen, die im Folgenden eingehender diskutiert werden, rasch ändern kann. 
Die Schilddrüsenhormone werden iodabhängig im Lumen der Follikel, welche aus Epithelzellen aufgebaut sind, gebildet. Basal an den Thyreozyten findet sich der NIS, ein aktiver Transporter, welcher das Iodid ins Zellinnere transportiert. Apikal findet der Weitertransport zum Ziel, ins Follikellumen, mittels Pendrin statt. Im Lumen selbst wird dann unter dem Einfluss der thyreoidalen Peroxidase Iodid in organisches Iod umgewandelt. Daraufhin erfolgt eine Iodierung von Thyrosylresten des Thyreoglobulin. Aus diesen iodierten Thyrosylresten entstehen durch enzymatische Kopplung schließlich Triiodthyronin und Tetraiodthyronin. Diese Schilddrüsenhormone werden abschließend über Pinozytose aus den Thyreozyten in den Intravasalraum gebracht (Löffler et al. 2006).

Die gesamte Synthese und Sekretion unterliegen einer sensiblen Steuerung über einen zentralnervösen Regelkreis. Die intrathyreoidale Hormonproduktion ist abhängig von den zirkulierenden freien Schilddrüsenhormonen. Fällt der Hormonspiegel, schüttet der Hypothalamus Thyreoliberin aus und stimuliert somit die Hypophyse zur Sekretion von Thyreotropin (TSH). Thyreotropin wiederum regelt die Sekretion der Schilddrüsenhormone an der Schilddrüse, aber auch die Aufnahme von Iodid ins Lumen. Darüber hinaus unterliegt die Schilddrüsenhormonproduktion einem weiteren, noch bedeutenderen Kontrollmechanismus über die Hypophyse. Dies geschieht über die sogenannte Deiodinase Typ 2. Es handelt sich um ein Selenoenzym der Gruppe der Peroxidasen, das durch stereospezifische Deiodierung fT4 zu fT3 metabolisiert. Freies T3 wiederum moduliert anschließend die TSH-Freisetzung (Kalsbeek et al. 2005).

Gehemmt wird die Produktion bei ausreichender Menge von Schilddrüsenhormonen im Blut durch einen simplen negativen Rückkopplungsmechanismus. Freies T3 und T4 stoppen sowohl die Thyreotropin- als auch die Thyreoliberinsekretion. Darüber hinaus gibt es noch eine intrathyreoidale Autoregulation, welche unabhängig vom TSH fungiert (Löffler et al. 2006).

Für eine physiologische Schilddrüsenfunktion muss somit zum einen ausreichend Iod vorhanden sein, zum anderen darf aber kein Iodüberangebot herrschen. In letzterem Fall spricht man von einer Iodkontamination. Der normale Iodgehalt im Schilddrüsengewebe liegt bei $700-900 \mu \mathrm{g} / \mathrm{g}$. Verringert sich die Iodmenge bis zu einer Konzentration von $200-300 \mu \mathrm{g} / \mathrm{g}$, kommt es cAMP bedingt zu einer Hypertrophie der Schilddrüse, aber noch ohne Zellzahlzunahme, da bis zu einem Schwellenwert von $150 \mu \mathrm{g} / \mathrm{g}$ durch Iodlacton die Zellproliferation über Hemmung der Proteinkinase $\mathrm{C}$ gehemmt wird. Iodlacton wird in der Follikelepithelzellmembran gebildet. In Iodmangelsituationen mit niedrigerem Iodgehalt ist Iodlacton nicht nachweisbar. Kommt es nun jedoch zu einer oben beschriebenen Iodkontamination, einem kurzfristigen oder chronischen Iodexzess, greift ein weiterer intrathyreoidaler Kontrollmechanismus. Der Wolff-Chaikoff-Effekt hemmt die Iodaufnahme und auch die Organifizierung. Dieser Kompensationsmechanismus ist heutzutage noch nicht abschließend ergründet, verhindert aber zuverlässig eine hyperthyreotische Kri- 
se bei stark erhöhtem Iod-Plasmaspiegel (Aufnahme > 5mg / d) wie zum Bespiel nach Kontrastmittelgabe (Füger et al. 2002; Schauder et al. 2011).

Eine strikte Beachtung der zuvor geschilderten Mechanismen ist auch bei der Vorbereitung zur RIT wichtig. So ist die gewünschte Aufnahme von radioaktiven ${ }^{131}$ Iod gestört, wenn im Vorfeld keine strikte Ioddiät (z. B. Seefisch, Meeresfrüchte) eingehalten worden ist. Darüber hinaus können, wie bereits erwähnt, auch iodhaltige Kontrastmittel oder bestimmte Medikamente zu einer Iodkontamination führen und die Iodkinetik im Verglich zur Testsituation stark verändern und letztendlich den Erfolg einer RIT erheblich beeinflussen. Ein verringerter Ioduptake korreliert um bis zu $30 \%$ mit einer Iodkontamination aufgrund der kompetitiven Eigenschaften von Radioiod und Iod an den entsprechenden Rezeptoren und des genannten Wolff-Chaikoff-Effekts (Meller et al. 2005).

Eine Kontamination kann selten mittels einer anamnestischen Befragung ausreichend evaluiert werden. Eine Messung der Uriniodausscheidung (UIE) kann hier Abhilfe schaffen und kontaminierte Patienten sollten folglich von einer RIT ausgeschlossen werden (Meller et al. 2002). Ein Schnelltest wurde in der Vergangenheit standardmäßig durchgeführt, allerdings stellte die Firma Merck KGaA 2002 die Produktion ein. Alternativ könnte eine aufwendige HPLC-Methode (high performance liquid chromatography) eingesetzt werden, die aber für Routineuntersuchungen zu kostenintensiv ist.

Um Veränderungen in der Iodkinetik zwischen Test und Therapie möglichst auszuschließen, ist die RIT unmittelbar im Anschluss an den Radioiodtest durchzuführen. In dieser Studie ist der empfohlene Zeitrahmen weitestgehend eingehalten worden. Der Abstand zwischen Test und Therapie betrug durchschnittlich 12,84 \pm 5,92 Tage und liegt somit im angestrebten Zeitfenster. Die Korrelationsanalyse nach Pearson wies dazu passend keinen signifikanten Zusammenhang zum Nicht-Erreichen der gewünschten Herddosis nach ( $\mathrm{p}=$ $0,423)$.

Eine Korrelation zwischen potentiell fehlerhaftem Zielvolumen und dem NichtErreichen der Herddosis konnte im Rahmen unserer Arbeit für keine Diagnose bestätigt werden $(\mathrm{p}=0,367)$.

Wie bereits bei der Diskussion der Methoden erwähnt, ist die Volumetrie von entscheidender Bedeutung in der Diagnostik und Therapie benigner Schilddrüsenerkrankungen. Die Volumenbestimmung des Gesamtvolumens ist an dieser Stelle aber streng von der Bestimmung des eigentlichen Zielvolumens zu differenzieren. Das Volumen einer unifokalen Autonomie kann für gewöhnlich ohne weitere Probleme verlässlich sonographisch bestimmt werden. Allerdings müssen zystische oder regressive Veränderungen innerhalb des beschallten Schilddrüsenparenchyms vom letztendlich gemessenen Zielvolumen subtrahiert werden (Joseph 1994). 
Die Volumenbestimmung mittels Ultraschall bei der multifokalen Autonomie und der disseminierten Autonomie scheint darüber hinaus noch schwieriger. Das Zielvolumen einer multifokalen oder disseminierten Autonomie ist sonographisch nicht genau zu erfassen (Debrand-Passard et al. 1994). Um bei diesen Patienten trotzdem verlässlich ein Zielvolumen zu definieren, haben sich zwei Ansätze etabliert. Der erste Ansatz ist von Emrich et al., die zeigen konnten, dass eine lineare Korrelation zwischen 99mTc-Pertechnetat-Uptake unter Suppressionsbedingungen (TcTUs) und dem Volumen gut charakterisierter nicht zystisch degenerierter autonomer Adenome - sonographisch gemessen - besteht. Daraus entwickelte die Arbeitsgruppe die These, dass das autonome Volumen multifokaler und disseminierter Autonomien in Strumen im Umkehrschluss über den TcTUs verbindlich ermittelt werden kann (Emrich et al. 1993; Reinhardt et al. 1995). Ein solches Verfahren ist in der Tat bei kleinen autonomen Volumina zielführend. Bei größeren Volumina ergibt sich rein theoretisch die Möglichkeit, dass die Strahlenattenuation dorsal gelegener Areale ein Ausmaß erreicht, die den TcTUs zu niedrig erscheinen lässt. In der Tat konnte bewiesen werden, dass das autonome Volumen bei großem Schilddrüsenvolumen auf diese Weise nicht zuverlässig bestimmt werden kann, und dass es bei der RIT, die diesen Ansatz zur Bestimmung des Volumens des autonomen Volumens verwendet, bei großen Schilddrüsenvolumina gehäuft zu therapeutischen Misserfolgen kommt (Meller et al. 2000).

Eine Fortentwickelung der Emrichschen Methode stammt aus der Arbeitsgruppe aus Rostock (Dunkelmann et al. 1999). Hier wird die Dosis, die auf ein autonomes Volumen, das per TcTUs ermittelt worden ist, appliziert wird, nach der Höhe des Uptakes zusätzlich differenziert.

Insgesamt hat sich der TcTUs-gestützte Ansatz zur Bestimmung des autonomen Zielvolumens nicht durchgesetzt. Dies hängt mit der Tatsache zusammen, dass die vor 20 Jahren im Iodmangelgebiet Deutschland erhobenen Werte für den TcTUs nicht mehr mit den heutig erhobenen TcTUs-Werten nach weitgehender Beseitigung des endemischen Iodmangels vergleichbar sind.

Alternativ hat sich der sogenannte „Dosimetrische Kompromiss“ bei der Dosiskalkulation bei disseminierter und multifokaler Autonomie durchgesetzt. Im Wissen, dass das reale autonome Volumen nicht exakt feststellbar ist, werden empirisch ermittelte Herddosen von 200 Gy auf das sonographisch ermittelte Gesamtvolumen appliziert, während bei der unifokalen Autonomie das Zielvolumen das sonographisch bestimmte Volumen der Autonomie ist, auf das 300 - 400 Gy appliziert werden.

In Deutschland ist der RIT zumindest bei der Therapie von Morbus Basedow eine medikamentöse Therapie vorzuschalten, aber auch bei funktionellen Autonomien können auf diese Weise die Symptome gelindert werden. Zu diesem Zweck werden sogenannte Thyreostatika verschrieben. Aktuell am häufigsten verabreicht werden die Präparate Pro- 
pylthiouracil (Propycil @) und Thiamazol (Favistan $($ )). Allgemein werden unterschiedliche Wirkmechanismen unterschieden. Propylthiouracil gehört zu den sogenannten Iodisationshemmern und inhibiert die Thyreoperoxidase direkt, welche infolgedessen Iodid nicht mehr zu Iod oxidieren kann, die Hormonproduktion wird gehemmt. Thiamazol verhindert die Bindung von Iod an das Enzym Thyreoperoxidase und hemmt so ebenfalls die Produktion der Schilddrüsenhormone Thyroxin und Triiodthyronin (Lüllmann et al. 2006).

Thioamide, zu denen sowohl Propylthiouracil als auch Thiamazol gehören, stehen schon länger im Verdacht, die Effektivität der RIT zu verringern. Insbesondere bei Verabreichung von Thioamiden in höheren Dosen wird der Radioioduptake und durch die beschriebene veränderte intrathyreoidale Iodkinetik auch die Verweildauer des ${ }^{131}$ Iod verringert (Müller et al. 1991; Urbannek et al. 2000). Darüber hinaus ist ein radioprotektiver Effekt der in Carbimazol, Thiamazol und Propylthiouracil enthaltenen Sulfhydrylgruppe in Diskussion. So vermutet man, dass die Sulfhydrylgruppe intrathyreoidal verstoffwechselt wird und mit Proteinen der Thyreozyten Disulfid-Brücken bildet, welche letztendlich diesen zellprotektiven Effekt begründen. Ein anderer Erklärungsansatz ist eine alterierte Wasserstoffperoxidproduktion der bestrahlten Zellen. Zudem interagiert Carbimazol kompetitiv am NIS (Kahmann et al. 2010).

Connell et al. untersuchten Effekt von Carbimazol auf den Therapieeffekt der RIT prospektiv im Jahr 1984 an hyperthyreoten Patienten $(n=55) .24$ Patienten wurden mittels Carbimazol vor der Radioiodtherapie in die Euthyreose überführt und das Thionamid fünf Tage vor der Therapie abgesetzt. Die restlichen Patienten wurden nicht vorbehandelt. Die Inzidenz an frühen postradioiodtherapeutischen Hypothyreosen wurde in der vorbehandelten Gruppe reduziert und vorbehandelte Patienten zeigten ein verzögertes Therapieansprechen im Vergleich mit den nicht vorbehandelten Patienten, was der Autor als ein einen möglichen Hinweis auf einen strahlenprotektiven Einfluss der Prämedikation wertete. Allerdings ist der wash-out von Carbimazol nach fünftägiger Pause sicherlich abgeschlossen, sodass ein direkter Einfluss der Vormedikation aus heutiger Sicht wohl eher unwahrscheinlich ist (Connell et al. 1984).

Bis zum heutigen Zeitpunkt wurden zahlreiche prospektive Studien zu diesem Thema publiziert (Sabri et al. 1999; Andrade et al. 2001; Körber et al. 2001). Sabri et al. publizierten 1999 eine prospektive Studie über 207 Patienten mit einer immunogenen Hyperthyreose. 106 dieser Patienten nahmen gleichzeitig zur RIT das Thyreostatikum Carbimazol ein. Es erfolgte keine Randomisierung. Die Patienten wurden im Follow-up untersucht und es zeigte sich in einer multivariaten Analyse, dass die Einnahme von Carbimazol ein unabhängiger Risikofaktor für einen therapeutischen Misserfolg war. Es ist anzunehmen, dass Patienten unter Thyreostase schwerere Verlaufsformen einer Hyperthyreose aufwiesen als Patienten ohne Thyreostase. Der gehäufte Misserfolg in der Thyreostatikagruppe könnte somit auch Ausdruck einer hohen Krankheitsaktivität bei diesen Patienten sein. Diese al- 
ternative Interpretation wird durch die Daten von Andrade unterstützt. Dieser Autor untersucht prospektiv und randomisiert Patienten mit einer Basedow Hyperthyreose, bei denen ein Teil der Patienten $(n=32)$ Thiamazol erhielten und der andere Teil der Patienten $(n=$ 29) ohne schilddrüsenspezifische Medikation verblieb. Die Dosiskalkulation erfolgte ohne die Bestimmung einer individuellen Iodkinetik und berücksichtigte lediglich den 24-hUptake und das sonographisch bestimmte Zielvolumen. Eine multivariate Analyse zeigte, dass schwerere Krankheitsverläufe, ablesbar an hohen T3-Werten, ein unabhängiger Risikofaktor für einen therapeutischen Misserfolg waren. Hingegen war die Medikation mit Thiamazol kein Risikofaktor für einen Misserfolg (Andrade et al. 2001). Aus dieser Studie kann man den Schluss ziehen, dass die Krankheitsaktivität selbst, aber nicht die Begleitmedikation einen wesentlichen Einflussfaktor auf Erfolg oder Misserfolg der RIT beim Morbus Basedow darstellt.

Körber et al. untersuchten prospektiv 559 Patienten (Morbus Basedow n $=141$, Autonomie $\mathrm{n}=418$ ). Alle Patienten erhielten eine RIT nach individueller Dosimetrie. Ein Einfluss der Thyreostase auf den Therapieerfolg beim Morbus Basedow konnte auch hier nicht nachgewiesen werden. Allerdings kam es bei thyreostatisch vorbehandelten Autonomien signifikant häufiger zu therapeutischen Misserfolgen. Die exakte Begründung, warum die thyreostatisch vorbehandelten Patienten Medikamente verordnet bekommen haben, ist leider unzureichend dokumentiert. So bleibt es wie in der Studie von Sabri et al. ungeklärt, ob der Krankheitsverlauf selbst oder die Thyreostase ein entscheidender Einflussfaktor auf den Therapieerfolg einer RIT ist. Darüber hinaus waren nicht alle Autonomiepatienten der Studie adäquat TSH-supprimiert (Körber et al. 2001).

Zusammenfassend gibt es bis heute keine gesicherten Daten, dass eine thyreostatische Medikation einen wesentlichen Einfluss auf den Erfolg einer RIT hat. Aus theoretischen Gründen scheint dies schon deswegen fraglich, da ein erniedrigter Uptake in der MarinelliFormel automatisch korrigiert würde.

Bei der Analyse der Patientendaten der nuklearmedizinischen Abteilung der UMG fanden sich keine Anhaltspunkte auf eine mögliche Korrelation zwischen schilddrüsenspezifischer Medikation und dem Verfehlen bzw. dem Erreichen der geplanten Herddosis $(p=0,229)$. Zusätzlich wurde ein potentieller Zusammenhang zwischen der Thyreostase und den Ergebnissen bzw. dem Verlauf des Radioiodtests evaluiert. Die Medikamente nehmen auch hier keinen signifikanten Einfluss $(p=0,972)$.

Wenige Studien befassen sich mit dem Geschlecht der Patienten als einflussübendem Faktor auf die RIT. Eine retrospektive Studie aus dem Jahr 2015 von Šfiligoj et al. aus Ljubljana untersuchte eine Reihe von Faktoren auf möglichen Einfluss auf den Erfolg der RIT bei Morbus Basedow. Insgesamt umfasste die Studie 724 Patienten, 569 Frauen und 155 Männer (Šfiligoj et al. 2015). Wie bereits durch Prabhaker et al. festgestellt, erkranken 
Frauen sechs bis acht Mal häufiger an Morbus Basedow (Prabhakar et al. 2003), wie auch die Geschlechterverteilung der retrospektiven Analyse von Šfiligoj et al. bestätigt. Dennoch weicht das Verhältnis zwischen männlichen und weiblichen Patienten zwischen der erfolgreich und nicht erfolgreich therapierten Gruppe nicht signifikant ab (Šfiligoj et al. 2015). Die RIT beinhaltete in dieser Studie ein Dosiskonzept mit einer fixen, nach Schilddrüsenvolumen modifizierten Dosis und ist daher nicht auf die Ergebnisse dieser vorliegenden Studie zu übertragen. Trotz individueller Dosimetrie erscheint das Geschlecht auch in unserer Untersuchung als irrelevant und korreliert nicht mit dem Erreichen bzw. NichtErreichen der Herddosis ( $\mathrm{p}=0,219)$.

\subsubsection{Diskussion der posttherapeutischen Daten}

Wenn energiereiche ionisierende Strahlung in Gewebe eindringt, tritt sie unweigerlich mit der bestrahlten Materie in Wechselwirkung. Ganz zu Beginn $\left(\sim 10^{-15} \mathrm{~s}\right)$ kommt es radiophysikalischen Veränderungen in Form von Elektronenfreisetzung. Kurz darauf $(\sim 1 \mu \mathrm{s})$ werden durch diese Elektronen radiochemische Prozesse ausgelöst. Es kommt zur Radikalbildung. Das in den Zellen befindliche Wasser wird durch die ionisierende Strahlung über einen Zwischenschritt zu Hydroxyl-Radikalen und Hydroxonium umgewandelt. Hydroxyl-Radikale sind extrem reaktionsfreudig und können, sofern sie nicht zu Sauerstoff und Wasser abgebaut werden, gravierende Schäden, unter anderem an der Desoxyribonukleinsäure (deoxyribonucleic acid $=$ DNA), verursachen. Solche biochemischen Veränderungen ereignen sich weniger als eine Sekunde bis etliche Minuten nach Auftreffen der Strahlen. So kann es zu Oxidationen, Reduktionen, Hydroxylierungen oder Decarboxylierungen am organischen Molekül kommen. Diese Schäden und Veränderungen an der DNA und anderen Strukturen innerhalb der Zellen ziehen Akut- und Spätfolgen und Mutationen nach sich (Mettler und Upton 2008).

Grundsätzlich kann man zwischen direkten und indirekten Strahlenschäden unterscheiden. Die direkte Strahlenwirkung einer ionisierenden Strahlung (z. B. Röntgenstrahlung, Gamma-Strahlung, Alpha- und Beta-Teilchen, Neutronen) zeichnet sich dadurch aus, dass Energieabsorbtion und biochemische Wirkung in derselben Struktur stattfinden. Bei den indirekten Strahlenschäden entstehen durch die ionisierende Strahlung anfänglich, wie oben bereits beschrieben, hoch reaktive freie Wasserradikale, welche zu sekundären Strukturen diffundieren und hier ihre biochemische Wirksamkeit entfalten können. Der strahlensensibelste intrazelluläre Bestandteil ist die DNA. Aktuell sind sechs verschiedene Schäden des DNA-Moleküls experimentell nachweisbar. So kann es zu DNA-Basenschäden, also einer irreversiblen Modifikation oder Deletion einer Base kommen, die Desoxyribose kann verändert werden und es kann zu Einzel- oder Doppelstrangbrüchen des DNAMoleküls kommen. Bei einem Doppelstrangbruch müssen beide Einzelstränge an den exakt gegenüberliegenden Stellen gebrochen sein. Darüber hinaus kann es zu DNA-DNA- 
und DNA-Protein-Vernetzungen, sogenannten crosslinks kommen oder gar zu multiplen Schäden (clustered damage). Ist es zu derartigen intrazellulären Läsionen gekommen, können verschiedene Reparaturmechanismen (Basenexzisionsreparatur, Nukleotidexzision, Mismatch-Reparatur, homologe Rekombination) in Gang gesetzt werden oder es kommt zum Absterben der Zelle (Mettler und Upton 2008).

Sind die Schäden zu ausgeprägt, wird der programmierte Zelltod (Apoptose) eingeleitet, bei hohen Dosen kann es auch direkt zu einer Nekrose kommen und bei speziellen Zelltypen auch zur Seneszenz. In reparaturprofizienten Zellen können oben genannte Reparaturmechanismen innerhalb von Minuten bis Stunden strahlenindizierte DNA-Schäden reparieren. An sogenannten checkpoints innerhalb des Zellzyklus kann der Zyklus beispielsweise mittels Expression des sogenannten Tumorsuppressorgens p53 gestoppt werden, sodass für etwaige Reparaturmechanismen genügend Zeit zur Verfügung steht oder die Apoptose eingeleitet werden kann (Joiner und Kogel 2009). Generell kann ein sogenannter Interphase-Tod (Tod im intermitotischen Abschnitt des Zellzyklus) von einem reproduktiven Tod abgegrenzt werden. Beim Interphase-Tod geht die letal strahlengeschädigte Zelle ohne weitere Teilung zugrunde, beim reproduktiven Tod einer Zelle kommt es nach oder während der Mitose zum Zelluntergang (Fritz-Niggli 1997).

Typisch für die Apoptose, dem programmierten Zelltod, ist die Zellschrumpfung mit Bildung apoptotischer Vesikel an der Zelloberfläche. Es kommt zur Chromatinkondensation und einer DNA-Fragmentierung im Nukleus sowie zur Umverteilung von Phosphatidylserin von der intrazellulären zur extrazellulären Seite der Plasmamembran (Rudner et al. 2001).

Die Apoptose kann über membranständige Rezeptoren (extrinsische Apoptose, Typ I) mittels sogenannter death receptors über einen extrinsischen Signalweg eingeleitet werden. Darüber hinaus führen Wachstumsfaktorentzug, Hypoxie, Hitzeschock, verschiedene zytotoxische Substanzen, ionisierende Strahlung und Kinaseinhibitoren zur Apoptoseinduktion (intrinsische Apoptose, Typ II) (Trump et al. 1997).

Zum extrinsischen Weg zählt der Tumornekrosefaktor-Rezeptor (TNF-Rezeptor) vom FasTyp oder Zelltodrezeptoren wie CD95, TRAIL-R1 oder TRAIL-R2. Die Verbindung von Ligand und Rezeptor führt dann über eine Aktivierung intrazellulärer Proteasen, der Caspasen, zum AICD (activation-induced cell death). Dabei handelt es sich um CysteinProteasen, die Proteine nach einem Aspartatrest schneiden. Zu Beginn wird eine initiale Caspase autoproteolytisch (Caspase 2, 8, 9, 10) aktiviert und in weiterer Folge kommt es zur Prozessierung der Effektorcaspasen (Caspase 3, 6, 7), welche daraufhin Zielproteine degenerieren. Der Zelltod tritt ein (Muzio et al. 1996).

Alle restlichen apoptotischen Faktoren führen zunächst über eine Schädigung des Mitochondriums (mitochondrialer Signalweg) zu einer Freisetzung proapoptotischer Faktoren 
aus dem Inneren des Mitochondriums. Darunter findet sich auch Cytochrom $\mathrm{C}$, welches zusammen mit Apaf-1 (Apoptoic Protease Activating Factor 1) aus der mitochondrialen Organellenmembran das sogenannte Apoptosom formiert. Der Apoptosom-Komplex kann nun die Caspase 9 aktivieren und den extrinsischen Weg über die Caspase 3 zusätzlich aktivieren. Kontrolliert wird die intrinsische Apoptoseinleitung unter anderem durch Bcell-lymphoma-Proteine. Dies geschieht über eine Steuerung des Membranpotentials der Mitochondrien und ihrer Membranintegrität. Es gibt sowohl apoptosefördernde (Bax, Bak, Bok, Bad) und -hemmende (Bcl-2) Vertreter der Bcl-Familie (Hakem et al. 1998).

Die Nekrose ist im Unterschied zur Apoptose ein passiver unkontrollierter Prozess, der meistens eine große Zellansammlung zerstört. Der nekrotische Zelltod kann durch direkten Schaden an der Zellmembran ausgelöst werden. Mit einer Nekrose geht eine Zellschwellung einher, es kommt zu einer plastischen Verformung der Mitochondrien und weiterer Organellen, einem Zerfall und Ablösen der Ribosomen, Ruptur der Zellorganellenmembran und teilweise auch zu einer Degeneration der Zellmembran (Kerr et al. 1972; Majno und Joris 1995; Trump et al. 1997). Letzteres führt dazu, dass der Zellinhalt in das umgebende Gewebe austritt. Chemotaktische Signale führen dann zum Einwandern inflammatorischer Mediatoren. Apoptotische Zellen hingegen kondensieren samt intrazellulären Strukturen und werden zeitnah phagozytiert, sodass es zu keiner Entzündungsreaktion kommt (Kurosaka et al. 2003).

Letztendlich sind beide Prozesse bei der Therapie mit radioaktiven ${ }^{131}$ Iod in der RIT gewissermaßen gewünscht. Die autonom hormonproduzierenden Thyreozyten sollen zerstört werden. Eine experimentelle Studie aus dem Jahr 2015 hat den Effekt von ${ }^{131}$ Iod auf zellulärer Ebene untersucht. Es wurden Zellkulturen auf ${ }^{131}$ Iod-haltiges Kulturmedium übertragen. Zellzahl und Radioaktivität und der Lebenzellanteil wurden bestimmt. Die chinesische Forschergruppe kam zu dem Ergebnis, dass ${ }^{131}$ Iod in Zellen der HTori-3 Zelllinie das Wachstum zeit- und dosisabhängig via Apoptose und G2/M-Phase-Arrest hemmt. Eine Hochregulierung der Fas-Rezeptorexpression und eine Verringerung der antiapoptotischen Bcl-2-Expression konnten beobachtet werden. Hingegen konnten keine veränderten Konzentrationen des p53-Protein nachgewiesen werden, sodass eine ${ }^{131}$ Iod-induzierte Apoptose über eine Aktivierung des TNF-Rezeptors, also des extrinsischen Weges und über Bcl-2 über den intrinsischen Weg ausgelöst wird, allerdings p53-unabhängig (Zhang et al. 2015). Eine experimentelle Studie an 28 Ratten hat ebenfalls die Art des Zelluntergangs evaluiert. 18 Tieren wurde intraperitoneal ${ }^{131}$ Iod injiziert. Sowohl bei hohen als auch bei niedrigen Dosen konnten intrathyreoidal Nekrose und Apoptose nachgewiesen werden (Turgut et al. 2006).

$\mathrm{Zu}$ den bereits erwähnten Strahlenwirkungen addieren sich sogenannte Bystander effects und das Stunning. Beim Bystander effect sezernieren bestrahlte Zellen Botenstoffe und kommunizieren auf diese Weise mit nicht bestrahlten Zellen, welche daraufhin ähnlich den 
bestrahlten Zellen reagieren bzw. zugrunde gehen. Diese Signalmoleküle sind entweder membranständig und beeinflussen lediglich Zellen im direkten Zell-Zellkontakt z. B. mittels GAP-Junctions oder sie sind löslich und können andernorts wirken. Die genaue Beschaffenheit dieser Transmitter ist noch nicht bekannt, sie scheinen zelltyp- und genotypsowie strahlenabhängig zu sein (Baskar 2010). Beim Stunning handelt es sich per definitionem um einen verminderten Uptake nach diagnostischer oder therapeutischer Applikation von ${ }^{131}$ Iod. Ein durch Stunning herabgesetzter Uptake geht mit einer strahleninduzierten Verringerung der mRNA von NIS und einigen Housekeeping Genen, also konstitutiv exprimierten Genen, einher (Meller et al. 2008). Eine Forschergruppe aus Göteborg konnte in einer experimentellen Studie nachweisen, dass eine Bestrahlung mit ${ }^{131}$ Jod die TSHabhängige Expression von NIS inhibiert, und auch die Insulin-like-growth-factor 1 - abhängige Expression von NIS zeigte sich strahlensensitiv (Nordén et al. 2007). Es scheint sich also beim Stunning um einen NIS-assoziierten Prozess zu handeln.

Bei der RIT kommt es also zur raschen Apoptose und Nekrose und funktionellen Veränderungen der Thyreozyten. Das intrathyreoidal gespeicherte Iod strömt unkontrolliert ins umliegende Gewebe und führt zu einer internen Iodkontamination. Bei den funktionellen Veränderungen steht das schon oben beschriebene Stunning im Vordergrund. Hierbei werden bei hohen Strahlendosen die NIS aus der Membran in das Zytosol transferiert, was die Iodaufnahme zusätzlich hemmt. Einen Einfluss der internen Iodfreisetzung auf den Uptake wurde 2005 von B. Meller et al. untersuchtet. In einer prospektiven Studie wurden die Daten von 197 Autonomiepatienten (UFA $n=29$, MFA $n=168$ ) auf einen potentiellen Zusammenhang zwischen der Uriniodausscheidung und dem Ioduptake innerhalb der RIT evaluiert. Die UIE wurde an zwei Zeitpunkten während der RIT bestimmt. Patienten mit einer hohen Iodausscheidung zeigten signifikant $(\mathrm{p}<0.001)$ geringere Uptakewerte. Ein doppelt so hoher UIE im Vergleich zum Normalwert (bestimmt vor der RIT) führte zu einer Verringerung des Uptakes um bis zu $25 \%$ (Meller et al. 2005). Zudem werden noch nicht nekrotische / apoptotische Zellen in ihrer Stoffwechselleistung (siehe Stunning) beeinträchtigt und selbst nicht direkt bestrahlte Zellen können über funktionell beeinträchtigt werden (siehe Bystander effects).

Die hier beschriebenen Prozesse erklären hinlänglich, warum die intratherapeutische HWZ bei fast allen Patienten kürzer ist als die HWZ während des Testes. Während in der Testsituation nur eine geringe funktionelle Beeinträchtigung der Thyreozyten zu erwarten ist, führen die hohen therapeutischen Dosen unmittelbar zum massiven Zelluntergang und funktionellen Störungen, wie sie oben ausführlich beschrieben wurden.

Die effektive HWZ verringerte sich im Rahmen unserer Studie von prätherapeutisch sieben Tagen (median) auf postradioiodtherapeutisch 5,7 Tage (median), die Uptakewerte, gemessen nach 24 Stunden posttherapeutisch, zeigten ebenfalls eine geringfügige, jedoch nicht signifikante Abnahme. Darüber hinaus korreliert die Dosisdifferenz (geplante Herddosis / 
erreichte Herddosis) signifikant mit dieser Abweichung innerhalb der Halbwertszeiten ( $\mathrm{p}=$ $0,000408)$.

Unsere Daten belegen, dass die therapeutische intrathyreoidale Iodkinetik mittels Radioiodtest nur unzureichend voraussagbar ist. Dies deckt sich mit den Daten der Kölner Arbeitsgruppe. In dieser retrospektiven Studie von Kobe et al. wurden 1417 Patientendaten mit den Diagnosen Morbus Basedow $(n=363)$, Struma $(n=50)$, MFA $(n=639)$ und UFA $(\mathrm{n}=365)$ evaluiert. Die Test- und Therapiebedingungen wie Volumenbestimmung mittels Sonographie, Dosiskalkulation, Messung inklusive der Messgeometrie, der effektiven Halbwertszeit und des maximalen Uptakes sind vergleichbar mit den Methoden der nuklearmedizinischen Abteilung der UMG. Bei der Datenerhebung während des prätherapeutischen Test wurde darüber hinaus beim Morbus Basedow zusätzlich zu den Messungen nach 24 Stunden und fünf Tagen eine weitere Messung nach sechs Stunden durchgeführt, da wie bereits bei der Diskussion der Methoden unter 4.1.2 erwähnt, entgegen dem angenommenen Speichermaximum nach 24 Stunden, besonders beim floriden untherapiertem Morbus Basedow dieses Maximum bereits vier Stunden nach Verabreichen von ${ }^{131}$ Iod erreicht sein kann (Kobe et al. 2010).

Diese zusätzliche Messung minimiert die mögliche Verzerrung der Ergebnisse durch ein zu früh erreichtes Speichermaximum. In dieser Dissertation fehlt diese zusätzliche Messung. Nichtsdestoweniger zeigen beide Studien klar eine signifikante Verkürzung der intrathyreoidalen effektiven HWZ auf. Tabelle 7 zeigt unsere Daten im Vergleich mit denen der Kölner Arbeitsgruppe:

\begin{tabular}{|l|l|}
\hline Diagnose & Krankheitsspezifische, empirische Halbwertszeiten \\
\hline DA & $\begin{array}{l}\text { Mittelwert: } 6,53(\mathrm{n}=10) \\
\text { Kobe et al.: }-\end{array}$ \\
\hline MFA & $\begin{array}{l}\text { Mittelwert: } 5,79(\mathrm{n}=10) \\
\text { Kobe et al.: } 5,2(\mathrm{n}=225)\end{array}$ \\
\hline UFA & $\begin{array}{l}\text { Mittelwert: } 5,8(\mathrm{n}=16) \\
\text { Kobe et al.: } 4,7(\mathrm{n}=175)\end{array}$ \\
\hline MB & $\begin{array}{l}\text { Mittelwert: } 4,7(\mathrm{n}=13) \\
\text { Kobe et al.: } 4,1(\mathrm{n}=100)\end{array}$ \\
\hline
\end{tabular}

Tabelle 6: krankheitsspezifische HWZ auf Basis der radioiodtherapeutischen Daten 


\subsection{Schlussfolgerungen}

Eine valide Bestimmung der intrathyreoidalen Iodkinetik mittels Radioiodtest zur Voraussage der intratherapeutischen Kinetik ist nur begrenzt möglich. Das schwer kalkulierbare Ausmaß früher direkter und indirekter Strahlenschäden ist nicht vorhersagbar.

Die Verwendung von präradioiodtherapeutisch gewonnenen Daten zur Therapieplanung führte in unserer Studie zu einer systematischen Unterdosierung bei der RIT. Die therapeutische intrathyreoidale effektive HWZ von ${ }^{131}$ Iod hat sich in dieser Doktorarbeit als die entscheidende, nicht sicher voraussagbare Größe erwiesen. Beim Vergleich von denen im Radioiodtest gewonnenen Werte mit denen der RIT verkürzt sich die effektive HWZ für jede Diagnosegruppe um mindestens einen Tag (siehe 3.2.4 Vergleich der prä- und posttherapeutischen effektiven HWZ bzw. des 24-h-Uptakes). Die Untersuchungsergebnisse ähneln denen der Arbeitsgruppe um Kobe et al. aus Köln aus dem Jahr 2010 (Kobe et al. 2010). Die Anwendung fixer Dosen und der gänzliche Verzicht auf einen Radioiodtest scheint dennoch keine nennenswerte Alternative zu sein. Die Gefahr, potentiell viel zu hohe Dosen zu applizieren, um einen gesicherten Therapieerfolg zu erreichen, widerspricht dem ALARA-Prinzip und den Strahlenschutzbestimmungen (Alexander und Larsen 2002; Jönsson und Mattsson 2004).

Eine Möglichkeit neben dem absoluten Verzicht einer individuellen Dosisbestimmung liegt in der Adaption der Dosiskalkulation mit empirischen, krankheitsspezifischen HWZ, welche auf Grundlage therapeutisch ermittelter Daten generiert worden sind. $\mathrm{Zu}$ diesem Zweck wird der Mittelwert aller therapeutisch gemessenen effektiven HWZ rubriziert nach Diagnose ermittelt und kann nun für weitere Dosisbestimmungen als effektive HWZ in die Marinelli-Formel miteingehen. Aufgrund des größeren Patientenkollektivs sind die Daten aus Köln den Ergebnissen dieser Dissertation für die etwaige Anwendung im klinischen Alltag vorzuziehen. 


\section{Zusammenfassung}

Ziel dieser retrospektiven Studie war erstens die Überprüfung, ob die im Radioiodtest geplante Herddosis während der RIT erreicht wird, zweitens die Ermittlung von Fehlerquellen und Einflussfaktoren auf das Erreichen bzw. Nicht-Erreichen der geplanten Herddosen und drittens die Analyse, inwiefern sich die therapeutische intrathyreoidale Iodkinetik von der simulierten Iodkinetik unterscheidet.

$\mathrm{Zu}$ diesen Zwecken wurden retrospektiv die Daten von 49 Patienten gesichtet, welche sich für die Therapie von Morbus Basedow ( $\mathrm{n}=13$ ), disseminierter Autonomie ( $\mathrm{n}=10)$, unifokaler $(n=16)$ oder multifokaler Autonomie $(n=10)$ in Behandlung in der Universitätsmedizin Göttingen befanden. Kriterien bei der Auswahl der Patienten stellten eine lückenlose Dokumentation der Nachsorge und die Durchführung des Radioiodtests in Form von mindestens zwei Uptake-Messungen unter Zugrundelegung des 24-h-Uptakes als Speichermaximum inklusive Ermittlung einer individuellen effektiven Halbwertszeit, dar. Unter Zuhilfenahme von Standarddosen aus dem empfohlenen Dosiskonzept der DGN, dem sonographisch ermittelten Schilddrüsenvolumen, dem Uptake, der effektiven Halbwertszeit und der Marinelli-Konstante wurde die zu applizierende Aktivität ermittelt.

Die Herddosis wurde in 43 von 49 analysierten Datensätzen nicht erreicht, das heißt 87,76 $\%$ der Patienten waren unterdosiert.

In einem zweiten Analyseschritt wurden mögliche Einflussfaktoren auf den Radioiodtest, die zu dieser Diskrepanz führen, evaluiert. Keine der untersuchten Variablen wie Lebensalter, Schilddrüsen- oder Zielvolumen, Abstand Radioiodtest/-Therapie, effektive Halbwertszeit, Aktivität, Geschlecht, Diagnose oder schilddrüsenspezifische Medikation korrelierten signifikant mit der Unterdosierung.

Darüber hinaus wurden die posttherapeutischen Daten zur effektiven HWZ und der 24-hUptake miteinander verglichen. Der prä- und posttherapeutische 24-h-Uptake korrelierten gut miteinander und unterschieden sich nicht signifikant $(r=0,8820, p=0,0889110)$. Die prä- und posttherapeutisch gemessenen effektiven $\mathrm{HWZ}$ wichen jedoch signifikant ab (z. B. MFA $\mathrm{p}=0,004184$ ). Es wird eine Verkürzung der effektiven HWZ um teilweise 1,86 Tage beobachtet (siehe 3.2.4 Vergleich der prä- und posttherapeutischen effektiven HWZ bzw. des 24-h-Uptakes). Diese Abweichung korrelierten signifikant mit dem Verfehlen der geplanten Herddosis ( $\mathrm{p}=0,000408)$.

Die unzureichende Vorhersage der effektiven HWZ, also die systematische Unterschätzung der effektiven HWZ, ist dieser Dissertation zufolge der einzige einflussübende Faktor auf die beobachtete Differenz zwischen geplanter und erreichter Herddosis. Eine Adaption des aktuellen Radioiodtestverfahrens bzw. der Dosiskalkulation mit empirischen, auf intratherapeutisch ermittelten Daten basierenden krankheitsspezifischen HWZ könnte diesen Fehler eliminieren. 


\section{Literaturverzeichnis}

Alexander EK, Larsen PR (2002): High dose of (131)I therapy for the treatment of hyperthyroidism caused by Graves' disease. J Clin Endocrinol Metab 구, 1073-1077

Allolio B: Praktische Endokrinologie: mit 184 Abbildungen. 2. Auflage; Urban \& Fischer, München 2010

Als C, Baer HU, Glaser C, Rösler H (1997): [Choice of therapy in unifocal functional autonomy of the thyroid gland with hyperthyroidism]. Schweiz Med Wochenschr $\underline{127}, 891-898$

Andermann P, Schlögl S, Mäder U, Luster M, Lassmann M, Reiners C (2007): Intra- and interobserver variability of thyroid volume measurements in healthy adults by $2 \mathrm{D}$ versus 3D ultrasound. Nukl Nucl Med $\underline{46}, 1-7$

Andrade VA, Gross JL, Maia AL (2001): The effect of methimazole pretreatment on the efficacy of radioactive iodine therapy in Graves' hyperthyroidism: one-year followup of a prospective, randomized study. J Clin Endocrinol Metab $\underline{86}, 3488-3493$

Bähre M, Hilgers R, Lindemann C, Emrich D (1988): Thyroid autonomy: sensitive detection in vivo and estimation of its functional relevance using quantified highresolution scintigraphy. Acta Endocrinol (Copenh) 117, 145-153

Baskar R (2010): Emerging role of radiation induced bystander effects: Cell communications and carcinogenesis. Genome Integr $\underline{1}, 13$

Bauer B, Veit R (2003): Dosiswerte in der Röntgendiagnostik: Hinweise für Überweisungen zu radiologischen Untersuchungen (04.08.2003). Dtsch Ärztebl

Becker W, Börner W, Gruber G (1986): Szintigraphie und Sonographie bei der Diagnostik der Schilddrüsenautonomie: Eine retrospektive Studie an 526 Patienten. Dtsch Med Wochenschr $1946 \underline{111}, 1630-1635$

Beierwaltes WH (1979): The history of the use of radioactive iodine. Semin Nucl Med $\underline{9}$, $151-155$

Bell E, Grünwald F: Radiojodtherapie bei benignen und malignen Schilddrüsenerkrankungen. Springer, Berlin [u.a.] 2000

Berberich R, Hundeshagen H, Diethelm L, Olsson O: Radiopharmaka, Gerätetechnik, Strahlenschutz. Springer, Berlin [u.a.] 1980

Berg GE, Michanek AM, Holmberg EC, Fink M (1996): Iodine-131 treatment of hyperthyroidism: significance of effective half-life measurements. J Nucl Med Off Publ Soc Nucl Med 37, 228-232

Berkhout WER (2015): [The ALARA-principle. Backgrounds and enforcement in dental practices]. Ned Tijdschr Tandheelkd 122, 263-270 
Bockisch A, Jamitzky T, Derwanz R, Biersack HJ (1993): Optimized dose planning of radioiodine therapy of benign thyroidal diseases. J Nucl Med Off Publ Soc Nucl Med 34, 1632-1638

Bogner L, Czempiel H (1993): [Approximation errors in the physical planning of radioiodine therapy of the thyroid]. Nukl Nucl Med 32, 236-246

Brunn J, Block U, Ruf G, Bos I, Kunze WP, Scriba PC (1981): [Volumetric analysis of thyroid lobes by real-time ultrasound (author's transl)]. Dtsch Med Wochenschr $1946 \underline{106}, 1338-1340$

Büll U, Hör G (Hrsg.): Klinische Nuklearmedizin. (Kurzlehrbuch), 2., korrigierte Auflage; Ed. Medizin VCH, Weinheim 1990

Büll U, Schicha H, Biersack H-J: Nuklearmedizin. Grundlagen, Diagnostik, Therapie. Thieme Georg Verlag, Stuttgart 1999

Burke G, Halko A, Silverstein GE, Hilligoss M (1972): Comparative thyroid uptake studies with $131 \mathrm{I}$ and 99m TcO 4 -. J Clin Endocrinol Metab 34, 630-637

Chapman EM (1983): History of the discovery and early use of radioactive iodine. JAMA $\underline{250}, 2042-2044$

Connell JM, Hilditch TE, McCruden DC, Robertson J, Alexander WD (1984): Effect of pretreatment with carbimazole on early outcome following radio-iodine (131I) therapy. Eur J Nucl Med 9, 464-466

Cooper DS (2003): Hyperthyroidism. Lancet Lond Engl 362, 459-468

Dai G, Levy O, Carrasco N (1996): Cloning and characterization of the thyroid iodide transporter. Nature $\underline{379}, 458-460$

Debrand-Passard A, Barzen G, Richter W, Wenzel KW, Felix R (1994): [Therapeutic results of radioiodine therapy of hyperthyroid thyroid gland diseases]. Med Klin $\mathrm{Mu}-$ nich Ger 1983 89, 319-323

Deckart H, Schicke B, Thiele K: Geschichte der Nuklearmedizin in Ostdeutschland. (Nuklearmedizin-Informationen 9); Götze, Berlin 1999

Delbridge L (2003): Total thyroidectomy: the evolution of surgical technique. ANZ J Surg $\underline{73}, 761-768$

Dietlein M, Dressler J, Grünwald F, Joseph K, Leisner B, Moser E, Reiners C, Rendl J, Schicha H, Schneider P, et al. (2003): [Guideline for in vivo- and in vitro procedures for thyroid diseases (version 2)]. Nukl Nucl Med $\underline{42}, 109-115$

Dunkelmann S, Endlicher D, Prillwitz A, Rudolph F, Groth P, Schümichen C (1999): [Results of TcTUs-optimized radioiodine therapy in multifocal and disseminated autonomy]. Nukl Nucl Med $\underline{38}, 131-139$ 
Eckardt J, Geworski L, Lerch H, Reiners C, Schober O: Empfehlungen zur Qualitätskontrolle in der Nuklearmedizin: Klinik und Messtechnik. 2. Auflage; Schattauer, Stuttgart 2009

Emrich D, Bitter F (Hrsg.): Nuklearmedizin: Funktionsdiagnostik und Therapie. 2. Auflage; Thieme, Stuttgart 1979

Emrich D, Erlenmaier U, Pohl M, Luig H (1993): Determination of the autonomously functioning volume of the thyroid. Eur J Nucl Med 20, 410-414

Franklyn JA, Maisonneuve P, Sheppard M, Betteridge J, Boyle P (1999): Cancer incidence and mortality after radioiodine treatment for hyperthyroidism: a population-based cohort study. Lancet 353, 2111-2115

Fritz-Niggli H: Strahlengefährdung, Strahlenschutz. Hans Huber Verlag, Bern 1997

Füger BJ, Dudczak R, Ch P, Zettinig G (2002): Jodstoffwechsel. J Für Ernährungsmedizin $\underline{4}, 6-8$

Garber JR, Greenlee MC, Irwin Klein MD (2011): Hyperthyroidism and other causes of thyrotoxicosis: management guidelines of the American Thyroid Association and American Association of Clinical Endocrinologists. Endocr Pract 17, e1

Genovese BM, Noureldine SI, Gleeson EM, Tufano RP, Kandil E (2013): What is the best definitive treatment for Graves' disease? A systematic review of the existing literature. Ann Surg Oncol 20, 660-667

Gerabek WE, Haage BD, Keil G, Wegner W (Hrsg.): Enzyklopädie Medizingeschichte. de Gruyter, Berlin [u.a.] 2005

Goretzki G: Medizinische Strahlenkunde: Physikalisch-technische Grundlagen. 2. Auflage; Elsevier, Urban \& Fischer, Amsterdam 2004

Gotthardt M, Stübinger M, Pansegrau J, Buchwald B, Goecke J, Pfestroff A, Corstens FHM, Behr TM (2006): Decrease of $(99 \mathrm{~m})$ Tc-uptake in autonomous thyroid tissue in Germany since the 1970s. Clinical implications for radioiodine therapy. Nukl Nucl Med 45, 122-125

Gurgul E, Sowinski J (2011): Primary hyperthyroidism--diagnosis and treatment. Indications and contraindications for radioiodine therapy. Nucl Med Rev Cent East Eur $\underline{14}, 29-32$

Haïssinsky M, Adloff J-P: Radiochemisches Lexikon der Elemente und ihrer Isotope. Dümmler, Bonn 1968

Hakem R, Hakem A, Duncan GS, Henderson JT, Woo M, Soengas MS, Elia A, de la Pompa JL, Kagi D, Khoo W, et al. (1998): Differential requirement for caspase 9 in apoptotic pathways in vivo. Cell $\underline{94}, 339-352$

Hampel R, Külberg T, Klein K, Jerichow JU, Pichmann EG, Clausen V, Schmidt I (1995): Goiter incidence in Germany is greater than previously suspected. Med Klin Munich Ger 1983 90, 324-329 
Hänscheid H, Canzi C, Eschner W, Flux G, Luster M, Strigari L, Lassmann M (2013): EANM Dosimetry Committee series on standard operational procedures for pretherapeutic dosimetry II. Dosimetry prior to radioiodine therapy of benign thyroid diseases. Eur J Nucl Med Mol Imaging 40, 1126-1134

Hermann H-J: Nuklearmedizin: Unter Mitarbeit von Anke Ohmstede. 5. Auflage; Urban \& Fischer Verlag/Elsevier GmbH, Amsterdam 2004

Hertz S, Roberts A (1946): Radioactive iodine in the study of thyroid physiology; the use of radioactive iodine therapy in hyperthyroidism. J Am Med Assoc 131, 81-86

Heufelder AE, Smith TJ, Gorman CA, Bahn RS (1991): Increased induction of HLA-DR by interferon-gamma in cultured fibroblasts derived from patients with Graves' ophthalmopathy and pretibial dermopathy. J Clin Endocrinol Metab $\underline{73}$, 307-313

Hotze LA, Schumm-Draeger P-M: Schilddrüsenkrankheiten - Diagnose und Therapie ; 132 Tabellen. 5. Auflage; BMV Berliner Medizinische Verlagsanstalt, Berlin 2003

Hurley DL, Gharib H (1996): Evaluation and management of multinodular goiter. Otolaryngol Clin North Am 29, 527-540

van Isselt JW, de Klerk JMH, van Rijk PP, van Gils APG, Polman LJ, Kamphuis C, Meijer R, Beekman FJ (2003): Comparison of methods for thyroid volume estimation in patients with Graves' disease. Eur J Nucl Med Mol Imaging 30, 525-531

Jarløv AE, Hegedüst L, Kristensen LØ, Nygaard B, Hansen JM (1995): Is calculation of the dose in radioiodine therapy of hyperthyroidism worth while? Clin Endocrinol (Oxf) $\underline{43}, 325-329$

Joiner MC, Kogel A van der: Basic Clinical Radiobiology Fourth Edition. CRC Press, Boca Raton 2009

Jönsson H, Mattsson S (2004): Excess radiation absorbed doses from non-optimised radioiodine treatment of hyperthyroidism. Radiat Prot Dosimetry $\underline{108}$, 107-114

Kahmann C, Wunderlich G, Freudenberg R, Zöphel K, Oehme L, Kotzerke J (2010): Radioprotection of thyroid cells mediated by methimazole. Int J Radiat Biol $\underline{86}, 811-$ 816

Kalsbeek A, Buijs RM, van Schaik R, Kaptein E, Visser TJ, Doulabi BZ, Fliers E (2005): Daily variations in type II iodothyronine deiodinase activity in the rat brain as controlled by the biological clock. Endocrinology 146, 1418-1427

Kauffmann GW, Moser E, Sauer R: Radiologie: Grundlagen der Radiodiagnostik, Radiotherapie und Nuklearmedizin; mit 44 Tabellen sowie Fragen und Antworten zu jedem Kapitel. Urban \& Schwarzenberg, München [u.a.] 1996

Kerr JF, Wyllie AH, Currie AR (1972): Apoptosis: a basic biological phenomenon with wide-ranging implications in tissue kinetics. Br J Cancer 26, 239-257

Klinke R, Pape H-C, Kurtz A, Silbernagl S, Baumann R, Brenner B, Gay R, Rothenburger A (Hrsg.): Physiologie. 6. Auflage; Thieme, Stuttgart [u.a.] 2010 
Knudsen N, Bols B, Bülow I, Jørgensen T, Perrild H, Ovesen L, Laurberg P (1999): Validation of ultrasonography of the thyroid gland for epidemiological purposes. Thyroid Off J Am Thyroid Assoc 9, 1069-1074

Kobe C, Eschner W, Wild M, Rahlff I, Sudbrock F, Schmidt M, Dietlein M, Schicha H (2010): Radioiodine therapy of benign thyroid disorders: what are the effective thyroidal half-life and uptake of 131I? Nucl Med Commun 31, 201-205

Kohn LD, Harii N (2003): Thyrotropin receptor autoantibodies (TSHRAbs): epitopes, origins and clinical significance. Autoimmunity $\underline{36}, 331-337$

Köhrle J, Schmutzler C (1998): Wie kommt Jod in die Schilddrüse? Neues zum NatriumIodid-Symporter (NIS). Internist $\underline{39}, 560-565$

Körber C, Schneider P, Körber-Hafner N, Hänscheid H, Reiners C (2001): Antithyroid drugs as a factor influencing the outcome of radioiodine therapy in Graves' disease and toxic nodular goitre? Eur J Nucl Med 28, 1360-1364

Krieger H: Grundlagen der Strahlungsphysik und des Strahlenschutzes. 3. Auflage; Vieweg und Teubner Verlag, Wiesbaden 2009

Krieger H: Strahlungsquellen für Technik und Medizin. 2. Auflage; Springer Spektrum, Wiesbaden 2013

Krohn K, Führer D, Holzapfel HP, Paschke R (1998): Clonal origin of toxic thyroid nodules with constitutively activating thyrotropin receptor mutations. J Clin Endocrinol Metab $\underline{83}, 130-134$

Krohn K, Wohlgemuth S, Gerber H, Paschke R (2000): Hot microscopic areas of iodinedeficient euthyroid goitres contain constitutively activating TSH receptor mutations. J Pathol 192, 37-42

Krohn T, Behrendt FF, Heinzel A, Müller B, Mottaghy FM, Verburg FA (2015): Pretherapeutic dosimetry before 131I therapy of benign thyroid disease. A clinical practice assessment of dosimetric parameters. Nukl Nucl Med 54, 131-136

Kurosaka K, Takahashi M, Watanabe N, Kobayashi Y (2003): Silent cleanup of very early apoptotic cells by macrophages. J Immunol Baltim Md $1950 \underline{171}$, 4672-4679

Lee SJ, Chong S, Kang KH, Hur J, Hong B-W, Kim HJ, Kim SJ (2014): Semiautomated thyroid volumetry using 3D CT: prospective comparison with measurements obtained using 2D ultrasound, 2D CT, and water displacement method of specimen. AJR Am J Roentgenol 203, W525-532

Leslie WD, Ward L, Salamon EA, Ludwig S, Rowe RC, Cowden EA (2003): A Randomized Comparison of Radioiodine Doses in Graves' Hyperthyroidism. J Clin Endocrinol Metab $\underline{88}, 978-983$

Löffler G, Petrides PE, Heinrich PC: Biochemie und Pathobiochemie. 8., völlig neu bearb. Auflage; Springer, Heidelberg 2006 
Lorenz R, Buck A, Reiners C (2015): Stationäre nuklearmedizinische Therapie 2010 bis 2012 in Deutschland Analyse der strukturierten Qualitätsberichte. Nukl Nucl Med $\underline{54}, 61-68$

Lüllmann H, Mohr K, Hein L: Pharmakologie und Toxikologie: Arzneimittelwirkungen verstehen - Medikamente gezielt einsetzen. 16. Auflage; Thieme, Stuttgart; New York 2006

Majno G, Joris I (1995): Apoptosis, oncosis, and necrosis. An overview of cell death. Am J Pathol $\underline{146}, 3-15$

Marinelli LD, Quimby EH, Hine GJ (1948): Dosage determination with radioactive isotopes; biological considerations and practical applications. Nucleonics $\underline{2}, 44-49$

Marischler C: BASICS Endokrinologie. (Basics), 1. Auflage; Elsevier, Urban \& Fischer, München [u.a.] 2007

Mathieu I, Caussin J, Smeesters P, Wambersie A, Beckers C (1997): Doses in family members after 131 I treatment. The Lancet 350, 1074

Meier DA, Brill DR, Becker DV, Clarke SEM, Silberstein EB, Royal HD, Balon HR, Society of Nuclear Medicine (2002): Procedure guideline for therapy of thyroid disease with (131)iodine. J Nucl Med Off Publ Soc Nucl Med 43, 856-861

Meller B, Haase A, Seyfarth M, Wenzel BE, Richter E, Baehre M (2005): [Reduced radioiodine uptake at increased iodine intake and 131I-induced release of „cold“ iodine stored in the thyroid]. Nukl Nucl Med $\underline{44}, 137-142$

Meller B, Gaspar E, Deisting W, Czarnocka B, Baehre M, Wenzel BE (2008): Decreased radioiodine uptake of FRTL-5 cells after (131)I incubation in vitro: molecular biological investigations indicate a cell cycle-dependent pathway. Eur J Nucl Med Mol Imaging $\underline{35}, 1204-1212$

Meller J, Becker W (2002): The continuing importance of thyroid scintigraphy in the era of high-resolution ultrasound. Eur J Nucl Med Mol Imaging 29 Suppl 2, S425-438

Meller J, Wisheu S, Munzel U, Behe M, Gratz S, Becker W (2000): Radioiodine therapy for Plummer's disease based on the thyroid uptake of technetium-99m pertechnetate. Eur J Nucl Med 27, 1286-1291

Meller J, Sahlman CO, Becker W (2002): Radioiodine-treatment (RIT) of functional thyroidal autonomy. Nucl Med Rev $\underline{5}, 1-10$

Meng W (2004): [Carl Adolph von Basedow--150th anniversary of his death]. Z Für Ärztl Fortbild Qual 98 Suppl 5, 7-12

Meng W, Schmidt K-G: Schilddrüsenerkrankungen. Pathophysiologie, Diagnostik, Therapie. Urban \& Fischer, München 1998

Mettler FAJ, Upton AC: Medical Effects of Ionizing Radiation. 3. Auflage; Saunders, Philadelphia, PA 2008 
Meyer-Gessner M, Benker G, Olbricht T, Windeck R, Cissewski K, Reiners C, Reinwein D (1989): [Side effects of antithyroid therapy of hyperthyroidism. A study of 1256 continuously treated patients]. Dtsch Med Wochenschr 1946 114, 166-171

Moreno P, Gómez JM, Gómez N, Francos JM, Ramos E, Rafecas A, Jaurrieta E (2006): Subtotal thyroidectomy: a reliable method to achieve euthyroidism in Graves' disease. Prognostic factors. World J Surg $\underline{30}$, 1950-1956

Morneburg H: Bildgebende Systeme für die medizinische Diagnostik: Röntgendiagnostik und Angiographie, Computertomographie, Nuklearmedizin, Magnetresonanztomographie, Sonographie, Integrierte Informationssysteme. 3., wesentlich überarb. und Auflage; Publicis MCD Verl., Erlangen 1995

Müller B, Bares R, Büll U (1991): [The effective half-life of 131I during the treatment of autonomous thyroid disease with radioiodine]. Nukl Nucl Med $\underline{30}, 71-76$

Muzio M, Chinnaiyan AM, Kischkel FC, O’Rourke K, Shevchenko A, Ni J, Scaffidi C, Bretz JD, Zhang M, Gentz R, et al. (1996): FLICE, a novel FADD-homologous ICE/CED-3-like protease, is recruited to the CD95 (Fas/APO-1) death--inducing signaling complex. Cell $\underline{85}, 817-827$

Neumüller O-A: Römpps Chemie-Lexikon. 8. Auflage; Franckh, Stuttgart 1972

Nordén MM, Larsson F, Tedelind S, Carlsson T, Lundh C, Forssell-Aronsson E, Nilsson M (2007): Down-regulation of the Sodium/Iodide Symporter Explains 131IInduced Thyroid Stunning. Cancer Res $\underline{67}, 7512-7517$

Nüchel C, Boddenberg B, Schicha H (1993): [The importance of the radioiodine test for the calculation of the therapeutic dose in benign thyroid diseases]. Nukl Nucl Med $\underline{32}, 91-98$

Nygaard B, Nygaard T, Court-Payen M, Jensen LI, Søe-Jensen P, Gerhard Nielsen K, Fugl M, Hegedüs L (2002): Thyroid volume measured by ultrasonography and CT. Acta Radiol Stockh Swed 1987 43, 269-274

Otsuka F, Noh JY, Chino T, Shimizu T, Mukasa K, Ito K, Ito K, Taniyama M (2012): Hepatotoxicity and cutaneous reactions after antithyroid drug administration. Clin Endocrinol (Oxf) 구 , 310-315

Parma J, Duprez L, Van Sande J, Cochaux P, Gervy C, Mockel J, Dumont J, Vassart G (1993): Somatic mutations in the thyrotropin receptor gene cause hyperfunctioning thyroid adenomas. Nature $\underline{365}, 649-651$

Paschke R (2011): Molecular pathogenesis of nodular goiter. Langenbecks Arch Surg Dtsch Ges Für Chir 396, 1127-1136

Pfannenstiel P (Hrsg.): Diagnose und Therapie hyperthyreoter Zustände: Verhandlungsbericht des 9. Wiesbadener Schilddrüsengespräches, Mai 1990. (Wiesbadener Schilddrüsengespräch); pmi-Verlag, Frankfurt/M. 1990

Prabhakar BS, Bahn RS, Smith TJ (2003): Current perspective on the pathogenesis of Graves' disease and ophthalmopathy. Endocr Rev 24, 802-835 
Prasek K, Płazińska MT, Królicki L (2015): Diagnosis and treatment of Graves’ disease with particular emphasis on appropriate techniques in nuclear medicine. General state of knowledge. Nucl Med Rev $\underline{18}, 110-116$

Reinartz P, Zimny M, Schaefer W, Mueller B, Buell U, Sabri O (2003): Radioiodine therapy in patients with hyperthyroid disorder: standard versus dosimetric activity application. Nucl Med Commun 24, 1247-1253

Reinhardt M, Emrich D, Krause T, Bräutigam P, Nitzsche E, Blattmann H, Schümichen C, Moser E (1995): Improved dose concept for radioiodine therapy of multifocal and disseminated functional thyroid autonomy. Eur J Endocrinol Eur Fed Endocr Soc $\underline{132}, 550-556$

Rokni H, Sadeghi R, Moossavi Z, Treglia G, Zakavi SR (2014): Efficacy of different protocols of radioiodine therapy for treatment of toxic nodular goiter: systematic review and meta-analysis of the literature. Int J Endocrinol Metab $\underline{12}$, e14424

Rooij A de, Vandenbroucke JP, Smit JWA, Stokkel MPM, Dekkers OM (2009): Clinical outcomes after estimated versus calculated activity of radioiodine for the treatment of hyperthyroidism: systematic review and meta-analysis. Eur J Endocrinol 161, $771-777$

Rudner J, Belka C, Marini P, Wagner RJ, Faltin H, Lepple-Wienhues A, Bamberg M, Budach W (2001): Radiation sensitivity and apoptosis in human lymphoma cells. Int J Radiat Biol 77, 1-11

Sabri O, Zimny M, Schulz G, Schreckenberger M, Reinartz P, Willmes K, Buell U (1999): Success rate of radioiodine therapy in Graves' disease: the influence of thyrostatic medication. J Clin Endocrinol Metab 4ㅜ, 1229-1233

Sancak S, Jaeschke H, Eren F, Tarcin O, Ozlem T, Guellueoglu B, Sen LS, Sever Z, Gozu HI, Bircan R, et al. (2011): High prevalence of TSHR/Gs $\alpha$ mutation-negative clonal hot thyroid nodules (HNs) in a Turkish cohort. Horm Metab Res Horm Stoffwechselforschung Horm Métabolisme 43, 562-568

Sawin CT, Becker DV (1997): Radioiodine and the treatment of hyperthyroidism: the early history. Thyroid Off J Am Thyroid Assoc 7, 163-176

Sawka AM, Thabane L, Parlea L, Ibrahim-Zada I, Tsang RW, Brierley JD, Straus S, Ezzat S, Goldstein DP (2009): Second primary malignancy risk after radioactive iodine treatment for thyroid cancer: a systematic review and meta-analysis. Thyroid Off $\mathbf{J}$ Am Thyroid Assoc 19, 451-457

Schauder P, Ollenschläger G, Adam O (Hrsg.): Ernährungsmedizin: Prävention und Therapie. 3., völlig überarb. Auflage, [Nachdr.]; Elsevier, Urban \& Fischer, München [u.a.] 2011

Schicha H, Schober O, Dietlein M: Nuklearmedizin: Basiswissen und klinische Anwendung; mit 66 Tabellen. 7., vollst. überarb. Auflage; Schattauer, Stuttgart 2013 
Schmidt G, Görg C: Kursbuch Ultraschall: Nach den Richtlinien der DEGUM und der KBV. 6. Auflage; Thieme, Stuttgart u.a. 2015

Schneider P, Körber C, Körber-Hafner N, Hänscheid H, Reiners C (2002): Does an individual estimation of halflife improve the results of radioiodine therapy of Graves' disease? Nukl Nucl Med 41, 240-244

Scholz GH, Hagemann E, Arkenau C, Engelmann L, Lamesch P, Schreiter D, Schoenfelder M, Olthoff D, Paschke R (2003): Is there a place for thyroidectomy in older patients with thyrotoxic storm and cardiorespiratory failure? Thyroid Off J Am Thyroid Assoc 13, 933-940

Schott M (2013): Hyperthyreose. Internist 54, 315-326; quiz 327

Šfiligoj D, Gaberšček S, Mekjavič PJ, Pirnat E, Zaletel K (2015): Factors influencing the success of radioiodine therapy in patients with Graves' disease. Nucl Med Commun $\underline{36}, 560-565$

Shu J, Zhao J, Guo D, Luo Y, Zhong W, Xie W (2011): Accuracy and reliability of thyroid volumetry using spiral CT and thyroid volume in a healthy, non-iodine-deficient Chinese adult population. Eur J Radiol 77, 274-280

Sosa JA, Mehta PJ, Wang TS, Boudourakis L, Roman SA (2008): A population-based study of outcomes from thyroidectomy in aging Americans: at what cost? J Am Coll Surg 206, 1097-1105

Spitzweg C (2004): [The practical relevance of the sodium iodide symporter]. Z Für Ärztl Fortbild Qual 98 Suppl 5, 25-32

Strahlenschutz in der Medizin - Richtlinie zur Verordnung über den Schutz vor Schäden durch ionisierende Strahlen (Strahlenschutzverordnung - StrlSchV)

Strieder TGA, Prummel MF, Tijssen JGP, Endert E, Wiersinga WM (2003): Risk factors for and prevalence of thyroid disorders in a cross-sectional study among healthy female relatives of patients with autoimmune thyroid disease. Clin Endocrinol

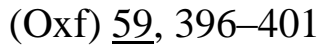

Thamm M, Ellert U, Thierfelder W, Liesenkötter K-P, Völzke H (2007): Iodine intake in Germany. Results of iodine monitoring in the German Health Interview and Examination Survey for Children and Adolescents (KiGGS). Bundesgesundheitsblatt Gesundheitsforschung - Gesundheitsschutz 무, 744-749

Trump BF, Berezesky IK, Chang SH, Phelps PC (1997): The pathways of cell death: oncosis, apoptosis, and necrosis. Toxicol Pathol $\underline{25}, 82-88$

Turgut B, Babul A, Ozdemir O, Erselcan T (2006): Evaluation of the cell death pathway and apoptosis-stunning effect relationship after low- and high-dose I-131 administrations in rat thyroid tissue. Cancer Biother Radiopharm 21, 342-351

Urbannek V, Schmidt M, Moka D, Hillger HW, Voth E, Wellner U, Schicha H (2000): [Effect of iodine application during radioiodine therapy in patients with impending therapy failure]. Nukl Nucl Med $\underline{39}, 108-112$ 
Weber T: Memorix Zahnmedizin: 116 Tabellen. 3., vollst. überarb. und Auflage; Thieme, Stuttgart [u.a.] 2010

Weetman AP (2000): Graves' disease. N Engl J Med 343, 1236-1248

Winkler C (1950): [Prospects of radioactive iodine therapy of malignant goiter]. Dtsch Med Wochenschr 1946 75, 1438-1440

Zakavi SR, Mousavi Z, Davachi B (2009): Comparison of four different protocols of I-131 therapy for treating single toxic thyroid nodule. Nucl Med Commun $\underline{30}, 169-175$

Zhang W, Gao R, Yu Y, Guo K, Hou P, Yu M, Liu Y, Yang A (2015): Iodine-131 induces apoptosis in HTori-3 human thyrocyte cell line and G2/M phase arrest in a p53independent pathway. Mol Med Rep 11, 3148-3154

\subsection{Internetquellen}

Bundesministerium für Umwelt, Naturschutz, Bau und Reaktorsicherheit I des B-. http://www.bmub.bund.de/themen/atomenergiestrahlenschutz/strahlenschutz/atomenergie-strahlenschutzdownload/artikel/richtlinie-strahlenschutz-in-der-medizin-zurstrlschv/?tx_ttnews\%5BbackPid\%5D=369\&cHash=215a29135db8d25ba28cd1cbe 332b114; Zugriff am 18.01.2016

Deutsche Gesellschaft für Nuklearmedizin e.V. http://www.nuklearmedizin.de/leistungen/leitlinien/leitlinien.php; Zugriff am 09.09.2016

http://www.din.de/de/mitwirken/normenausschuesse/nar/normen/wdcbeuth:din21:75206754; Zugriff am 08.09.2015

http://www.din.de/de/mitwirken/normenausschuesse/nar/normen/wdcbeuth:din21:75279826; Zugriff am 08.09.2015 


\section{Anhang}

\subsection{Rohdaten}

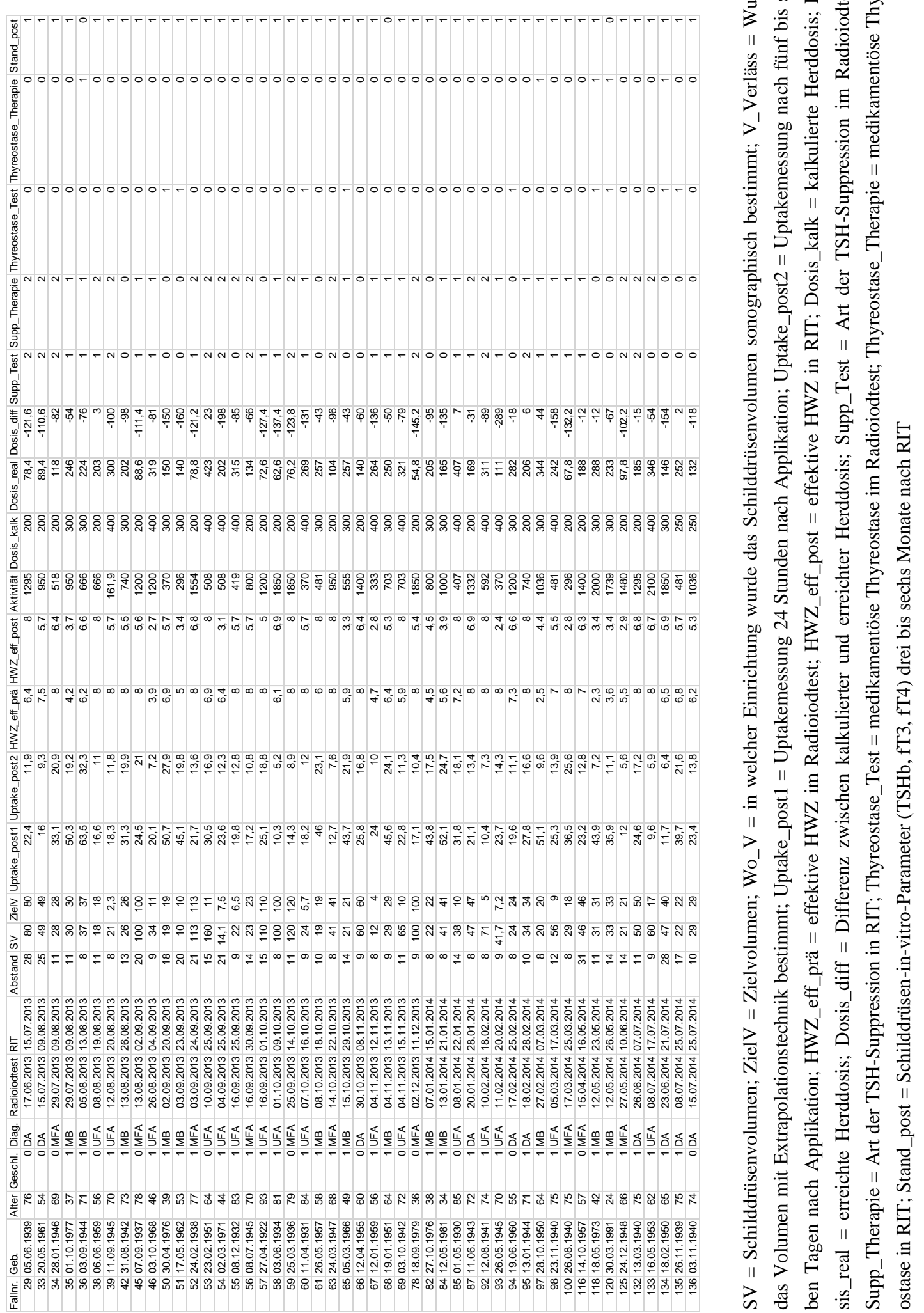


Anhang

\subsection{Kodierung der Daten}

\begin{tabular}{|c|c|c|}
\hline Variablenname & Kodierung & Einheit \\
\hline Fallnummer & - & - \\
\hline Geschlecht & $0=$ Männlich, 1 = weiblich & - \\
\hline Geburtsdatum & - & Jahre \\
\hline Abstand & - & Tage \\
\hline Diagnose & $1=\mathrm{MB}, 2=\mathrm{DA}, 3=\mathrm{UFA}, 4=\mathrm{MFA}$ & - \\
\hline SV & - & $\mathrm{ml}$ \\
\hline ZielV & - & $\mathrm{ml}$ \\
\hline Uptake_post1 & - & Prozent \\
\hline Uptake_post2 & - & Prozent \\
\hline HWZ_eff_prä & - & Tage \\
\hline HWZ_eff_post & - & Tage \\
\hline Aktivität & - & $\mathrm{MBq}$ \\
\hline Dosis_gewünscht & - & Gy \\
\hline Dosis_erreicht & - & Gy \\
\hline Dosis_diff & - & Gy \\
\hline Supp_Test & $0=$ nicht supprimiert, 1 = endogen supp., 2 = exogen supp. & - \\
\hline Supp_Therapie & $0=$ nicht supprimiert, 1 = endogen supp., 2 = exogen supp. & - \\
\hline Thyreostase_Test & $0=$ nein, $1=\mathrm{ja}$ & - \\
\hline Thyreostase_Therapie & $0=$ nein, $1=\mathrm{ja}$ & - \\
\hline Stand_post & $\begin{array}{l}0=\text { Misserfolg, } 1 \text { = Hypothyreose / Euthyreose / keine relevante } \\
\text { Restautonomie / Euthyreose unter Thyroxin }\end{array}$ & - \\
\hline
\end{tabular}




\section{Lebenslauf}

Mein Name ist Friederike Kobbe, derzeit bin ich in der Konrad-Broßwitz-Straße 29 in 60487 Frankfurt am Main wohnhaft. Telefonisch bin ich zuverlässig unter folgender Telefonnummer zu erreichen: 0175 / 4993050 oder per Email unter friederike.kobbe@tonline.de.

Ich wurde am 15. Mai 1990 in Hamm in Westfalen geboren. Ich bin derzeit 26 Jahre alt und ledig.

Im Sommer 1996 wurde ich auf der Schillerschule in Hamm-Pelkum eingeschult und besuchte anschließend ab dem Jahr 2000 das Märkische Gymnasium in Hamm, welches ich am 13. Juni 2008 mit der allgemeinen Hochschulreife beendete. Ich besuchte seinerzeit eine sogenannte Profilklasse und konnte auf diese Weise mein Abitur bereits nach sieben Jahren absolvieren. In diesem gewonnenen Jahr arbeitete ich unter anderem im Maximilianpark Hamm und verbrachte ein halbes Jahr mit einem „Work and Travel“-Visa in Australien.

Im Oktober 2009 schrieb ich mich nach einer erfolglosen Bewerbung um einen Studienplatz für Medizin bei der ZVS an der Universität Osnabrück für den Zwei-Fach-Bachelor Physik / Chemie ein. Bei einem zweiten Bewerbungsversuch konnte mir ein Studienplatz für Zahnmedizin zugewiesen werden und ich begann im April 2010 mein Studium an der Georg-August-Universität in Göttingen. Seit dem Sommer 2014 arbeite ich parallel zum Studium und später parallel zu meiner zahnärztlichen Tätigkeit an meiner Dissertation mit dem Thema „Vergleich von prä- und posttherapeutischer Dosimetrie bei Radioiodtherapie von benignen Schilddrüsenerkrankungen“" in der nuklearmedizinischen Abteilung der Universitätsmedizin in Göttingen. Darüber hinaus kam ich während des Studiums in der vorlesungsfreien Zeit und teilweise auch im Semester verschiedensten Nebentätigkeiten nach. So wurde ich unter anderem vom Messe- und Veranstaltungsservice Andrea Banusch $\mathrm{GmbH}$ auf mehreren Messen als Veranstaltungsbetreuung engagiert oder war als studentische Hilfskraft in der medizinischen Mikrobiologie der Universitätsmedizin Göttingen tätig.

Nach erfolgreich abgeschlossenem Zahnmedizinstudium im Sommer 2015 trat ich am 28. September 2016 meine erste Stelle als Assistenzzahnärztin in einer Gemeinschaftspraxis in Oldenburg (Dres. Prasse) an. Nach dreizehn Monaten verließ ich Oldenburg, um ehrenamtlich in Kambodscha zahnärztlich zu arbeiten. Im Anschluss an meinen Auslandsaufenthalt begann ich im Januar 2017 meine kieferorthopädische Weiterbildung zur Fachzahnärztin in Bensheim an der Bergstraße (Dr. med. dent. Claudia Ricken). 


\section{Danksagung}

Ich möchte mich bei allen, die zur Realisierung dieser Dissertation beigetragen haben herzlich bedanken. Allen voran bei meinem Doktorvater Prof. Dr. Meller. Natürlich bedanke ich mich für das Überlassen des Themas, für die Hilfe bei der Planung, Durchführung und Auswertung der Arbeit, aber auch für die optimistische Zuversicht während den vielen Wochen bis zur Fertigstellung. Ich konnte mich jederzeit auf Herrn Prof. Dr. Meller und seine Expertise verlassen.

Weiterhin danke ich der gesamten Abteilung Nuklearmedizin der Universitätsmedizin Göttingen, im Besonderen Herrn Dr. Sahlmann, Herrn Pröhl, Frau Gerke, Frau Steffanowski und Frau Hanne für die großartige organisatorische Hilfe. 